OSMAR APARECIDO MACHADO

QUALIDADE DA INFORMAÇÃO: UMA ABORDAGEM ORIENTADA PARA O CONTEXTO

São Paulo

2013 


\section{QUALIDADE DA INFORMAÇÃO: UMA ABORDAGEM ORIENTADA PARA O CONTEXTO}

Tese apresentada à Escola Politécnica da Universidade de São Paulo para obtenção do título de Doutor em Ciências.

São Paulo 


\title{
QUALIDADE DA INFORMAÇÃO: UMA ABORDAGEM ORIENTADA PARA O CONTEXTO
}

\author{
Tese apresentada à Escola Politécnica da \\ Universidade de São Paulo para obtenção do \\ título de Doutor em Ciências. \\ Área de concentração: \\ Sistemas Digitais \\ Orientador: \\ Prof. Dr. Jorge Rady de Almeida Junior
}

\section{São Paulo}


Este exemplar foi revisado e corrigido em relação à versão original, sob responsabilidade única do autor e com a anuência de seu orientador.

São Paulo, de junho de 2013.

Assinatura do autor

Assinatura do orientador

FICHA CATALOGRÁFICA

Machado, Osmar Aparecido

Qualidade da informação: uma abordagem orientada para o contexto / O.A. Machado. -- versão corr. -- São Paulo, 2013.

$175 \mathrm{p}$.

Tese (Doutorado) - Escola Politécnica da Universidade de São Paulo. Departamento de Engenharia de Computação e Sistemas Digitais.

1.Informação (Qualidade) I.Universidade de São Paulo. Escola Politécnica. Depar-tamento de Engenharia de Computação e Sistemas Digitais Il.t. 
Dedico:

Ao Gustavo. Quando comecei este projeto você tinha apenas 13 anos e certamente perdemos muitos dias de sol por causa dele. Mas jamais perdemos um dia sequer sem um abraço. Tenho orgulho do homem que se tornou.

À Fernanda. Começamos juntos nossos projetos, doutorado e a faculdade de veterinária. Hoje, também finalizamos juntos os projetos e tenho orgulho da mulher que se tornou. Meiga, forte e determinada como poucas que conheço.

À Ana Paula. Você me proporcionou neste período uma das maiores alegrias: o Matheus. Obrigado pela alegria de vê-la feliz.

À Ezilda. Este projeto só foi possível porque tive você durante este longo percurso me apoiando e incentivando. Muitas vezes você até me substituiu... foi "um pouco pai" quando eu estava ausente, tudo para que eu não perdesse o foco. Jamais deixou de ser minha grande companheira, esposa e mulher que admiro e dedico com muito amor, este projeto. 


\section{AGRADECIMENTOS}

Ao Pai, que me permitiu sonhar e me fez perceber que as pedras no caminho não eram obstáculos, era Ele dizendo: Eu acredito em você!

De forma especial ao Profo Dr. Jorge Rady de Almeida Júnior, pela belíssima orientação. Soube conduzir com sabedoria e de forma tranquila os momentos de estresse, naturais em estudos desta natureza.

À Fundação Educacional do Município de Assis - FEMA, pelo apoio e incentivo.

Aos meus amigos e professores, prof. Dr. Luiz Ricardo Begosso e prof. Dr. Alex Sandro R. De Souza Poletto, pelas valiosas contribuições.

À Soledade Maroubo pela revisão deste trabalho e às inesgotáveis palavras de incentivo.

À professora Dra Suzana Rezende Lemanski, pelas valiosas sugestões sobre os processos estatísticos.

Ao Núcleo de Estatística da UEL - Universidade Estadual de Londrina, pelas sugestões na elaboração dos instrumentos das pesquisas.

Aos meus familiares, especialmente meus irmãos, que souberam entender minhas ausências.

Aos amigos, que vibram e choram juntos nas vitórias e derrotas: obrigado! Sem vocês a vida seria um tédio. 


\section{RESUMO}

O cenário atual da gestão da informação é de extrema complexidade. A multiplicidade de ambientes computacionais gera extensos volumes de dados, mas nem sempre garante informações de qualidade. Elas embasam a maioria dos processos de tomadores de decisões. Nesse sentido, o presente estudo busca compreender a percepção da qualidade das informações entre profissionais e usuários de sistemas de informação. Além disso, desenvolve uma proposta de dimensões da qualidade baseadas no contexto de uso que, apesar de serem mais difíceis de mensurar, sustentam outras formas de qualidade da informação, adotadas ou não pelas organizações. O trabalho está dividido em duas partes. Primeiramente, levanta informações sobre a percepção da qualidade da informação entre os profissionais da informação, divididos em três perfis - produtores, consumidores e gestores da informação. Em seguida, avalia a classificação das dimensões propostas, considerando a importância de cada dimensão e a sua correspondente valorização para as organizações, na visão dos profissionais da informação. Os resultados do estudo podem orientar as organizações e, principalmente, os profissionais da área de Tecnologia da Informação, em relação à importância de adotarem práticas de melhoria da qualidade da informação. As dimensões propostas nesta classificação são baseadas no contexto de uso e, portanto, são as que estão mais próximas da realidade dos indivíduos que lidam com as informações, no dia a dia das organizações.

Palavras-Chave: Gestão da Informação. Qualidade da Informação. Valor da Informação. 


\begin{abstract}
The present scenario of information management is extremely complex. The multitude of computing environments generates large volumes of data, but does not always guarantee quality information. They underlie most processes of decision makers. On this way, this work aims to understand the perception of the information quality for the professionals and users of information systems. Also, the work develops a classification proposal of quality dimensions based on the context of use. These, though harder to measure, maintain all other forms of information quality, used or not by organizations. The work has two specific objectives. First, gathering information on the perceived quality of information among information professionals, shared in three profiles - producers, consumers and managers of information. Secondly, assessing the classification of the dimensions proposed, considering the importance of each dimension and its corresponding value for the organizations, in accordance to the view of information professionals. The results of this work can guide organizations and especially the professionals, about the importance of adopting practices to improve the quality of information. The proposed classification is based on the context, therefore, although they are difficult to be measured, they are also those which are closest to the reality of individuals who deal with the information, every days in the organizations.
\end{abstract}

Keywords: Information management. Information Quality. Value of Information. 


\section{LISTA DE FIGURAS}

Figura 1- Esquema básico de um sistema de comunicação

Figura 2- Ciclo da Informação 31

Figura 3- Etapas na geração de Conhecimento e Inteligência. .40

Figura 4- Conhecimento segundo o agente gerador e beneficiário 43

Figura 5- Uma taxonomia da prática de Valores. .55

Figura 6- Framework Conceitual da Qualidade de Dados 65

Figura 7- Fluxo das informações entre os níveis organizacionais 76

Figura 8- Perspectiva de Valor da Informação na abordagem de Contexto 106

Figura 9- Visão tridimensional da abordagem de Contexto 108

Figura 10- Esquema da metodologia TDQM 112

Figura 11- Cadeia de Valor da Informação 113

Figura 12- Agrupamento da escala Likert na proposta 123

Figura 13- Configuração do contexto da qualidade das informações. .147 


\section{LISTA DE GRÁFICOS}

Gráfico 1- Demonstrativo de participantes que conhecem os conceitos da QI.......120

Gráfico 2- Demonstrativo dos participantes que usam os conceitos da QI.............121

Gráfico 3- Demonstrativo de empresas que incentivam a prática da QI.................121

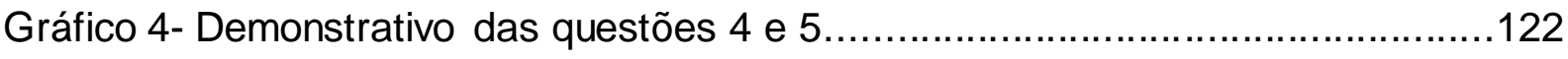

Gráfico 5- Importância atribuída às dimensões por perfil......................................142

Gráfico 6- Valorização atribuída às dimensões por perfil .......................................143 


\section{LISTA DE QUADROS}

Quadro 1- Exemplo de Semiótica conotativa. 34

Quadro 2- Exemplo de uso da Semiótica denotativa para análise de dados .38

Quadro 3- Exemplo: Escala Likert das dimensões do IPQI 107

Quadro 4- Manufatura de produtos vs manufatura de informação. 111

Quadro 5- Resultados da ANOVA: Escalas x grupos..... .145

Quadro 6- Diferenças entre grupos: Produtor e Consumidor .146 


\section{LISTA DE TABELAS}

Tabela 1- Dimensões da Qualidade baseadas no contexto de uso.

Tabela 2- Dimensões da proposta .105

Tabela 3- Demonstrativo dos participantes por cargo .119

Tabela 4- Demonstrativo dos participantes por perfil 114

Tabela 5- Relevância: Médias Gerais .124

Tabela 6- Relevância: Médias por Perfil .124

Tabela 7- Valor Esperado: Médias Gerais .126

Tabela 8- Valor Esperado: Médias por Perfil 127

Tabela 9- Valor Percebido: Médias Gerais 128

Tabela 10- Valor Percebido: Médias por Perfil 128

Tabela 11- Valor Agregado: Médias Gerais 129

Tabela 12- Valor Agregado: Médias por Perfil .130

Tabela 13- Completude: Médias Gerais .131

Tabela 14- Completude: Médias por perfil 131

Tabela 15- Impacto: Médias gerais 132

Tabela 16- Impacto: Médias por perfil 133

Tabela 17- Pontualidade: Médias gerais .134

Tabela 18- Pontualidade: Médias por perfil

Tabela 19- Eficácia da Recuperação: Médias gerais 135

Tabela 20- Eficácia da Recuperação: Médias por perfil 135

Tabela 21- Quantidade Adequada: Médias gerais 136

Tabela 22- Quantidade Adequada: Médias por perfil .137

Tabela 23- Adequação da Indexação e Classificação: Médias Gerais 138

Tabela 24- Adequação da Indexação e Classificação: Médias por perfil 138 


\section{LISTA DE SIGLAS E ABREVIATURAS}

BI

Business Intelligence ou Inteligência Empresarial

CBO Classificação Brasileira de Ocupações

Cl Ciência da Informação

DBA Data Base Administrator

DW Data Warehouse

EIS Executive Information System

ERPs Enterprise Resource Planning

ETL Extract, Transform and Load

EUA Estados Unidos da América

FNQ Fundação Nacional da Qualidade

IP

Information Product ou produto informação

IPQI Inventário de Percepção da Qualidade da Informação

IPVI Inventário de Percepção de Valor da Informação

P4R Move peão para linha 4 da coluna do rei (Xadrez)

PNQ Prêmio Nacional da Qualidade

QI Qualidade da informação

SIG Sistema de Informações Gerenciais

SAD Sistema de Apoio à Decisão

ROI Return Over Investiment

TDQM Total Data Quality Management

TI Tecnologia da Informação

TDQM Total Data Quality Management

VOI Value of information 


\section{SUMÁRIO}

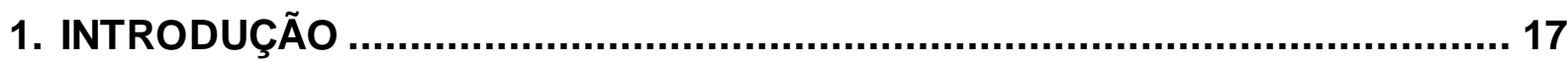

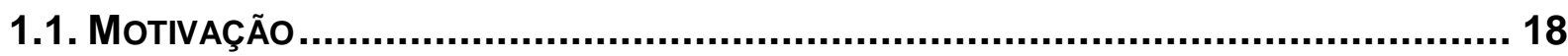

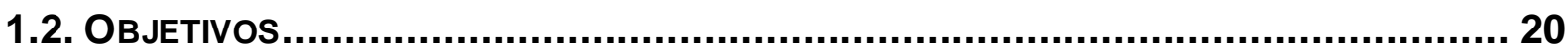

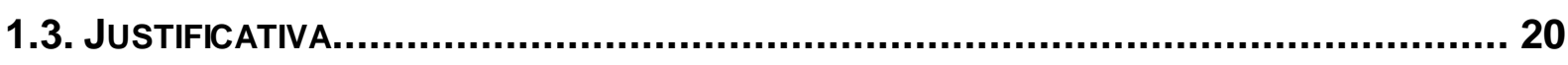

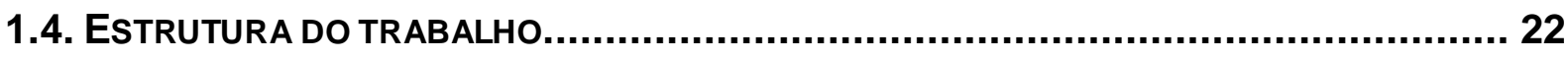

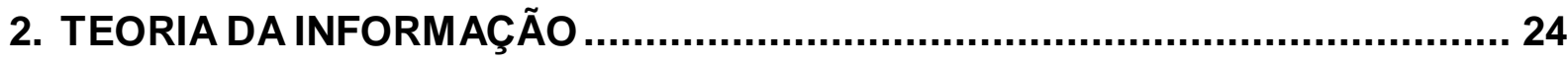

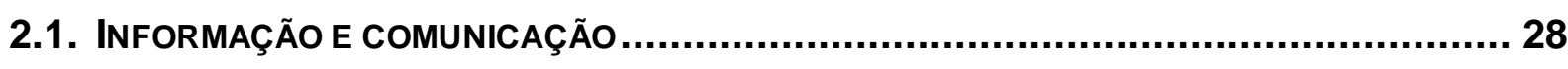

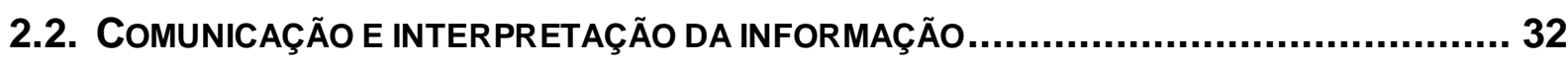

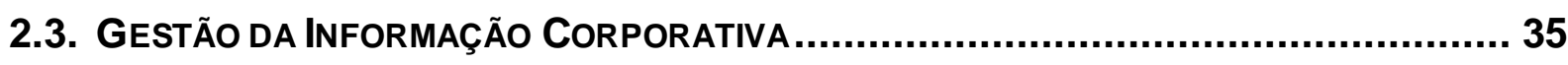

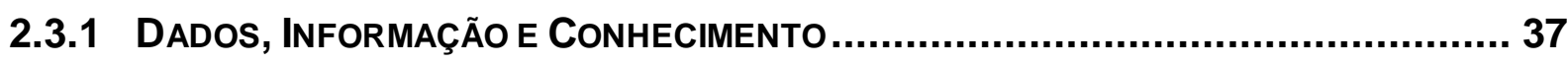

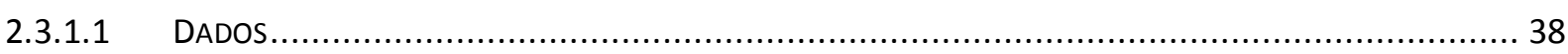

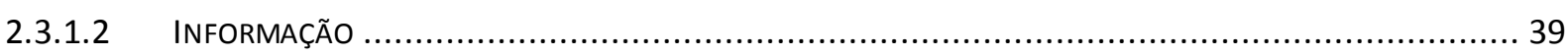

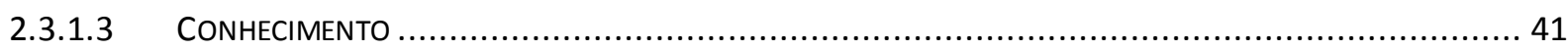

2.3.2 A INFORMAÇÃO COMO UM ATIVO ORGANIZACIONAL .......................................44

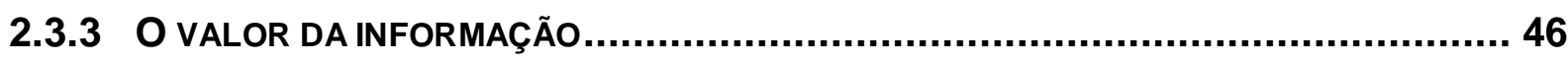

3. VALOR E QUALIDADE DA INFORMAÇÃO …............................................. 54

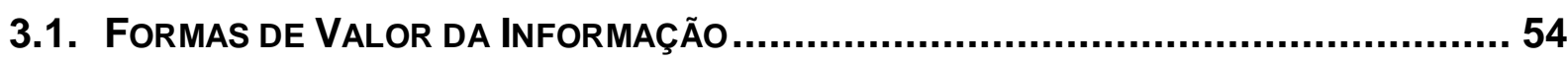

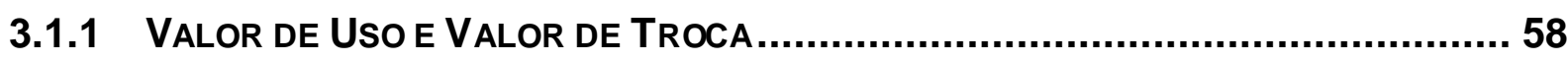

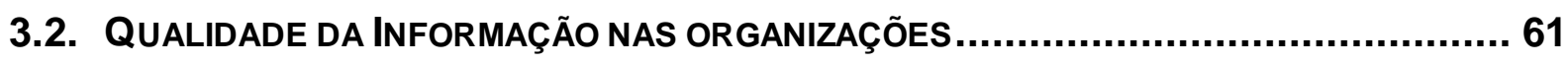

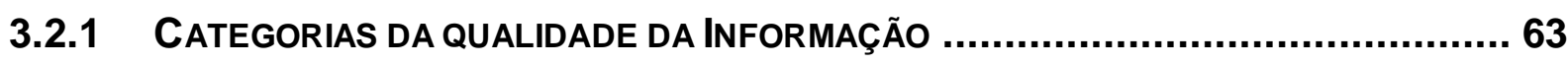

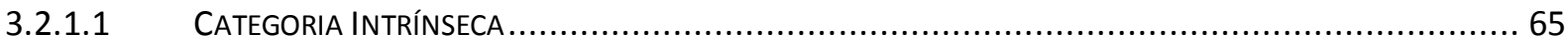

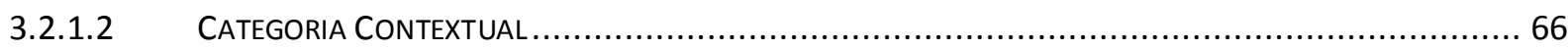

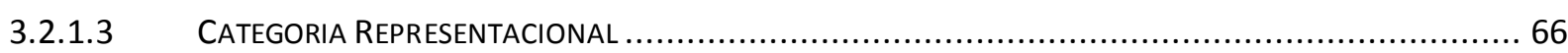

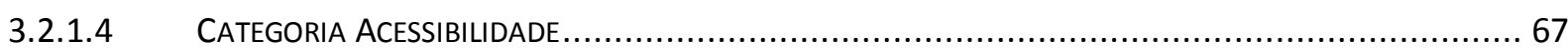

3.2.2. RELAÇÃO ENTRE AS ABORDAGENS DA QUALIDADE E A PERCEPÇÃO NOS NEGÓcIOS 68

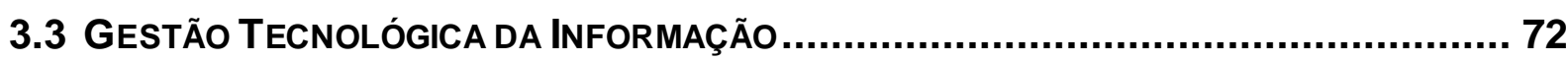

3.4 CaRACTERíSticas do Profissional da InformaÇão....................................... 76

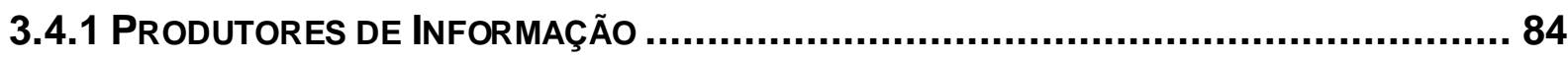

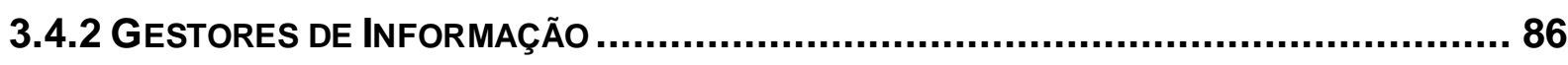

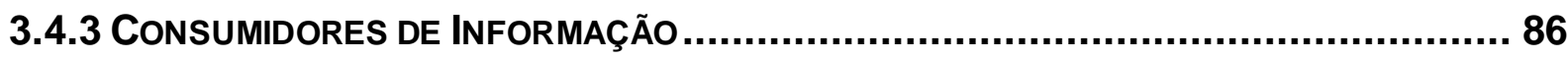

3.5 CaRACTERÍSTICAS ConTEXTUAIS dA INFORMAÇÃo......................................... 87 
4. PROPOSTA PARA AVALIAÇÃO DA IMPORTÂNCIA E VALORIZAÇÃO DA INFORMAÇÃO

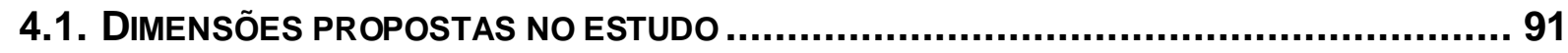

4.1.1. AdEQUAÇÃO DA INDEXAÇÃo E CLASSIFICAÇÃO ............................................. 92

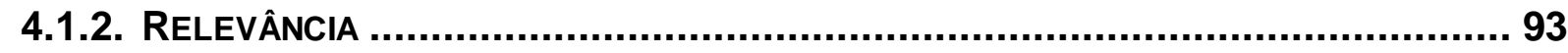

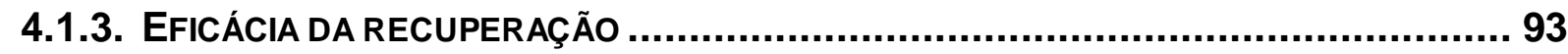

4.1.4. IMPACTO

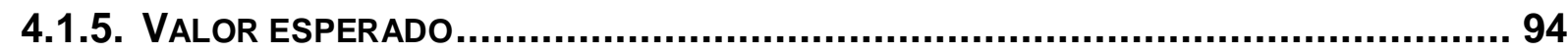

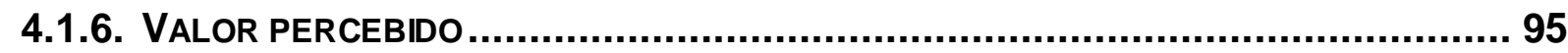

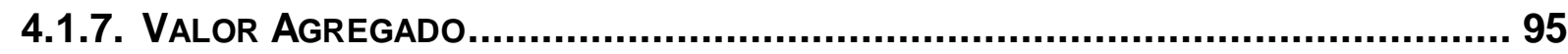

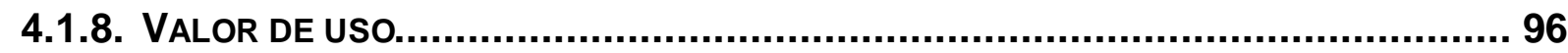

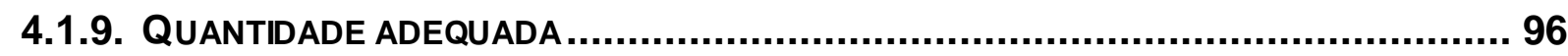

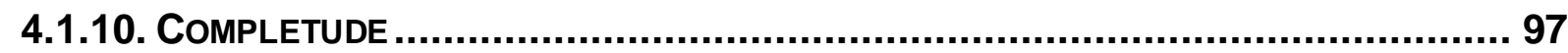

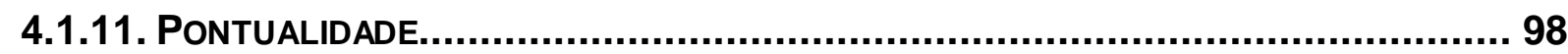

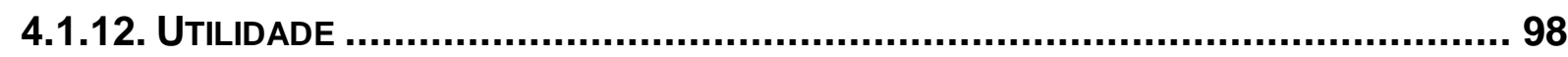

4.2. Pesquisa Piloto: IdentificaÇão da PeRCEPÇão de VALOR da INFORMaÇão. ..... 99

4.3. PESQUiSa Principal: IDENTIFICAÇÃo da PERCEPÇão da QUALIDADE da INFORMAÇão .

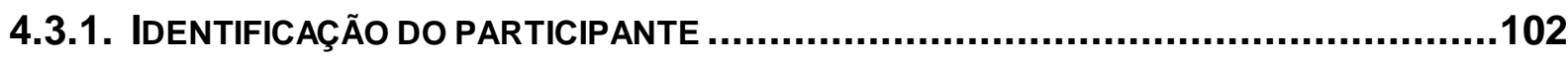

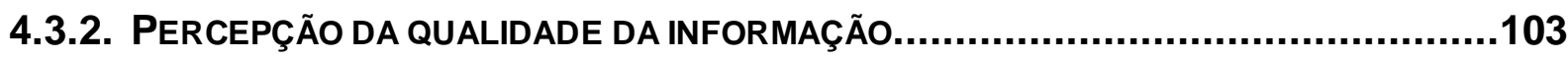

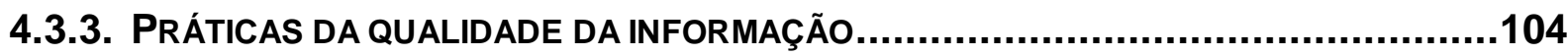

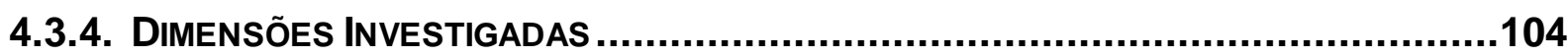

4.3.5. INVENTÁRIO dE PERCEPÇÃo dA QUALIDADE dA INFORMAÇÃO - IPQI ..................107

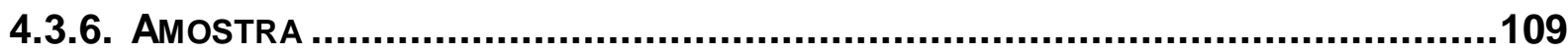

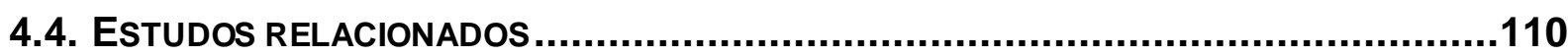

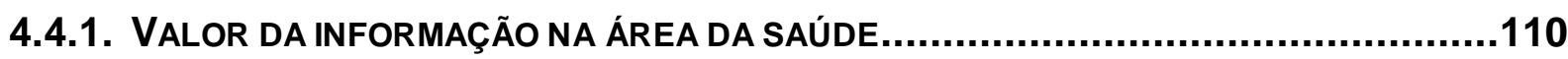

4.4.2. GERENCIAMENTO TOTAL DA QUALIDADE DE DADOS ....................................111

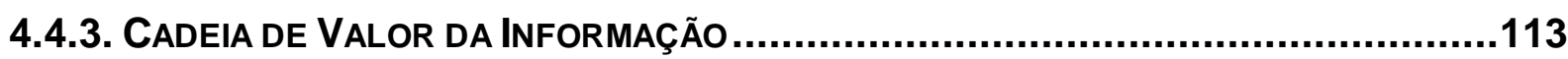

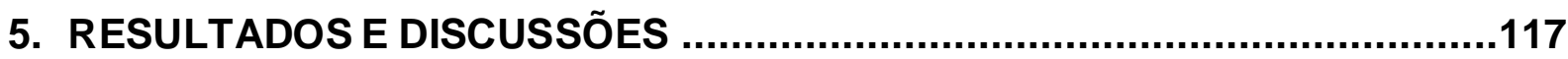

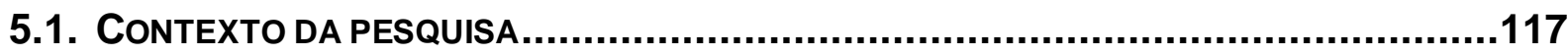

5.1.1. RELAÇÃO dOS PROFISSIONAIS COM AS DIMENSÕES DA QUALIDADE DA INFORMAÇÃO 119

5.2 Profissionais da INFORMaçÃo X Dimensões da QUalidade de dadoS ..............122

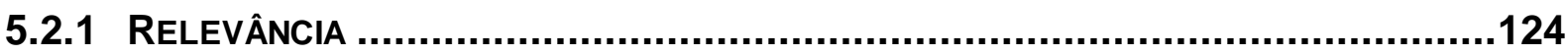

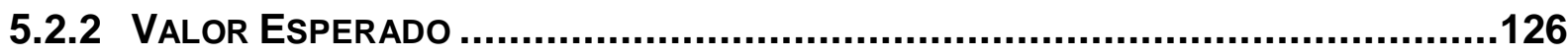




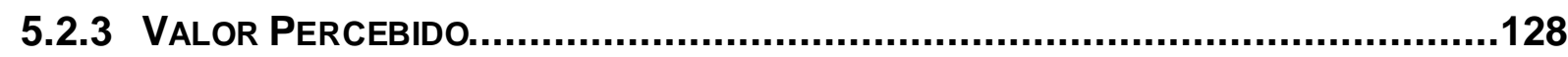

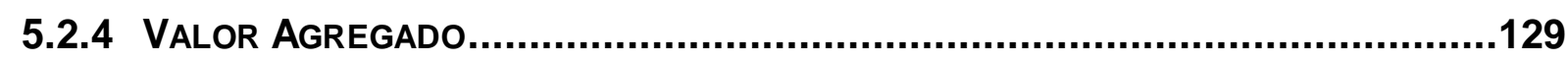

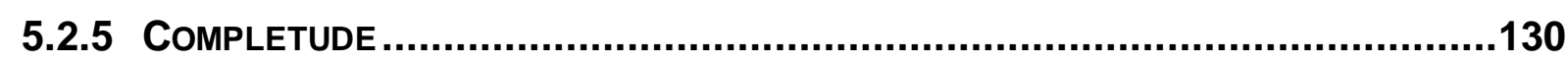

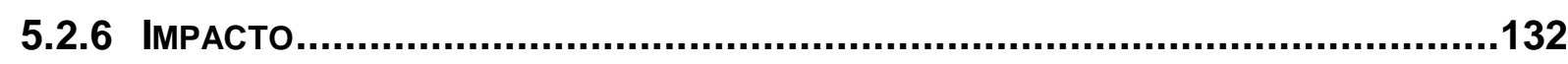

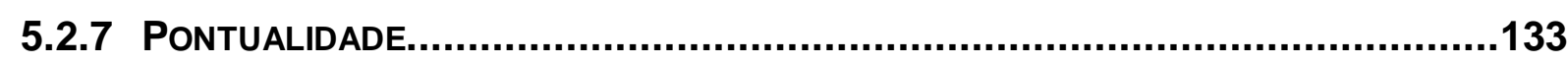

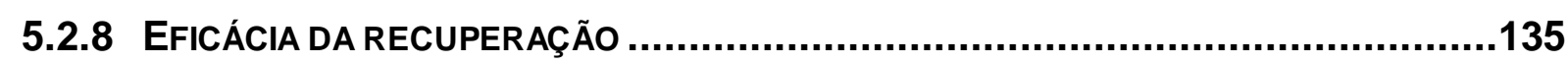

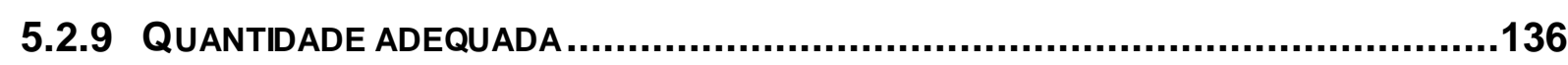

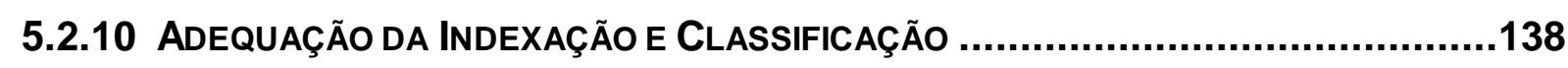

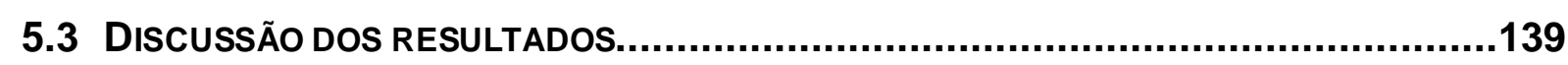

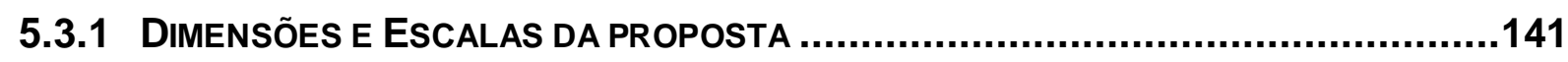

5.3.2 ASSOCIAÇÃO ENTRE ESCALAS E CARGOS DOS PARTICIPANTES.........................144

5.3.3 ESCALAS IMPORTÂNCIA X ESCALA VALORIZAÇÃO .......................................145

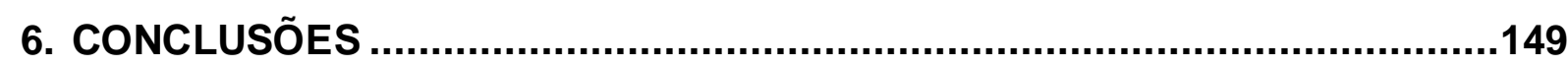

REFERÊNCIAS BIBLIOGRÁFICAS......................................................155

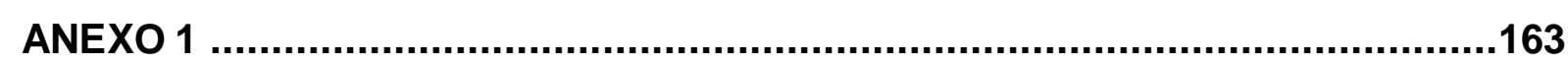

ANEXO 2 


\section{INTRODUÇÃO}

As principais mudanças ocorridas nas instituições, nas últimas décadas, foram provocadas ou influenciadas, direta ou indiretamente, pela evolução tecnológica, mais especificamente, pela relação da informação com as tecnologias atuais.

A informação foi e continua sendo a responsável, em grande parte, por esse processo evolutivo, devido à velocidade com que ela passou a ser gerada, processada e transmitida a partir da segunda metade do século XX. Na realidade, é um ciclo, pois à medida que os dispositivos de geração, transmissão e difusão da informação evoluem, ela passa a chegar mais rápido e mais longe, ampliando sua capacidade de disseminação e, novamente, promovendo sucessivas evoluções.

Um dos reflexos desse ciclo evolutivo são os processos de coleta, armazenamento e processamento de dados, que ampliaram a eficácia operacional dos sistemas de informação, os quais passaram a coletar dados com maior eficiência, armazenar grandes volumes de dados, processar e distribuir as informações com maior velocidade. Por conta disso, a informação passou a chegar mais rapidamente às mãos dos gestores, e a tomada de decisão passou a ser fundamentada em fatos concretos e não mais sobre estimativas e projeções feitas a partir de médias de períodos passados, situação bastante comum até meados da década de 1990 .

Se, por um lado, o volume de informações produzidas possibilitou melhorias e agilidade na execução dos processos; por outro, nem sempre tal volume pode ser utilizado com eficiência adequada pelas instituições. Além disso, segundo Davenport (2003), essas instituições costumam investir, de forma excessiva, em Tecnologia da Informação ( $\mathrm{TI})$, na crença de que a $\mathrm{TI}$ seja suficiente para solucionar os problemas inerentes à qualidade da informação. Na visão do autor, os gestores deveriam aterse mais ao recurso informação propriamente dito, em detrimento dos investimentos em atrativos recursos da TI.

Na mesma linha, De Sordi (2008, p. 22) salienta que a área de TI é apontada como a responsável pela "problemática gestão da informação que ocorre no ambiente das 
organizações, caracterizado por volume crescente de dados disponíveis (fatos registrados), porém, sem o acréscimo proporcional das informações (interpretações relevantes ao negócio)" e ainda, que as "intensas discussões sobre padrões, procedimentos e novos recursos de TI predominam sobre a discussão das dimensões da qualidade da informação".

A gestão das informações está diretamente relacionada com a qualidade das informações. Gradativa e, mais intensamente nos últimos anos, as instituições estão tomando consciência da importância da qualidade das informações e, sobretudo, dos prejuízos que podem advir da falta dessa qualidade.

Em consonância com essa realidade, este estudo objetiva investigar a informação e suas dimensões, do ponto de vista dos usuários, como forma de auxiliar no aumento da qualidade dos processos de seleção e classificação das informações. Esse aumento leva, consequentemente, à melhoria dos processos de gestão da informação.

\subsection{MotiVAÇÃo}

Atualmente, nas organizações, quando se pensa em informação, intuitivamente se associa à informação útil para as tarefas e atividades da instituição e da capacidade de conexão e disseminação da informação entre os vários setores. Geralmente há a expectativa de que a informação traga, de forma implícita, qualidade para os processos organizacionais. Isto porque a tecnologia tem possibilitado às instituições uma evolução significativa em seus processos produtivos, influenciados em grande parte pela velocidade na geração e disseminação da informação.

Muitos processos antes realizados de forma manual, hoje requerem complexos sistemas de informações e automação para o seu controle e, por consequência, geram grandes quantidades de dados. Mesmo com a evolução ocorrida nas últimas décadas nos processos de armazenamento e recuperação de dados, nem todos os 
dados gerados e armazenados são utilizados no dia a dia das instituições e, portanto, acumulam-se, refletindo, de forma negativa, nos processos de guarda e recuperação de informações.

Como afirma Oleto (2006), com o acúmulo de informações no último século e o desenvolvimento dos processos técnicos de registro e acesso às informações, um problema tornou-se fundamental, o de selecionar, nesse imenso volume de informações, aquelas que têm qualidade.

É importante que o volume de dados gerados nas instituições seja organizado adequadamente, de forma a não prejudicar a qualidade da gestão e, consequentemente, disponibilizar informações que venham a conduzir a falhas nas decisões. Da mesma forma, se tais dados não puderem contribuir para a geração de informação e conhecimentos válidos, representarão apenas recursos obsoletos.

O cenário fica ainda prejudicado quando esses dados não têm a qualidade que se espera. Portanto, a carência assim como o excesso de informações prejudica as organizações, porém a falta de qualidade nas bases de dados traz consequências mais graves.

Uma solução viável é encontrar um modelo que possibilite transformar essa quantidade de informações em informações de qualidade, alinhadas com as necessidades do negócio. Isso significa atribuir qualidade às informações. É um processo que vai além do uso de tecnologias, envolvendo as pessoas e seu contexto de uso das informações.

Constantemente surgem novas ferramentas que buscam auxiliar os processos de geração e seleção de informações de qualidade, geralmente associadas com as estratégias do negócio. Destacam-se, neste cenário, os Data Warehouses e Data Marts, como suporte aos processos de tomada de decisão, além dos SIG (Sistema de Informações Gerenciais), EIS (Executive Information System), SAD (Sistema de Apoio à Decisão), dentre outros. Entretanto, os problemas mais comuns relatados em relação à gestão da informação estão associados com os usuários e a própria compreensão da informação, no seu contexto de uso. 


\subsection{OBJETIVOS}

Este estudo objetiva compreender a relação dos profissionais e usuários da informação com as dimensões da qualidade da informação baseadas no contexto de uso, assim como a percepção que eles têm a respeito dessa qualidade. Tendo como base o conjunto de dimensões estabelecidas na literatura, é um dos objetivos desta tese definir quais são as dimensões importantes e valorizadas, no contexto de uso.

Trata-se de uma proposta implementada por meio da criação de um instrumento concretizado através de um inventário de pesquisa. Tal instrumento foi utilizado em pesquisas de campo. Dessa forma, esta proposta visou responder questões acerca da relação dos profissionais e usuários com a qualidade da informação e da relação da qualidade com os processos de valorização da informação.

A informação disponibilizada no local de trabalho do usuário é o insumo básico para a realização das atividades desses profissionais. Portanto, é essencial entender como eles usam o recurso informação no seu dia a dia e, sobretudo, como avaliam a qualidade das informações.

\subsection{JUSTIFICATIVA}

Em grande parte dos casos, a informação disponibilizada no local de trabalho do usuário constitui-se no insumo básico para a realização de suas atividades e, portanto, é essencial entender como esse usuário percebe e usa o recurso informação no seu dia a dia. A informação quando bem elaborada e bem utilizada pode representar benefícios para as organizações e, por outro lado, resultar em prejuízos quando mal elaborada ou utilizada. 
Informações e conhecimentos sem qualidade é a pior situação organizacional possível; pior, inclusive, que o caso das empresas que não realizam esforços para obtenção desses recursos, considerando-se que estas não arcam com custos de geração, como também não vivenciam problemas decorrentes do uso de informação e conhecimento de má qualidade. [...]. (DE SORDI, 2008, p. 140)

Fatores como a falta de mão de obra especializada em número suficiente para atender à demanda das organizações; falta de conhecimentos técnicos sobre a informação pelos usuários e profissionais envolvidos com o uso das informações; os grandes volumes de informações geradas diariamente pelos sistemas de informações, nem sempre gerenciados, fazem com que as organizações entrem em círculo vicioso em que mais informações são geradas na expectativa de atender às necessidades, sem que se avalie a real qualidade das informações. É possível que as informações necessárias para gerar o conhecimento almejado, de fato, já estejam na organização, mas acabam por se perderem pela falta de gerenciamento da qualidade da informação.

É preciso que a relação do usuário com a informação no ambiente organizacional seja pautada em critérios técnicos. A qualidade da informação é um conceito que deve estar presente tanto na mente do profissional que desenvolve os sistemas de informação como do usuário das informações. As proposições levantadas, que sustentam esta tese, se embasam exatamente nesta perspectiva.

No mesmo sentido, os estudos de Marchand (1990) com a abordagem transcendente, baseada no usuário, no produto, na produção e no valor, alinhada aos objetivos do negócio, apontam para a necessidade de se investigar a relação da qualidade da informação nas organizações, como um fator de aumento da competitivdade e alinhamento estratégico. Dessa forma, a abordagem baseada no usuário é a que se apresenta mais alinhada com os objetivos desta tese. Ela considera elementos e características relacionadas ao contexto e ao usuário da informação, sobretudo da percepção e dos critérios dos usuários para avaliar a qualidade da informação.

Além disso, os estudos em torno das dimensões da qualidade da informação propostas por Wang e Strong (1996) e Strong e Wang (1997), Wang (1998), e dos 
aspectos do valor da informação propostos por Repo (1989) sustentam e justificam a necessidade de estudos dessa natureza.

Assim, esta proposta classifica um conjunto de dimensões orientadas ao contexto, passíveis de serem implementadas nas organizações. Além disso, a proposta elabora um instrumento para identificar a percepção dos usuários sobre a qualidade da informação. A partir dessa identificação, poderão surgir novas possibilidades de estudos no sentido de aplicar de fato a qualidade da informação nos processos de gestão da informação.

Espera-se, por fim, que os resultados do inventário proposto na coleta de respostas orientem ações no sentido de ampliar as percepções dos usuários sobre as dimensões da qualidade da informação, aqui denominadas de abordagem de contexto e de uso. Além disso, os resultados podem apontar correlações positivas e significativas entre os perfis dos usuários com as dimensões da classificação aqui proposta.

\subsection{ESTRUTURA DO ESTUDO}

O estudo está estruturado em 5 capítulos, além da Introdução. O capítulo 2 aborda os conceitos da Teoria da Informação, abrangendo desde os conceitos filosóficos aos conceitos técnicos e práticos da informação e, por fim, dos modelos de gestão que utilizam a informação como insumo nas organizações.

O capítulo 3 trata dos principais aspectos relacionados à gestão da informação no ambiente organizacional. Explora também conceitos relativos à valorização da informação.

No capítulo 4 é apresentada a proposta central da tese, no qual se realiza uma contextualização do ambiente da proposta e da importância de estabelecer um valor para a informação. 
O Capítulo 5 descreve os resultados obtidos por meio das pesquisas realizadas neste estudo e apresenta uma análise detalhada sobre a relação das dimensões da proposta com os elementos de contexto, descritos no capítulo anterior.

Por fim, o capitulo 6 refere-se aos aspectos conclusivos do presente estudo. Nele são apresentadas também as limitações do estudo e, em seguida, despertam para a necessidade de novas investigações que visem à melhoria nos processos de avaliação e gestão das informações nas organizações. 


\section{TEORIA DA INFORMAÇÃO}

O estudo da informação envolve diversas áreas do conhecimento. Dentre elas, a Ciência da Informação é a que mais tem explorado os seus conceitos. Nas ultimas décadas, ampliou-se a compreensão do campo da ciência da informação e, por consequência, ela se aproximou das ciências sociais e humanas (ARAÚJO, 2003), como a História, Antropologia, Sociologia, entre outras.

Capurro e Hjørland (2007) realizaram uma ampla revisão dos conceitos que envolvem a informação. Os autores tratam da evolução histórica da Ciência da Informação $(\mathrm{Cl})$ e resgatam reflexões e definições da informação, contemplando desde as visões de filósofos como Platão, Aristóteles, Cícero, Agostinho e Descartes e mostram a Ciência da Informação como o resultado das reflexões ocorridas ao longo do tempo. Explica que a definição atual da Ciência da Informação foi estabelecida apenas no século $\mathrm{XX}$, resultado de vários processos, de suas formas de organização e documentação, das bibliotecas especializadas e finalmente da cibernética. Além disso, de acordo com esses autores, os reflexos dessas transformações podem ser percebidos na substituição do termo "documentação" por "informação" nas denominações de entidades profissionais, como escolas de documentação e biblioteconomia, adotadas também nos estudos relacionados à Ciência da Informação.

Para Capurro e Hjørland (2007, p. 154-155), ao se usar o termo informação, deverse-ia ter em mente que "informação é o que é informativo para uma determinada pessoa" e o "que é informativo depende das necessidades interpretativas e habilidades do indivíduo". Entretanto, ressaltam que essa é uma visão mais atual do termo e que o sentido de uso da palavra, de origem latina, tem se alterado significativamente através dos tempos: informatio e informo eram inicialmente utilizados no sentido de dar forma a algo ou de moldar a mente. 
em que elas informam o próprio espírito voltado para esta parte do cérebro [...] uma ideia era algo presente para a mente, uma imagem, cópia ou representação, com uma relação problemática com as coisas reais do mundo (Descartes, 1996, apud CAPURRO E HJORLAN, 2007, p. 158).

Como se observa, Capurro e Hjørland (2007) fazem referência, em seu estudo, às diversas afirmações em que se percebem as mudanças conceituais em torno do entendimento da informação e afirmam que "houve uma mudança ou inversão de conceitos da palavra informação" (Idem, p. 156-157). De acordo com eles, o termo antes utilizado para dar forma à matéria passa agora a comunicar algo a alguém. Foi somente no século $X X$, a partir do surgimento da teoria da informação, que o conceito de informação deixou de ser abstrato. Um dos reflexos desta mudança é que o local da informação mudou do mundo amplo para a mente humana e os sentidos. Outras reflexões acerca do termo relatadas por Capurro e Hjørland (2007, p. 156) referem-se às formas de entendimento de como a mente era informada pelas sensações do mundo, porque "parecia descrever os mecanismos da sensação: os objetos do mundo in-formam os sentidos [...]; a sensação é inteiramente diferente da forma, uma é sensorial, a outra intelectual; uma é subjetiva, a outra objetiva”.

Em relação aos usos mais modernos do termo, Capurro e Hjørland (2007, p. 156) afirmam que eles "indicam um período de transição, em que o conceito ontológico medieval de moldar a matéria não apenas foi abandonado, mas refeito sob as premissas empíricas e epistemológicas". Porém, ao longo do tempo, diversos fatores dificultaram o entendimento e a própria conceituação da informação. Os resultados de uma revisão de estudos realizados no período de 1900 a 1981, sobre a Ciência da Informação, relatam problemas contraditórios em relação ao termo:

[...] descobriu que a literatura sobre $\mathrm{Cl}$ é caracterizada pelo caos conceitual, que advém de uma variedade de problemas na literatura conceitual da $\mathrm{Cl}$, como citação a-critica de definições anteriores, fusão de teoria e prática, afirmações obsessivas de status científico, uma visão estreita da tecnologia, descaso pela literatura, definições circulares e multiplicidade de noções vagas, contraditórias e, às vezes, bizarras quanto à natureza do termo informação. (Schrader, 1983, apud por CAPURRO e HJØRLAND, 2007).

Há que avaliar, porém, se o caos conceitual citado faz parte do passado ou é retrato do presente. A busca pelo entendimento da informação, como se observa, é 
complexa, pois ora ela é descrita como um objeto ou serviço, ora como uma ideia, um pensamento. As dificuldades de chegar ao consenso sobre o que é informação perpassam por várias épocas e áreas do conhecimento, cada qual, em seu momento, procurando interpretá-la à luz do desenvolvimento social, tecnológico ou cognitivo disponível. O paradigma das comunicações atuais, ampliado pelos recursos da internet, adicionaram-se novos elementos para a já conturbada análise do que é a informação, como a comunicação sem fio, as redes sociais e sua capacidade de ampliar o escopo da informação, dentre outros.

Entender a informação e explorar suas características nos mais diferentes contextos tem sido o objeto de inúmeros estudos e, certamente, a diversidade de estudos produzidos sobre o assunto contribuiu para o entendimento atual da informação, sobretudo em relação aos aspectos sociais e cognitivos, como se observa nesta relação de estudiosos, descrita por Capurro e Hjørland (2007, p.162):

I. Gunther (1963): desenvolveu a ideia de Wiener a respeito da informação como um terceiro princípio metafísico;

II. Titze (1971): argumentou que informação não é um princípio substantivo ou metafísico, mas expressa uma tendência para a ordem e a evolução;

III. Weizsäcker (1974): desenvolveu seus argumentos sobre a relação entre linguagem e informação, particularmente no diálogo com Heidegger (1959).

IV. Oeser (1976): coloca a informação no contexto da epistemologia como um conceito-chave referente à criação do conhecimento científico, referindo-se explicitamente às raízes latinas e gregas do termo informação, assim como à sua função central na epistemologia e ontologia medievais;

V. Schnelle (1976): realizou uma revisão histórica do conceito, mas referindose à linguística e a cibernética.

Como se pode perceber, muitos aspectos ou visões a respeito da informação permanecem ainda inexplorados, outros autores buscaram explicações até mesmo metafísicas para a informação. Entretanto Wiener (apud CAPURRO e HJØRLAND, 2007, p.165) afirmam que "Informação é informação, não matéria ou energia. Nenhum materialismo que não admita isto pode sobreviver na atualidade". 
Se por um lado, a diversidade de estudos sobre a informação trouxe contribuições, por outro, ela desarticulou a estruturação em um único conceito, o que tem dificultado o consenso entre os pesquisadores sobre o fenômeno (ARAÚJO, 2009). Essa capacidade intrínseca da informação de ser utilizada e atender às várias áreas, nos contextos mais diversos, deve-se a algumas de suas características que a torna diferente de outros produtos. Tal como expõem Repo (1986), a informação é:

I. Humana: Somente há informação por intermédio da percepção humana.

II. Compressível: pode-se sintetizar, comprimir, resumir a informação de diferentes formas.

III. Transferível: a velocidade e a facilidade com que se transmite uma informação é um fator a ser considerado para o desenvolvimento das demais áreas do conhecimento.

IV. Facilmente transportável: usando novas aplicações e novas tecnologias é possível transportá-la em diversas mídias e formatos.

V. Difusiva: tende a se tornar pública, mesmo que não seja o desejo de quem a detém.

VI. Compartilhável: ao contrário de outros bens, quem a vende ainda permanece com ela.

VII. A informação é multiplicável: quanto mais nós a usamos, mais útil ela se torna (Cleveland, citado por Fernandes, 1991).

VIII. A informação é substituível: ela pode substituir outros recursos como dinheiro, pessoas, matéria-prima (Cleveland, citado por Fernandes, 1991).

Poucos elementos, dentre os conhecidos atualmente, possuem essa capacidade de atrair a atenção de pesquisadores das diversas vertentes do conhecimento, de influenciar numerosos estudos e, ainda assim, não apresentar uma definição que seja consensual. Ao contrário, é um desafio, um fator motivador para o desenvolvimento de novos estudos sobre o assunto, que parece não se esgotar. 


\subsection{INFORMAÇÃO E COMUNICAÇÃO}

A comunicação, componente fundamental da Teoria da Informação, tornou-se elemento vital para as organizações, nas quais os processos de comunicação são em sua maioria sustentados por recursos tecnológicos, geralmente embarcados em modernos aparatos tecnológicos, que operam a aquisição, a transmissão e a disseminação da informação interna e externa nas atividades organizacionais.

A comunicação e a informação são conceitos diferentes, apesar de intrinsecamente relacionados. Para Le Coadic (1996, p.13) "comunicação é um ato, um processo, um mecanismo, e que a informação é um produto, uma substância, uma matéria".

O Glossário da Sociedade da Informação (Glossário/apdSI, 2011, p.24) explica a comunicação como o "processo de transferência de informação através de um canal ou meio de comunicação qualquer, entre pessoas, pontos ou equipamentos, sem alteração ou quebra da sequência, estrutura ou conteúdo".

Em 1948, por intermédio dos estudos de Shannon (1948), surgiu a Teoria da Informação, como é atualmente denominada. Claude Shannon tornou-se conhecido como o pai dessa teoria, inicialmente formulada como uma teoria matemática e objetivava auxiliar na solução de problemas relacionados ao custo de transmissão de sinais. Por fim, acabou ultrapassando esses limites e tornou-se uma disciplina de importância considerável em diversas áreas do conhecimento, como economia, psicolinguística, pedagogia, computação, biologia, dentre outras (EPSTEIN, 1986).

O modelo proposto por Shannon (Figura 1) esquematiza o processo básico de comunicação. Percebe-se, no esquema, que o ruído pode interferir na qualidade do sinal transmitido, diminuindo a probabilidade de que a mensagem recebida pelo destinatário seja a definida pela fonte da informação. 


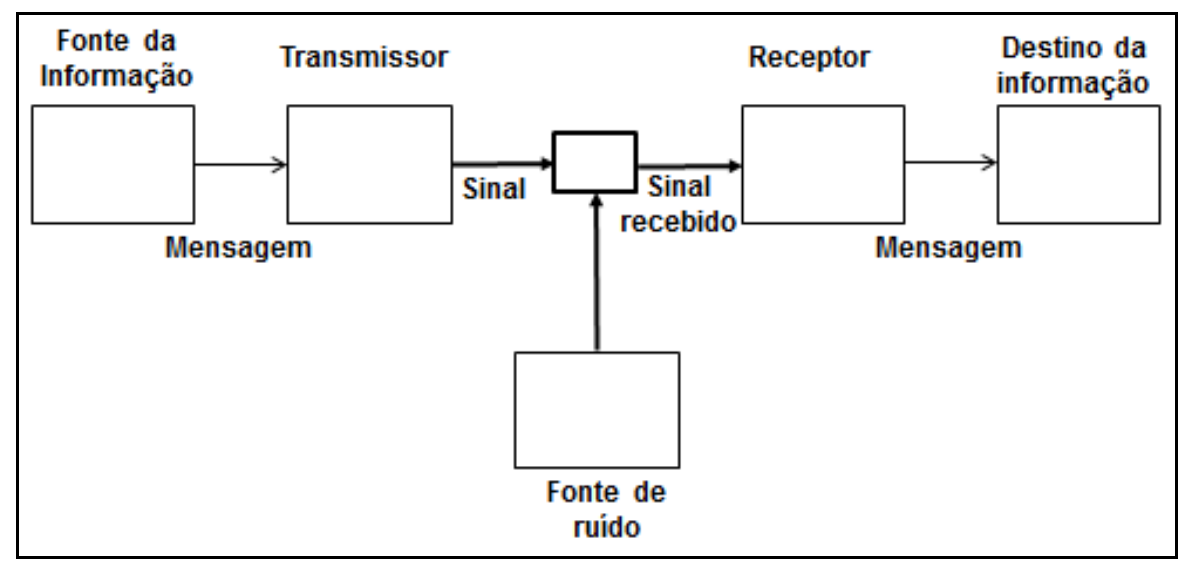

Figura 1: Esquema básico de um sistema de comunicação Fonte: Shannon (1948, p. 2)

De forma geral, a Teoria da Informação trata dos meios pelos quais uma mensagem é emitida, transmitida e recebida por um ou mais receptores, humanos ou não. Além da probabilidade e a aleatoriedade, conceitos como, ruído, redundância, entropia fundamentam essa teoria (PAIM e NEHMY, 1998). Estes conceitos não são explícitos, visíveis na superfície da informação, contudo, sustentam, de maneira eficiente, o uso das informações em diversas áreas do conhecimento.

A probabilidade estatística, por exemplo, é uma linguagem utilizada para representar as possibilidades de sucesso ou não da transmissão (emissão - transmissão recepção) de uma mensagem (EPSTEIN, 1986).

A redundância, por sua vez, representa uma redução da variedade ou informação, tornando possível a percepção ou compreensão do mundo (EPSTEIN, 1986) expressa geralmente por meio das formas. Ela pode ser definida como a repetição de uma determinada informação, de forma não aleatória, como os pontos sobre a curva geométrica, como exemplifica Epstein (1986). Além disso, Pignatari (1970, apud SOARES, 2001) explica que a redundância pode ser adotada para neutralizar os possíveis ruídos gerados durante a transmissão de uma mensagem. Ela garante, assim, a efetiva transmissão da mensagem.

Do mesmo modo, a aleatoriedade é baseada em conceitos estatísticos (FERNANDES e AZEVEDO, 2006) e está relacionada à variedade das informações. 
A variedade máxima de um conjunto de eventos ocorre quando eles são independentes entre si, ou seja, não apresentam articulação ou coerção mútua. Isso significa que a variedade máxima de informação, espalhada ao acaso, refere-se à aleatoriedade (EPSTEIN,1986).

Ao contrário da aleatoriedade, as formas, outro conceito da Teoria da Informação, garantem a coerção entre sinais elementares e podem ser representadas matematicamente por meio de expressões e equações:

[...] o conjunto de pontos espalhados ao acaso numa superfície pode exemplificar este estado. O Aleatório na distribuição dos pontos significa que a variedade do conjunto é máxima [...]. Um conjunto de pontos situados sobre uma curva geométrica não são posicionalmente independentes entre si. Para se transmitir suas posições, não é necessário que se conheçam as coordenadas de todos eles. A informação necessária é "comprimida" na forma de equação da função matemática que representa esta curva. A curva, por sua vez, é percebida como forma. (EPSTEIN, 1986, p. 6,7).

A proposta de Shannon (1948), quando estabeleceu a Teoria da Informação, tinha como foco o estudo de problemas técnicos da comunicação. Essa característica da proposta acabou por se tornar a principal limitação desse modelo, a de lidar com problemas complexos, como os sistemas sociais (ARAÚJO, 2003).

Essa teoria foi essencial para a evolução dos aspectos técnicos da informação e dos meios de transmissão. A qualidade da informação, de acordo com esse ponto de vista, "estaria relacionada à medida da capacidade de transmissão das sequências produzidas por uma fonte, podendo a informação ser destituída de um significado" (NEHMY e PAIM, 1998, p. 89).

Novos estudos relataram que a abordagem técnica da proposta dissociava o conteúdo semântico da informação, ou seja, não bastava apenas considerar os aspectos técnicos, mas, sobretudo, os aspectos sociais da informação. Por consequência, o sucesso dessa teoria deixou o usuário da informação em segundo plano. Somente a partir dos anos 1970, ele passa a ser privilegiado como receptor da informação, especialmente nos sistemas de informação (NEHMY e PAIM, 1998). 
A dissociação entre os aspectos técnicos e semânticos no contexto da transmissão de sinais já havia sido percebida pelos próprios autores:

\begin{abstract}
A palavra informação, nesta teoria, é usada em um sentido especial que não deve ser confundido com seu uso comum. Em particular, informação não deve ser confundida com significado. Na verdade, duas mensagens, uma das quais é intensamente carregada de significado e outra que é pura falta de sentido, podem ser exatamente equivalentes, segundo o ponto de vista desta teoria, com relação à informação. É isto, sem dúvida que Shannon quer dizer quando afirma "os aspectos semânticos da comunicação são irrelevantes para os aspectos da engenharia". Mas, isto não significa que os aspectos da engenharia são necessariamente irrelevantes para os aspectos semânticos. (Shannon e Weaver, 1972, p.8, apud CAPURRO e HJØRLAND, 2007 p.161-162).
\end{abstract}

O modelo de Shannon (1948) explica fatores relacionados aos aspectos práticos da transmissão da informação, que podem ser medidos e quantificados para garantir o desempenho da transmissão. Entretanto, apesar de sua importância, o modelo não explora os aspectos relacionados à percepção humana da informação, que implicam no entendimento e uso da informação, em função do contexto e do usuário da informação. O modelo trata, na realidade, de uma contribuição significativa para os aspectos técnicos da transmissão de sinais, que, na verdade, eram os objetivos dos autores.

Como alternativa ao modelo habitualmente utilizado, de uma relação bilateral entre informador-informado, Le Coadic (1996) sugere o ciclo da informação (Figura 2) que, na visão do autor, traz uma libertação em relação a tais modelos.

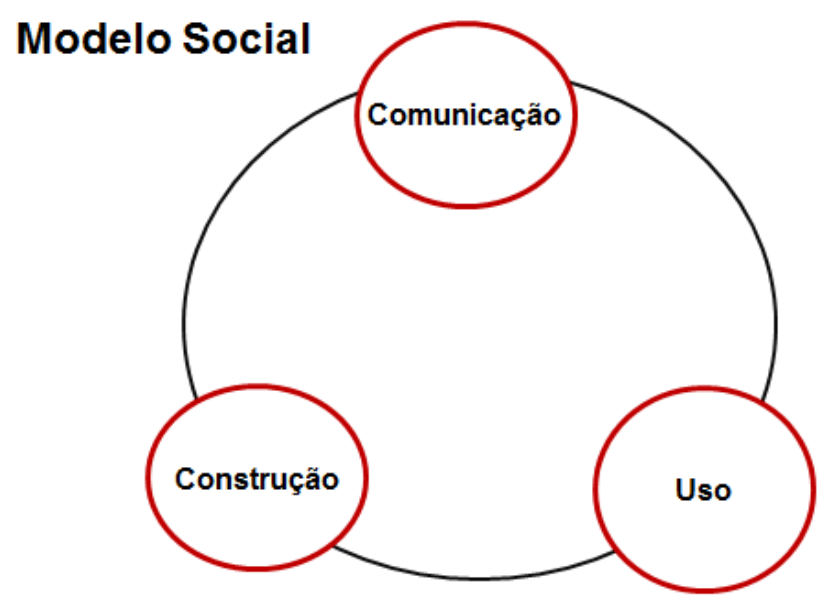

Figura 2: Ciclo da Informação Fonte: Le Coadic (1996, p. 11) 
Além disso, na visão do autor, o ciclo da informação rompe o caráter técnico da transmissão da informação imposto pelo modelo de Shannon. A comunicação, por sua vez, nesse sentido, é definida como "um ato, um processo, um mecanismo, e que a informação é um produto, uma substância, uma matéria" (LE COADIC, 1996, p. 13).

\subsection{COMUNICAÇÃO E INTERPRETAÇÃO DA INFORMAÇÃO}

Um dos aspectos fundamentais explorados pela Teoria da Informação é a capacidade de interpretar as mensagens e suas formas. Uma informação aparentemente simples pode carregar diversas mensagens implícitas e de difícil entendimento para sujeitos não familiarizados com elas, mas facilmente interpretadas por aqueles que estão habituados ao contexto da mensagem. Em outras palavras, a informação pode carregar códigos ou mensagens implícitos, interpretados de acordo com a intenção, o conhecimento ou contexto dos emissores e/ou receptores. Para Le Coadic (1996, p.5),

\footnotetext{
A informação comporta um elemento de sentido. É um significado transmitido a um ser consciente por meio de uma mensagem inscrita em um suporte espacial-temporal: impresso, sinal elétrico, onda sonora, Essa inscrição é feita graças a um sistema de signos (a linguagem) que é um elemento da linguagem que associa um significante a um significado: signo alfabético, palavra, sinal de pontuação.
}

A comunicação da informação, independentemente do meio de transmissão, envolve elementos como o contexto do emissor e do receptor, os conhecimentos e experiências do receptor, o formato, bem como a necessidade da informação.

Epstein (1986), nesse sentido, analisa o caráter dual atribuído à informação: por um lado, ela é definida como variedade em que a quantidade máxima ocorre na desordem ou estado caótico. Por outro, a teoria da Gestalt preconiza a forma como 
uma alternativa para se entender a informação, isto é, a forma é uma representação da informação, é um tipo de organização que torna a informação mais objetiva.

Para Soares (2001, p. 9),

\begin{abstract}
A informação é antes de tudo uma forma, um fluxo de formas, de ideias. Então, determinadas formas têm mais informação do que outras. [...] a informação reside na forma e no tipo de atividade em que o indivíduo sintetiza o conteúdo da consciência, de acordo com sua visão de mundo e suas necessidades.
\end{abstract}

Epstein (1986) utiliza o exemplo do jogo de xadrez, em que um jogador envia um lance, P4R, a seu adversário. Essa mensagem só tem sentido em um jogo de xadrez e se refere às posições dos quadrados do tabuleiro, às peças específicas e à sua movimentação no tabuleiro. Além disso, segundo o autor, a informação P4R pode conter mais mensagens do que as sugeridas pelo lance. Inerentes à informação são as regras ou códigos do jogo, que podem não estar expostos materialmente, mas certamente existem na cabeça dos jogadores. Essas regras é que dão sentido e vida ao processo no qual estão envolvidos, no caso, os jogadores.

A semiótica busca compreender os signos ou sinais, e oferece conteúdos importantes para a compreensão das mensagens obtidas por meio de códigos e sinais. Ao mesmo tempo, ela ajuda a minimizar a limitação do modelo de Shannon. Aqui se utiliza um de seus conceitos, o plano da expressão ou significante, para ajudar a mapear a mensagem P4R, do jogo de xadrez citado anteriormente.

Segundo esse conceito, também denominado semiótica denotativa, a mensagem P4R é composta pela expressão e conteúdo ou significado para a jogada correspondente, conforme o Quadro 1 (EPSTEIN, 1986). Agregando outros significados, Hjelmslev (1975 apud EPSTEIN, 1986) apresentou um conceito considerado como uma extensão da semiótica denotativa, que atribui a cada mensagem um conteúdo consoante, elevando, assim, a semiótica denotativa ao nível de semiótica conotativa. Nesse processo, um código subjacente pode ser inserido à mensagem P4R a fim de classificá-la de acordo com a sua importância (força, perigo), como se observa no Quadro 1. 


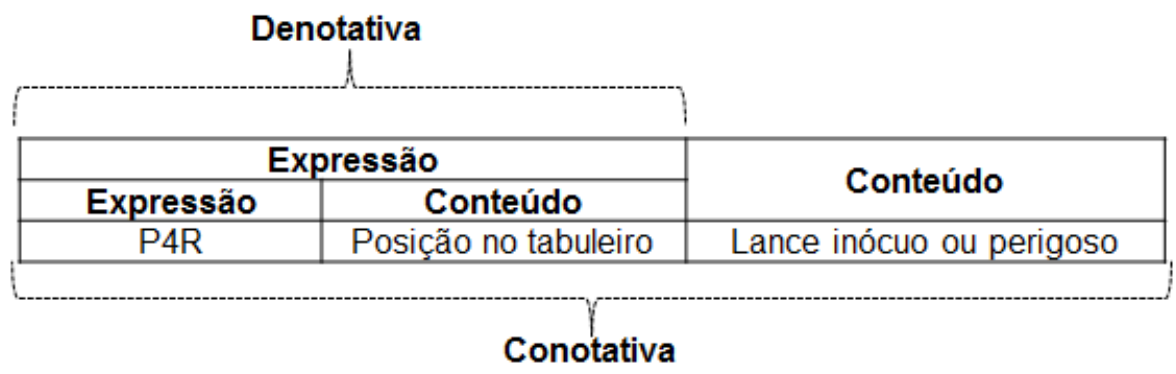

Quadro 1 - Exemplo de semiótica conotativa, adaptado de Epstein (1986).

Informação e comunicação são elementos complementares no processo de transmissão de sinais. Enquanto a comunicação envolve o significado ou interpretação das mensagens, a informação depende somente da variedade ou do número de mensagens possíveis, abrangidas pelo código (EPSTEIN, 1986). Assim, a informação P4R corresponde, segundo o autor, a uma redução da incerteza antes de seu uso efetivo, computável pelo número de lances possíveis naquela situação, para o lance realmente efetivado, no caso, P4R.

A informação carrega, como se observa, mensagens diversas as quais podem ser interpretadas em função de seu contexto. No ambiente corporativo, esses conceitos tornam-se especialmente úteis na medida em que as diversas mensagens podem ser codificadas e seus significados identificados e tratados. É possível inferir que uma mesma informação pode gerar ações e reações diferentes nos seus receptores em função do entendimento e/ou envolvimento no contexto para o qual ela foi gerada.

Em síntese, a Teoria da Informação trata dos aspectos relacionados à informação, desde a sua fonte ou origem até sua comunicação final ou destino. Atualmente, por causa do advento das novas tecnologias de comunicação como internet, dispositivos sem fios, redes, celulares, parece existir uma relação intrínseca entre a Teoria da Informação e a computação.

$\mathrm{Na}$ realidade, trata-se de uma via de mão dupla, em que a computação contribuiu para que os conceitos da Teoria da Informação fossem explorados em todos os seus aspectos, difundindo-os pelo uso de diversas tecnologias, desde empregos mais complexos, como a consulta de saldo bancário realizada em processo on-line, em que diversos aspectos da Teoria da Informação estão encapsulados no sistema a 
fim de garantir a segurança da informação, tanto para o usuário quanto para a instituição bancária, até a utilização de recursos mais comuns, como a transmissão e recepção de um simples e-mail.

\subsection{GESTÃo dA INFORMAÇÃo CORPORATIVA}

As instituições sobrevivem por meio da interação de seus recursos humanos, tecnológicos, financeiros, materiais e de produção. Os planos e as ações organizacionais, em sua maioria, são planejados em função de tais recursos. Nesse cenário, a informação é o elemento que viabiliza a integração dos recursos com os planos e as ações. Porém, a agilidade com que as empresas desenvolvem suas atividades, atualmente, comparada com as últimas décadas, evolui de forma significativa e constante. Isso se deve, provavelmente às facilidades implementadas e disponibilizadas nos processos de coleta, carga, processamento, armazenamento e disseminação da informação, propiciadas pela evolução tecnológica.

Esses processos, assim como os demais recursos da organização, podem ser expressos em termos de custos e benefícios. Nesse sentido, um dos pressupostos comumente utilizados pelas teorias que investigam o assunto, é a visão da informação como um recurso organizacional, portanto, passível de ser mensurada e avaliada, tornando-se um recurso controlável.

Em um estudo denominado "A Economia da Informação", Fernandes (1991) faz algumas considerações relevantes sobre as expectativas e possibilidades de valorizar a informação como um recurso econômico. O contexto tratado pelo autor diz respeito aos serviços de informação e bibliotecas. Entretanto, são também abordadas algumas questões que ultrapassam os limites do ambiente contextualizado, especialmente em relação aos serviços de informação. 
Dentre os vários conceitos explorados pelo autor, a relação custo-benefício dos serviços de informação traz à tona uma questão envolta ainda em inúmeros questionamentos, sobre os custos e benefícios acerca do uso das informações no ambiente corporativo. A análise de custo-benefício remete a uma consideração econômica da informação.

Diversos pesquisadores citados por Fernandes (1991) fazem restrição a essa forma de análise, por considerarem que os benefícios nem sempre podem ser expressos em termos monetários. Uma das questões recorrentes para justificar os custos envolvidos na produção e uso da informação é se ela, a informação, deve ser vista como um bem econômico. Nesse sentido, Buckland (1991), dentre outras visões exploradas na literatura concernentes ao tema, entende que ela deve ser tratada como um bem econômico qualquer e, independente da situação há que se avaliar os seus custos e benefícios.

Essas questões em torno dos custos e dos benefícios da informação são recorrentes na literatura e se originam geralmente em função da dificuldade de se mensurar os benefícios obtidos por meio do uso da informação. Drucker (1993) já defendia a informação como a base e a razão para um novo tipo de gestão em que os conceitos de capital e de trabalho seriam substituídos por informação e conhecimento. Nesse sentido, independetemente da possibilidade ou não de se mensurar tais benefícios, há uma abundância de estudos que são enfáticos ao afirmarem que as instituições que adotam práticas de gestão do recurso informação obtêm, geralmente, melhores resultados em relação às instituições que não as adotam.

Diversos estudos (DE SORDI, 2008; SANTOS,2009; SANTOS, 2005; TARAPANOFF et al., 2011) relatam a existência de uma relação muito próxima entre a gestão da informação e do conhecimento com a capacidade competitiva das organizações.

Um exemplo disso é o sucesso obtido pelas empresas japonesas nas últimas décadas. Nonaka e Takeuchi (1997) justificam a especialização e criação do conhecimento organizacional como fatores que conduziram tais empresas ao sucesso, mais até do que sua capacidade de fabricação. 


\subsubsection{Dados, Informação e Conhecimento}

Comumente os termos dados e informação são utilizados como sinônimos, conforme o contexto. Mas têm significados diferentes: dados combinados geram informação; informação utilizada no contexto adequado gera conhecimento; e conhecimento, combinado com experiência e bom julgamento, entre outros fatores, resulta em sabedoria (GOUVEIA, 1996; DE SORDI, 2008).

A literatura é farta em definições sobre cada um destes elementos. Com o propósito de complementar as distinções propostas anteriormente, é interessante ressaltar algumas definições que buscam posicionar os dados, as informações e o conhecimento como elementos interdependentes. Audy, Andrade e Cidral (2005) listam algumas definições geralmente referenciadas em bibliografias da área de sistemas de informação. Segundo elas, informação representa dados que:

a) Foram moldados em um formato que possui um significado e utilidade para o homem.

b) Têm um significado em um contexto.

c) São dotados de pertinência e propósito.

d) São processados de uma forma significativa para o usuário com valor real ou percebido para decisões correntes e posteriores.

e) São a agregação ou processamento dos dados que provêm do conhecimento ou da inteligência.

f) São signos (ou conjunto de signos) que impulsionam uma ação. 


\subsubsection{Dados}

Os conceitos em torno dos dados permitem compreender a essência e importância desse elemento, o qual na realidade é o registro da própria informação, descontextualizada e ainda em forma bruta.

Segundo Audy, Andrade e Cidral (2005), dados se configuram como a informação codificada e registrada, segundo certa convenção. São elementos da informação, como um conjunto de letras, números ou dígitos, que, tomados isoladamente, não transmitem nenhum conhecimento. Exemplo: quente, 75.

Pode se afirmar que o dado interpretado, trabalhado, útil, tratado, com valor significativo atribuído ou agregado e com um sentido natural e lógico, gera informação. Por exemplo, isoladamente os dados "quente e 75 " podem ter algum significado, mas não expressam necessariamente uma informação. Já os dados "temperatura+ quente+ 75 " expressam significados e interpretados em determinado contexto resultam em informação.

Dados podem ser agregados a fim de melhorar a compreensão do contexto (CORTES, 2008), por exemplo, a adição do dado "Celsius" permite que a informação seja mais bem compreendida: os dados "temperatura + 75 + Celsius + quente" podem ser interpretados como temperatura de 75 graus Celsius, a qual para determinada situação é considerada quente, conforme se observa no quadro 2, exemplo em que dados e seus significados são expressos com o uso da semiótica conotativa.

\begin{tabular}{|c|c|l|}
\hline \multicolumn{2}{|c|}{ Expressão } & \multicolumn{2}{c}{ Conteúdo } \\
\hline Expressão & Conteúdo & \multicolumn{2}{c|}{ Cemperatura muito baixa para esterilização de } \\
\hline $75^{\circ} \mathrm{C}$ & Quente & $\begin{array}{l}\text { Tequipamentos } \\
\text { equipan }\end{array}$ \\
\hline $02^{\circ} \mathrm{C}$ & Frio & Temperatura muito alta para criogenia \\
\hline
\end{tabular}

Quadro 2 - Exemplo de uso da Semiótica denotativa para análise de dados (Adaptado de Epstein, 1986) 
Esses mesmos dados podem assumir representação diferente se forem expressos, por exemplo, na escala Fahrenheit, 167ํF. O que importa, de fato, é que a água está quente. O quanto está é uma informação que pode ser registrada por intermédio de um número, cuja interpretação possibilitará o conhecimento desejado (CORTES, 2008).

Além disso, o mesmo dado $\left(75^{\circ} \mathrm{C}\right.$ ou $\left.167^{\circ} \mathrm{F}\right)$ utilizado em contextos diferentes pode representar situações diferentes: extremamente alta (quente) para manutenção de um ambiente social, por exemplo, e inadequada (frio) para a esterilização de instrumentos cirúrgicos, por exemplo, como exposto no quadro 2.

Para De Sordi (2008, p.7-8), "dados são a coleção de evidências relevantes sobre um fato" e no processo de coleta dos dados existe uma filtragem que se realiza sobre o dado observado, pela percepção do usuário (observador), segundo sua relevância. $O$ autor sugere alguns complementos passíveis de agregação às definições de dados, tais como "possíveis de serem transmitidos ou processados por máquinas ou pelo homem; matéria-prima para a geração de informação; podem compreender números, palavras e imagens, dentre outros".

Os dados são, em síntese, os elementos por meio dos quais as informações são geradas. O entendimento desses conceitos é fundamental para o processo de desenvolvimento de sistemas de informação, uma vez que os sistemas registram, em suas bases de dados, os dados que proverão as informações necessárias ao atendimento das necessidades organizacionais.

\subsubsection{Informação}

A informação é gerada por meio de uma sequência ordenada de operações

aritméticas ou lógicas. É na visão de De Sordi (2008, p. 10), "a interpretação de um 
conjunto de dados segundo um propósito relevante e de consenso para o públicoalvo (Leitor)".

Tanto a informação quanto o conhecimento são elementos-chave para as instituições. São elementos de trato refinado. Informação de boa qualidade, utilizada em quantidade e formas adequadas, no momento certo, pode resultar em vantagens competitivas.

Assim, o domínio do uso da informação é uma característica que pode ser desenvolvida e praticada pelas instituições e quando isto ocorre, ajuda a atingirem mais rapidamente os seus objetivos, pois viabilizam maior qualidade e rapidez nas decisões. Além disso, influenciam de forma positiva nos processos de geração de conhecimento e inteligência organizacional (Figura 3). Por outro lado, a falta de informação pode induzir a erros e a perda de oportunidades.

Zorrinho (1995, p. 15) ensina que "A informação é tudo o que reduz a incerteza; é um instrumento de compreensão do mundo e da ação sobre ele", é o combustível que possibilita, por meio dos indivíduos, o desenvolvimento da gestão do conhecimento.

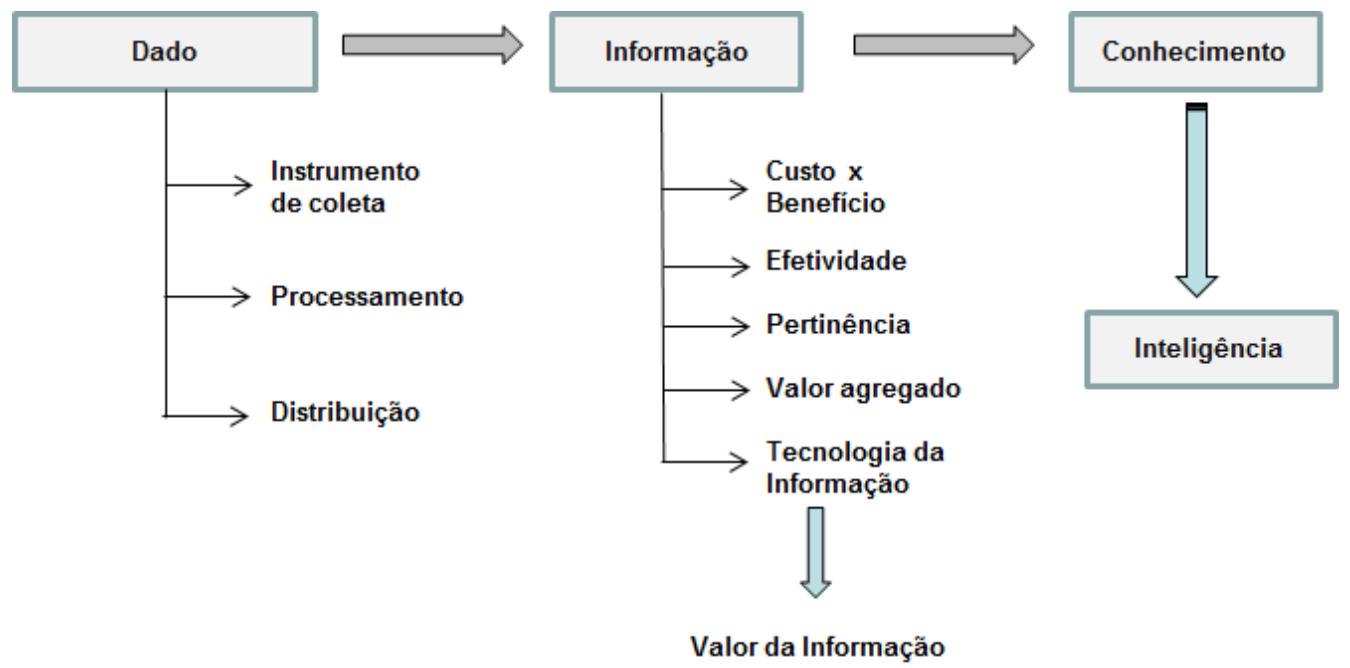

Figura 3 - Etapas na geração de conhecimento e Inteligência

Fonte: Tarapanoff, Araújo Junior, Cormier (2000, p. 91) 
No entanto, apesar da reconhecida importância da informação no ambiente corporativo, faltam elementos que viabilizem o melhor proveito de seu uso. As instituições possuem estoques significativos de informação em suas bases de dados, todavia, na mesma proporção, são relatados com frequência problemas na qualidade das informações. Informações de qualidade ruim podem influenciar de modo negativo nas atividades relacionadas à tomada de decisão e na geração ou criação do conhecimento.

\subsubsection{Conhecimento}

A criação do conhecimento, segundo Nonaka e Takeuchi (1997, p. 63), refere-se à capacidade da organização de criar, difundir e incorporar o conhecimento em produtos, serviços e sistemas. As distinções entre informação e conhecimento, podem ser sintetizadas da seguinte forma:

- O conhecimento, ao contrário da informação, diz respeito a crenças e compromissos;

- $\quad$ O conhecimento, diferentemente da informação está relacionado à ação;

- $\quad$ O conhecimento, como a informação, diz respeito ao significado;

- $\quad$ O conhecimento é identificado com a crença produzida (ou sustentada) pela informação.

"A informação é um produto capaz de gerar conhecimento e a informação que um sinal transmite é o que podemos aprender com ela...O conhecimento é identificado com a crença produzida (ou sustentada) pela informação" (DRETSKE, 1981, apud NONAKA E TAKEUCHI, 1997, p. 64). 
A distinção entre conhecimento, informação e dado, é um conceito cuja compreensão é relevante, porque possibilita um olhar mais acurado sobre os dados coletados, processados e disponibilizados como informação, possibilitando, dessa forma, uma melhor compreensão de seus benefícios no ambiente corporativo (DE SORDI, 2008; FOINA, 2010).

Para Soares (2001), os termos informação, conhecimento e dados são utilizados também para estabelecer a variação no processamento e uso de uma mensagem, ou seja, para explicitar o significado da transição entre os estágios dos elementos, de dado em informação e de informação em conhecimento.

Entretanto, ao contrário dos dados e informações que podem ser filtrados e selecionados para atividades e tarefas específicas, o conhecimento depende do indivíduo e de suas experiências anteriores, conforme expressa Barreto (2004, apud DODEBEI, 2009 p. 9, grifo do autor):

[...] Para que o conhecimento opere, é necessário uma transferência desta informação para a realidade dos receptores e uma conjuntura favorável de apropriação desta informação pelo indivíduo. Nesse momento, nada é menos globalizado que a informação, pois nada é mais subjetivo, privado e individual que, a assimilação do conteúdo de uma informação pelo receptor. $\mathrm{Na}$ solidão da assimilação o receptor é uno e a apropriação da informação é dele, de mais ninguém. É este então o lugar do conhecimento.

Um conhecimento novo "se justifica pela individualidade de cada mente humana, ou seja, do modelo mental do indivíduo que está analisando as informações" (DE SORDI, 2008, p. 13).

Nessa perspectiva, a figura 4, demonstra esta relação do usuário no processo de geração do conhecimento. Carbone et. al.(2006, p. 38), salientam que "o conhecimento é visto aqui como uma construção social [...] que não tem vida própria e não existe sem a figura do conhecedor". Pode se afirmar que, como um observador, o usuário recebe os estímulos do mundo, em determinado contexto, de onde coleta dados úteis e necessários para o desenvolvimento de suas atividades. 
A partir de uma filtragem conceitual, os dados, alinhados com as expectativas do observador, geram as informações. O conhecimento é gerado somente na perspectiva do observador, de acordo com seu modelo mental e de sua bagagem conceitual e por isso, alinhado com valores individualizados, realiza um processo de retroalimentação do conhecimento, ciclicamente provocando novos estímulos.

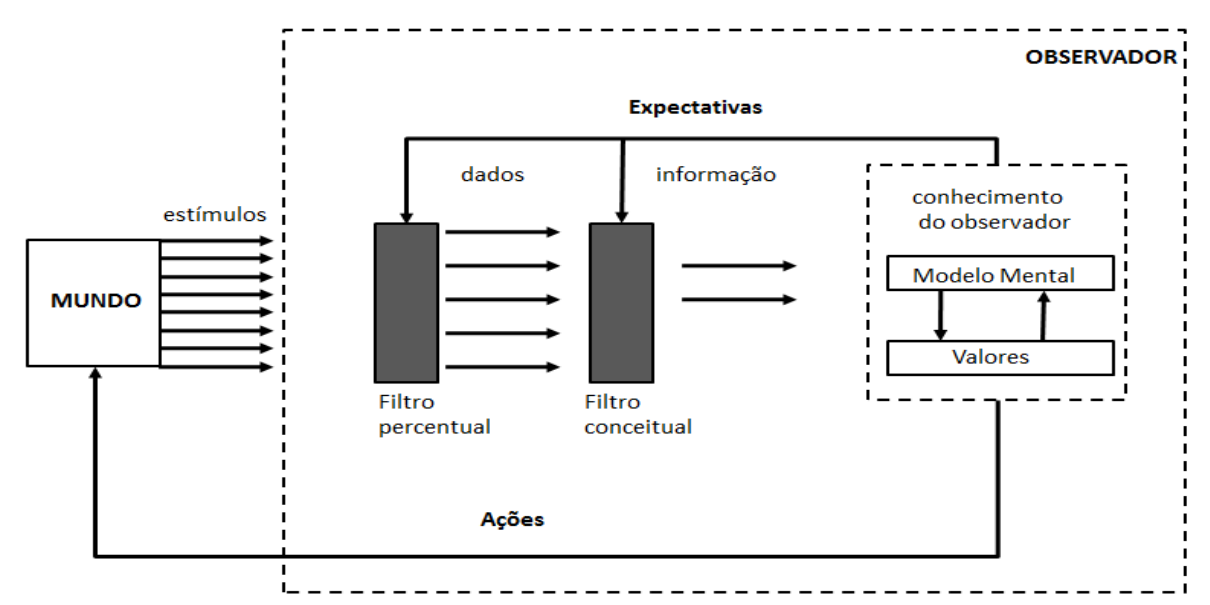

Figura 4 - Conhecimento segundo o agente gerador e beneficiário Fonte: De Sordi (2008, p. 13)

Dados e informações são insumos necessários para a geração do conhecimento, porém não surtirão efeito, caso sua análise e interpretação seja realizada por indivíduos com pouca base conceitual sobre o assunto ou contexto de uso..

O conhecimento é construído socialmente por indivíduos inteligentes, por meio de processos dinâmicos de aprendizagem que têm como essência a solução de problemas que decorrem de eventos incertos do mundo do trabalho (Nonaka e Takeuchi, 1997).

Carbone et al. (2006, p. 38) afirmam:

deve-se ressaltar o trabalho humano como questão central num contexto em que as pessoas são percebidas como atores críticos dos processos de criação do conhecimento [...]; que vão dar à empresa a sua identidade própria, na medida em que permitem à organização o estabelecimento de inúmeras combinações de competências. 
Para Davenport e Prusak (1998) são as pessoas que interpretam dados e geram informações úteis capazes de transformar em conhecimento. $O$ conhecimento está próximo da ação e está relacionado à habilidade e competência do uso da informação que o gera e pela qualidade das ações ou decisões realizadas.

Entende-se, portanto, que desde o surgimento da chamada era da informação, em meados dos anos 1990, o conhecimento passou a ter mais valor para as instituições do que os próprios bens tangíveis (NONAKA e TAKEUCHI, 1997). Assim, segundo esses autores, aplicado aos negócios, o conhecimento pode tornar a empresa mais competitiva.

No mesmo sentido, Carbone et al. (2006) afirmam ser o conhecimento o resultado da informação trabalhada por pessoas e/ou recursos computacionais, interpretadas, possibilitando a geração de cenários, simulações, ações e oportunidades. Concluindo, afirmam que a inteligência organizacional, representada pelos sistemas de informação e conhecimento, pela competência dos funcionários, pela qualidade dos processos de produção e atendimento aos clientes, tornou-se fator decisivo no ambiente corporativo contemporâneo.

\subsubsection{A informação como um ativo organizacional}

Apesar de sua importância ressaltada pela literatura, nas organizações, a informação é vista e utilizada como um recurso, mas ainda não é tratada como tal. Ela faz parte de um seleto grupo de ativos, os intangíveis. Significa que, para as instituições, é um recurso não mensurável que requer investimentos para sua produção, uso e disseminação. Entretanto, ela não é, de fato, tratada como um recurso quando comparada a outros recursos envolvidos nos processos de produção ou de gestão.

São muitos os aspectos que dificultam o tratamento da informação como um ativo. Entre eles está a dificuldade em mensurar o retorno sobre os investimentos (ROI Return Over Investment) realizados na produção da informação. Por exemplo, os 
investimentos realizados em máquinas e equipamentos no processo produtivo visam geralmente à melhoria e otimização do processo. Existem, nesses casos, metodologias que possibilitam a mensuração e a avaliação dos custos e da qualidade dos recursos envolvidos, de forma que é possível estabelecer uma comparação entre os custos e os benefícios relacionados aos investimentos realizados.

Já os investimentos realizados na produção da informação, da mesma forma, objetivam a melhoria e otimização dos processos de coleta, processamento, armazenamento e distribuição das informações (AUDY, ANDRADE e CIDRAL, 2005). Os resultados desses investimentos são significativos, em termos de melhoria dos processos, porém, é difícil estabelecer uma relação entre os custos realizados e os benefícios obtidos, porque as "diferenças da informação em relação a outros recursos dificultam ou impossibilitam a sua categorização em termos econômicos [..." (MORESI, p. 15).

O fato é que a informação é um recurso extremamente versátil e que pode ser utilizado para atender à maioria das necessidades para as quais é solicitado, porém deve haver clara percepção e compreensão do contexto de seu uso.

Nesse sentido, Oliveira (2001, p.37) afirma que:

A eficiência na utilização do recurso da informação é medida pela relação do custo para obtê-la e do valor do benefício derivado do seu uso [...]; a preocupação maior deveria residir em descobrir o nível ótimo de geração da informação, ou seja, de utilidade efetiva, pois incorpora o conceito de valor, que sempre embute certa subjetividade. Por sua vez, o custo pode ser mais facilmente determinado.

Neves (2006, p.2), por sua vez, completa que "os custos da informação estão diretamente relacionados com os custos da sua coleta, processamento e distribuição", serviços estes inerentes à Tecnologia da Informação.

Entretanto, quanto ao estabelecimento de uma relação entre valor investido em Tecnologia da informação e as taxas de retorno ROI, existem algumas propostas, ainda que não sejam práticas de resultados exatos. Ocorre que variáveis ambientais, como a falta de pessoal devidamente qualificado, infraestrutura sucateada, dentre 
outras, podem interferir nas expectativas de retorno dos investimentos (STRASSMAN, 2005).

Por isso, tratar a informação como um ativo é uma tarefa difícil e esbarra em muitos conflitos por causa de suas especificidades. Em síntese, não é possível tratar a informação como um ativo quando a intenção for de controlá-la como um bem físico, simplesmente pela impossibilidade de controle sobre ela, de contabilização, por exemplo, como sugere Buckland (1991). Além disso, com o passar do tempo, os ativos sofrem valorização ou desvalorização. Nessa questão reside uma das principais dificuldades para considerar a informação como ativo, ou seja, a dificuldade para definir o custo e o valor das informações em uma base de dados, por exemplo, e contabilizá-la como um ativo.

\subsection{3 $O$ valor da informação}

O valor da informação é um assunto também envolto em muitas contradições teóricas e dificuldades técnicas para estabelecê-lo. As dificuldades em atribuir um valor para a informação são semelhantes às encontradas para utilizá-la como um ativo. O processo de valorização da informação não se limita apenas à possibilidade ou não de quantificar os custos dos recursos envolvidos nos processos de coleta, processamento, armazenamento e distribuição das informações.

Pois, como observa Neves (2006, p.2), "dar valor à informação apresenta certa dificuldade, pois não está diretamente ligado à mesma, e sim, aos resultados que se obtêm da sua utilização dentro da organização".

O processo vai além, pois a diferença substancial do produto informação está em suas características econômicas que a distinguem dos ativos tangíveis. Ela pode ser transformada, multiplicada, agregada, conjugada, reutilizada, substituída, transportada, distribuída, compartilhada, não se deprecia, é disponível livremente e seu valor cresce com a reutilização. De acordo com Tarapanoff et al. (2000), ela é 
difícil de ser controlada e de manter suas características originais, entretanto, ela pode sempre possibilitar a geração de conhecimentos.

Devido a todas essas peculiaridades, é difícil elaborar uma teoria que permita calcular o seu valor. É possível, contudo, que essa dificuldade seja superada quando, afinal, se desenvolver um método capaz de estabelecer uma relação entre os custos envolvidos no processo de produção da informação com o retorno dos investimentos e dos serviços aplicados sobre eles. Uma vez que se consiga atingir essa variável, será possível estabelecer um valor, único e exclusivo, para os dados armazenados e pelas informações distribuídas pelos sistemas de informações.

A busca por métodos ou modelos para dar valor às informações não é um evento recente nem restrito a uma única área do conhecimento. A realidade exposta pela variedade de pesquisas em torno do assunto (MARCHAND, 1990; REPO, 1986; 1989; TARAPANOFF, 2007;) revela o interesse de diferentes áreas do conhecimento na obtenção de um método que possibilite, enfim, atribuir um valor para a informação. As especificidades de cada área, porém, buscam interpretar as formas de valorização de acordo com suas características e necessidades e, nesse sentido, existem diferentes visões acerca dos conceitos de seu valor.

Um dos pressupostos geralmente utilizados para dar valor à informação é a relação com os custos envolvidos na sua produção, porém, conforme salientam Almeida e Varvakis (2005, p.4), o valor dos serviços de informação vai além das atividades consideradas agregadoras de valor, como os serviços de coleta, análise, processamento e distribuição da informação.

Segundo esses autores (idem, ibidem):

[...] quando se refere a valor da informação toma-se um pressuposto na Ciência da Informação, a máxima do uso efetivo feito pelo usuário, que não pode ser confundido com outras tentativas de mensurar a informação a partir de seu custo de produção ou manutenção do pessoal que colabora.

Para a maioria dos produtos e serviços, o processo de atribuir valor é relativamente fácil, sejam valores despendidos na aquisição de algum bem, sejam serviços, 
produtos ou acessórios utilizados no dia a dia de uma instituição, sejam os custos oriundos do uso de equipamentos, tempo gasto, marca, custos operacionais, dentre outros. Esses são facilmente calculáveis e podem ser expressos, segundo a visão econômica em valor de uso e valor de troca, conforme expõe Sandroni (1999, p. 625-626):

- Valor de uso: refere-se às características físicas dos bens que os capacitam a ser usados pelo homem, ou seja, destina-se a satisfazer necessidades de qualquer ordem, materiais ou ideais. Está, geralmente, relacionado à utilidade de um objeto. Coisas que não têm valor de uso possuem, em geral, pouco ou nenhum valor de troca.

- Valor de troca: os bens são intercambiados uns pelos outros, direta e indiretamente, por intermédio do dinheiro.

Para a informação, no entanto, pelas suas características torna-se complexo o processo de se the atribuir valor, de aquisição, de uso ou de troca.

Entretanto, um dos fatores inerentes à valorização da informação é o seu uso efetivo. Nos sistemas computacionais, isso pode ser determinante para se atribuir um valor para a informação, não um valor econômico, material, mas uma forma de valor que permita a escolha, de maneira automática ou não, de determinadas informações em detrimento de outras. Para determinados eventos, é possível selecionar informações com maior uso efetivo em situações semelhantes, ou seja, a escolha e uso de determinada informação pode ser baseada no seu valor de uso estabelecido em situações parecidas.

Dentre os estudos que investigam o valor da informação, destacam-se os estudos de Repo (1986; 1989). O autor lista uma série de tópicos, obtidos a partir de uma revisão bibliográfica, na década de 1980, sobre efetividade, eficiência e valor dos custos e benefícios relacionados ao valor da informação. Os mais de 100 estudos revisados pelo autor foram classificados e sintetizados, em função de seus objetivos, nos seguintes tópicos: 
I. Custo dos produtos e serviços da informação;

II. Preço da informação;

III. Avaliação da efetividade e eficiência de serviços de informação de bibliotecas;

IV. Análise de custo benefício de transferência de informação;

V. Valor da informação à luz de exemplos;

VI. Serviço de informação como um processo de valor agregado;

VII. Recuperação econômica de informação;

VIII. Estudos de macroeconomia da informação e produtividade;

IX. Processamento econômico da informação.

Repo (1986) considera importante que os estudos sobre o valor da informação considerem a visão dos usuários da informação. Adota, assim, uma abordagem dual, do valor de uso e do valor de troca da informação. Isso ocorre porque, para o autor, a decisão de usar ou não determinada informação não depende somente de características da informação como validade, qualidade ou facilidade de uso, mas, sobretudo, do cenário de uso, do ambiente e do usuário que vai utilizá-la para determinada tarefa.

Outras formas de valor da informação são exploradas pela literatura, por exemplo: o valor cultural, relacionado com o contexto da informação e não expresso por uma unidade de medida.

[...] Nos serviços de ação cultural, a medição, o cálculo e outras estimativas do valor da informação são inviáveis. O valor dessa informação é um valor de estima e, por isso, subjetivo, tornando impreciso o cálculo e seu valor real. (ALMEIDA e VARVAKIS, 2005, p. 7);

Além disso, há o valor agregado, gerado no processo de transformar dados sem significado algum em informação. Kielgast e Hubbard (1997) sugerem quatro etapas - organização da informação, análise da informação, síntese e julgamento - para a realização desse processo.

Outros conceitos como valor intrínseco, extrínseco ou instrumental, valor inerente e valor contribuinte da informação, são utilizados geralmente por outras áreas do 
conhecimento, como a filosofia e a ciência da informação. Por questões de concernência com os objetivos do estudo esses conceitos não serão aqui tratados.

Pedro (1994) sugere que o valor assumido pela informação é variável, ou seja, depende de fatores como destinatário, formação, origem, objetivos, quantidade, qualidade, oportunidade, contexto da instituição, raridade e utilidade, que são determinantes na valorização da informação. Para o autor, caso se transmita uma informação a vários destinatários, cada um a avaliará segundo seus próprios interesses. A formação dos destinatários certamente fará com que cada um a considere de maneira diferente. Até a posição do destinatário na instituição impactará na valorização da informação, uma vez que determinadas posições exigem informações mais elaboradas, sumarizadas, enquanto outras carecem de mais detalhes.

Segundo esse autor, outros fatores, como a origem da informação, garantem maior ou menor credibilidade, impactando, automaticamente, seu valor. O objetivo da informação também influencia sobremaneira o seu valor, da mesma forma que a sua quantidade, "as doses em que é servida. Há uma grande diferença entre um relatório e uma dúzia" (idem, p.2).

A qualidade é considerada como uma característica que atribui valor à informação e pode estar relacionada à confiança inicial depositada e, posteriormente, à verificação dos efeitos da informação adquirida, a qual implica avaliação e critérios. A oportunidade é outro fator evidente na valorização da informação, pois pouco efeito resultará de uma informação disponibilizada tardiamente, quando já não é mais necessária.

O contexto da instituição também tem um efeito relevante no sentido de valorizar muito ou pouco a informação: se o contexto for de alta competitividade, a informação poderá valer muito; caso contrário, valerá pouco, segundo o autor.

Pedro (1994, p.3) salienta que a raridade da informação é também um fator que certamente influenciará em seu valor, "[...] trata-se de uma lei válida para os diamantes ou para qualquer bem produzido". E, por fim, a utilidade responde, muito 
significativamente, pelo valor da informação, por exemplo: a informação de que o valor médio previsto do dólar, para o próximo mês é $R \$ 2,15$ (dois reais e quinze centavos) pode ser altamente significativa para um indivíduo envolvido em atividades de exportações, mas pouco significativa para quem não possui envolvimento com o assunto, ainda que os resultados reais da informação influenciem a vida e os negócios de ambos.

No mesmo sentido, Bringberg, Pinelli e Barclay (1995) entendem que o valor da informação depende de quem a usa e para o que usa. Para alguns, ele pode ser a confortável sensação pelo aumento do conhecimento e redução da incerteza proporcionada pelo seu uso, ou o aumento da confiança em uma tomada de decisão. Para outros, porém, relacionados ao mercado, por exemplo, pode ser o preço que o comprador paga pela informação e, da mesma forma, o preço que o vendedor recebe pelo fornecimento da informação. Já para o investidor, é a diferença entre os custos de aquisição ou construção (no caso de sistemas) em relação aos retornos derivados do seu uso. Para o usuário final, é o benefício derivado, na forma de melhora nas decisões ou solução de problemas. Entretanto, os autores não apresentam formas concretas ou práticas para dar valor à informação.

Dessa forma, neste estudo, considerando as teorias expostas, entende-se que é possível atribuir um valor não financeiro para a informação. Contudo, ressalta-se que determinar qual a informação mais importante e o seu valor correspondente é uma tarefa complexa, pois mesmo as informações mais simples carregam em si outras informações adjacentes, que, juntas, sustentam as operações do ambiente, corporativo ou não.

Vejamos um exemplo: a informação P4R (Epstein, 1986) registra um lance de um jogo de xadrez e será aqui utilizada para exemplificar as características e a dificuldade de se atribuir valor para a informação. P4R tem significado apenas para indivíduos que conhecem as regras e técnicas do jogo de xadrez (significa mover o peão do rei 4 casas). É possível apenas com esses dados atribuir um valor à informação P4R? Obviamente que não, diversos fatores estão envolvidos na análise da informação e influenciam a sua valorização, como: 
- A importância da partida: caso a partida em que a informação é utilizada faça parte de um campeonato, sua importância e valor podem ser maiores em relação a uma simples partida de final de semana. Dependendo do contexto a informação pode assumir diferentes valores.

- O momento do jogo: o valor da informação pode estar relacionado a uma determinada etapa do jogo. Num momento " $x$ ", ela serve apenas para movimentar as peças do jogo, mas num momento "y", ela significa colocar o oponente em xeque. Portanto, como no ambiente corporativo, o valor da informação pode oscilar, aumentando muito em um determinado momento e diminuindo em outro.

- Os jogadores: no caso hipotético de um jogo de xadrez, os jogadores teoricamente conhecem as informações. O sucesso ou fracasso está associado em utilizá-las ou não, em função de suas estratégias e/ou habilidades no jogo. No ambiente corporativo, da mesma forma, o sucesso ou fracasso pode estar associado ao conhecimento, pelos jogadores, das informações disponíveis, das habilidades e estratégias para utilizá-las. Portanto, para um determinado jogador, em função de suas estratégias e de suas habilidades, a informação pode valer muito, ao passo que pode nada valer para outro.

Existem semelhanças estratégicas entre o ambiente corporativo e o jogo de xadrez, como a habilidade de gerenciar as jogadas, de movimentar as peças, de induzir o adversário ao erro. Em ambos os ambientes, somente informações de boa qualidade, o conhecimento e a habilidade em utilizá-las é que garantem o sucesso das partidas.

O ambiente corporativo certamente torna a gestão das informações muito mais complexa. Por todas essas características, a informação é um recurso extremamente caro, não pelo sentido financeiro, de valor, mas pelas suas características intrínsecas. O seu valor pode variar em função do contexto ou da interpretação de quem a usa, ou ainda do momento em que é necessária. Ela pode ser vendida, trocada e o seu valor não estar necessariamente atrelado ao seu uso. 
O seu valor está geralmente mais atrelado ao que ela representa do que ao custo e esforços para obtê-la.

Neste capítulo, foram explorados os aspectos da informação mais relevantes para o estudo. Além disso, buscou-se na literatura uma compreensão do que é a informação especialmente para a ciência da informação, mas também para outras áreas do conhecimento. Explorou-se também a relação da informação com a gestão do conhecimento e sua composição a partir dos dados. Foi também realizada uma reflexão acerca da possibilidade ou não de se tratar a informação como um ativo organizacional. Em síntese, esses são conceitos relevantes para o pleno entendimento dos aspectos da informação que serão tratados no próximo capítulo. 


\section{VALOR E QUALIDADE DA INFORMAÇÃO}

Considerando os aspectos em torno da gestão da informação, vistos nos capítulos anteriores, será realizada neste capítulo, uma reflexão acerca dos elementos considerados relevantes para a proposta deste estudo. Tendo como foco a abordagem contextual da informação ou seja, da percepção da informação no seu ambiente de uso, serão apresentados os elementos denominados como sendo de contexto. Dessa forma, a qualidade da informação, o valor da informação, os profissionais da informação e o contexto de uso das informações, são assuntos pertinentes aos objetivos do estudo e, portanto, serão tratados nas próximas seções.

\subsection{Formas de Valor da Informação}

As informações podem ser utilizadas em sua totalidade ou desmembradas, em partes, e cada parte ser utilizada distintamente de outras partes. Assim, cada pedaço de informação pode ter importância e valorização relativa ao seu uso. Porém, ao final do uso, ainda não será possível estabelecer o valor da informação.

Isso porque não existe uma teoria disponível capaz de explicar completamente o conceito de valor da informação. Tampouco parece provável que alguém possa desenvolver facilmente uma teoria capaz de estabelecer um valor específico para cada pedaço de informação (REPO, 1989).

Dentre os estudos que buscam compreender o valor da informação e suas vertentes, Repo (1989) descreve duas visões sobre as quais os conceitos de valor da informação se desenvolvem: uma visão filosófica, que possibilita uma reflexão acerca dos valores em termos comportamentais, culturais e das crenças relacionados à informação; e uma visão prática, relacionada aos aspectos de uso e de troca da informação (Figura 5). 


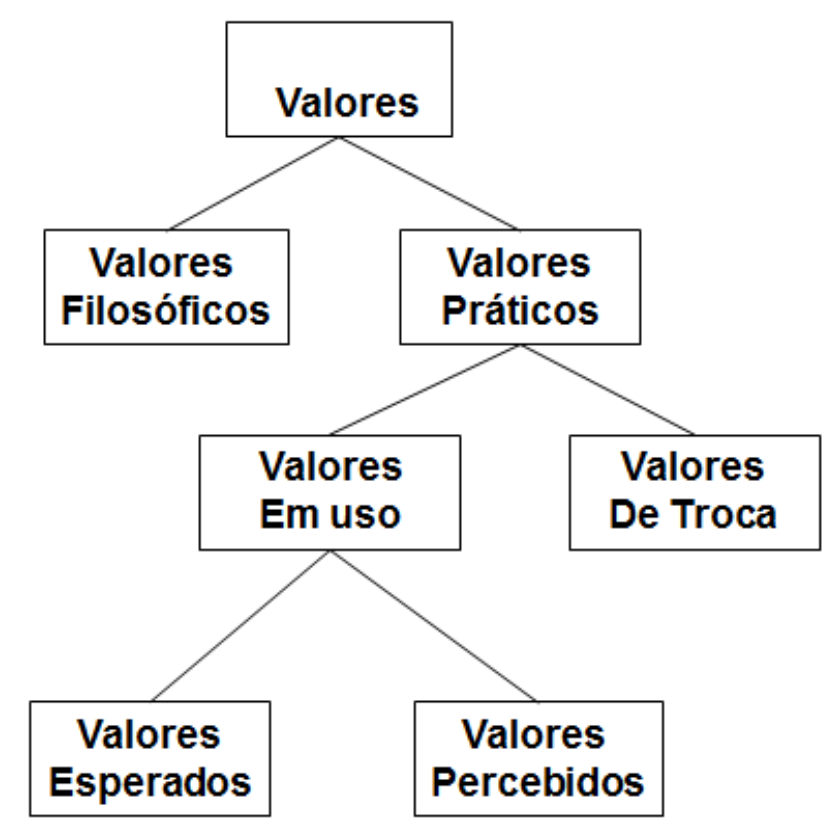

Figura 5 - Uma taxonomia da prática de valores Fonte: Adaptado de Repo (1989, p. 82)

A visão filosófica (intrínseca) tem significados relacionados aos aspectos intelectual, ético e emocional e são difíceis de serem especificados. A visão prática (instrumental), por sua vez, pode ser dividida em valor de uso e valor de troca, descritos da seguinte forma:

- Valor de uso: é categorizado de acordo com o fato de uso, ou seja, como a informação é usada e os benefícios obtidos por meio de seu uso. É considerado por alguns cientistas como a base conceitual para o valor da informação, ou seja, o principio do valor está associado ao uso da informação.

- Valor de troca: é um conceito econômico e refere-se ao produto informação e seu valor de troca. Ele pode ser derivado do valor de uso. Caso se encontre o seu valor (equivalente em dinheiro), pode se usar o custo de oportunidade para comparar a outros possíveis usos para o custo investido. O autor sugere que, caso isso ocorra, deve se realizar a ação de troca, porque somente por meio do valor de troca se pode efetuar uma comparação direta entre os valores. 
A partir de uma revisão da literatura sobre estudos realizados por pesquisadores envolvidos com as áreas econômicas, contábeis e gerenciais sobre o assunto, Repo (1989) salienta que embora a ideia da informação como forma de reduzir incerteza tenha sido bem aceita na literatura, as abordagens econômicas utilizando a probabilidade, por exemplo, não tiveram sucesso em termos práticos para medir o seu valor.

Em suma, os estudos não apontaram novidades em relação a métodos ou ferramentas para medir o valor da informação, mas foi possível obter ideias relacionadas à abordagem econômica, que se repetiram entre os estudos, conforme expõe Repo (1989):

- Informação reduz incerteza: a incerteza é usualmente descrita em termos da probabilidade, entretanto, na prática isso não é produtivo, por causa de problemas na formulação dos dados. Uma solução sugerida pelo autor é abandonar as formulações matemáticas e coletar dados estatísticos ou descritivos de estudos empíricos e verificar a existência ou não de alguma generalização.

- Informação perfeita: existe informação perfeita e ótima, usada em conexão com o mercado da informação. Um bom processo de seleção do produto informação torna-se importante por conta do dilúvio de informações (produtos) disponibilizadas atualmente pelos sistemas de informação.

- O papel da aprendizagem no uso da informação: esse papel é especialmente importante quando relacionado com a solução de problemas de informação.

Ainda, na visão desse autor, apenas alguns poucos estudos de caso ofereceram evidências empíricas do valor da informação, em especial os de abordagem econômica e que trataram do valor de troca da informação. Entretanto, muitos desses estudos relataram o valor da informação quando na realidade estavam avaliando sistemas de informação ou, simplesmente, o produto informação. 
Além disso, Repo (1989) afirma que em alguns estudos sobre a abordagem multimensional do valor da informação, se observa certa negligência no trato das abordagens. Por vezes, se percebe maior ênfase ao valor de uso sem se considerar o valor de troca e, da mesma forma, outros alternam entre valor de troca e valor de uso sem nenhuma distinção.

Desse modo, dentre as duas visões de valor da informação referênciadas, a filosófica e a prática, Repo (1989) adota a segunda visão em seus estudos, à qual ele denominou abordagem dual da informação, referindo-se ao valor de uso e ao valor de troca da informação.

Bringberg, Pinelli e Barclay (1995), por sua vez, postularam quatro forças que justificam ou orientam a importância de se construir uma teoria para definir o valor da informação:

- A perspectiva filosófica, que procura definir como a informação de forma geral ou mesmo em partes (pedaços) específicas, melhora a sociedade por meio da educação e da cidadania. Salientam, além disso, que a informação, nessa perspectiva, é o combustível do processo pelo qual as inovações são realizadas e ainda, provê mecanismos para o mercado funcionar, além de orientar a alocação de recursos escassos no sentido de melhorar o bem-estar econômico do Estado.

- As investigações teóricas que constantemente buscam por uma explicação inclusiva das várias forças que interagem para criar o valor da informação mercado e cognição.

- A abordagem operacional que atenta para quantificar - em termos financeiros os custos e o retorno da informação, no sentido de atender às necessidades, à tomada de decisão, para comprar ou investir em conteúdo informacional e tecnológico.

- A avaliação do processo para determinar quando um serviço de informação existente deve ser preservado, melhorado ou eliminado. 
Sendo parte dos objetivos desta proposta investigar a percepção do usuário da informação no contexto de uso da informação, o valor de uso se torna diretamente relacionado a este trabalho.

\subsubsection{Valor de Uso e Valor de Troca}

O valor de uso ou valor em uso é o núcleo de acesso ao valor da informação (Repo, 1989). Ele pode às vezes ser realizado de forma objetiva por meio de medidas como tempo e dinheiro economizados ou também como uma possibilidade de comparar o valor de troca de uma informação como produto e o valor de uso de seu conteúdo. Contudo, isso pode ser somente realizado de forma parcial, e o valor de uso pode ser caracterizado somente por medidas qualitativas.

Esse valor se refere à valorização da informação pelas partes interessadas, em função do seu uso. É um valor não monetário, atribuído pelo usuário à informação como uma representação da sua importância. A informação é adquirida como produtos e serviços da informação. Nesse sentido, o processo cognitivo dos indivíduos envolvidos nas tarefas das informações, juntamente com questões como tempo e aprendizagem para diferentes tipos de informação devem ser estudados (Repo, 1989).

Ainda, segundo esse autor, o valor de uso é categorizado de acordo com o fato do uso. Isto é, como a informação é usada e os benefícios do seu uso. Esse valor pode ser definido em três partes e cada uma tem um papel importante no acesso ao valor da informação na prática, São eles:

- Valor de uso subjetivo esperado: esse valor é posto em prática quando o indivíduo decide se procura e usa um produto ou serviço de informação ou não. A sua avaliação é baseada em experiências passadas ou expectativas do produto informação e serviços disponíveis. Ele está relacionado ao processo de criação trabalho/conhecimento, em que a informação pode primeiramente ter um valor de uso esperado, para despertar o interesse do usuário, que decide se a 
usa ou não. Exemplos desse tipo de valor podem ser expressos quando o indivíduo escolhe informações que considera importantes para o sucesso de determinada tarefa, baseado em conhecimentos e experiências anteriores em situações semelhantes.

- Valor de uso subjetivo: esse tipo de valor é geralmente baseado em opiniões individuais do valor da informação quando usado para o desenvolvimento das atividades, geralmente no ambiente de trabalho. A redução de incerteza é uma expressão usada comumente para esse valor.

- Valor de uso objetivo: é o valor real do efeito obtido pela informação na tarefa e seus resultados.

Esses conceitos, segundo o autor, pressupõem que o usuário da informação atribui valor para uma parte da informação quando ela é usada, o que explica da seguinte forma:

- Primeiramente a informação tem valor de uso esperado para despertar o interesse do usuário, que decide ou não pelo seu uso (subjetivo esperado).

- O valor em uso pode ser identificado se for possível relacionar o papel da informação para o processo de conhecimento/trabalho adquirido pelo usuário (valor subjetivo).

- Isolados os impactos de uma informação, em particular para uma saída ou resultado, o usuário atribui um valor para a informação (valor objetivo).

Repo (1989) sugere que é importante distinguir entre o que é esperado e o que é percebido, em termos de valor de uso. Assim, esse valor pode ser desmembrado em valor esperado e valor percebido, contudo, isso somente pode ser fixado pelo usuário enquanto estiver utilizando os conhecimentos, obtidos com a informação, em suas tarefas e analisando os resultados delas. Isso acontece porque as bases para determinar o valor de uso da informação é o conhecimento que se obtém na realização das tarefas. Além disso, considera impossível medir o valor de uso em 
sua totalidade, pois somente alguns indicadores podem ser utilizados pelos usuários para avaliar como as informações influenciam em suas atividades.

Por outro lado, Nonaka e Takeuchi (1997) explicam que um indivíduo pode, em determinadas tarefas, acrescentar conhecimentos ao seu repertório por intermédio da resolução de problemas. O conhecimento resultante da realização da tarefa é um novo conhecimento, o qual pode ser formulado ou formatado como informações de saída, determinando desse modo o valor de troca da informação, por exemplo.

Informações de saída são um meio pelo qual uma pessoa pode se comunicar com outra e, dessa forma, atribuir um valor de troca para a informação ou usar a informação como produto. Assim, valores de troca podem ser identificados e medidos em determinada comunidade ou mercado.

Entretanto, na prática, o mercado indefinido da informação torna essa valorização muito difícil de ser estabelecida (REPO, 1989). Como se observa, o valor de troca é um conceito econômico e refere-se à informação como um produto e seu correspondente valor. É uma forma de valor necessária quando se deseja comparar valores entre si, em situações em que é preciso determinar o preço de uma parte da informação em determinado mercado.

Nesse sentido, definir uma forma de valor para informação atende às expectativas situadas em dois aspectos principais: de um lado, a necessidade de um valor que possibilite alguma forma de classificação e seleção da informação útil para determinados processos e eventos, que seja possível de ser praticada pelas organizações; de outro, uma forma de valor que possibilite o comércio (compra, venda, troca) da informação. Ambas as formas de valor são importantes. Entretanto, do ponto de vista do uso, a primeira se mostra mais relevante; já do ponto de vista do investidor, a segunda apresenta maiores atrativos.

Dentre as várias formas de valor da informação tratadas na literatura, serão utilizados na presente proposta, o valor esperado, o valor percebido e o valor agregado, a fim de identificar como os participantes deste estudo percebem tais conceitos. 


\subsection{QUALIDADE DA INFORMAÇÃO NAS ORGANIZAÇÕES}

O termo qualidade, na norma ABNT NBR ISO 9000 (2005, p. 14), é definido como "o grau no qual um conjunto de características [...] inerentes satisfaz a requisitos". Nesse sentido, a qualidade pode ser entendida como que a totalidade das características de uma entidade que the confere a capacidade de satisfazer as necessidades do cliente.

Marshall Junior et al. (2008 p. 32-33) salientam que a similaridade funcional entre produtos e bens de consumo é cada vez maior e que o diferencial está na sintonia com os colaboradores. Justificam que "a qualidade está mais associada à percepção de excelência nos serviços" e os serviços estão diretamente relacionados às pessoas, ou seja, o "elemento humano e sua qualidade representam o grande diferencial contemporâneo [...]". Relatam ainda que os conceitos da qualidade podem ser estruturados em cinco abordagens principais (a transcendental, a baseada no produto, a baseada no usuário, a baseada na produção e a baseada no valor) para a definição do que seja a qualidade.

Por questões de concernência com os objetivos deste estudo, serão utilizadas apenas as abordagens baseada no usuário e baseada no valor, cujos conceitos estão alinhados com os objetivos da proposta, exceto pelo fato de se tratar da qualidade da informação, que apresenta características muito específicas em relação a outros produtos, recursos e serviços.

A abordagem baseada no usuário preconiza que a qualidade consiste na capacidade de satisfazer os desejos do usuário. Ou seja, a qualidade de um produto depende de até que ponto ele se ajusta aos padrões de preferências do consumidor.

A informação se enquadra em um grupo de ativos denominados intangíveis. O PNQ (Prêmio Nacional da Qualidade) concebido e administrado pela FNQ (Fundação Nacional da Qualidade) possui dentre os seus oito critérios de excelência, o item informações e conhecimento, cujo objetivo é examinar a gestão das informações nas organizações avaliadas, especificamente sobre os processos de identificação, desenvolvimento, manutenção e segurança dos ativos intangíveis, subdivididos em: 
Informações da organização, informações comparativas e ativos intangíveis (MARSHALL JUNIOR et al., 2008).

A qualidade é um conceito de amplo escopo e envolve tanto os ativos tangíveis (bens físicos) quanto os intangíveis (bens não físicos - informações, conhecimento, dentre outros). Nesse sentido, a área do conhecimento denominada qualidade da informação trata dos aspectos relevantes da informação e, ao mesmo tempo, possibilita identificar atributos e características para os processos de avaliação e qualificação da informação, a fim de garantir sua eficácia nas organizações.

Muitos são os autores que buscaram compreender como se processa a qualidade da informação nas organizações e a sua relevância nos contextos em que é necessária. Para Marchand (1990), ela pode garantir vantagens competitivas para determinadas instituições e, por outro lado, a sua ausência pode resultar em prejuízos. Essas afirmações são uma síntese dos resultados dos diversos estudos produzidos sobre a qualidade da informação (CAPURRO e HJØRLAND, 2007; MARCHAND, 1990; PAIM, NEHMY e GUIMARÃES, 1996; OLETO, 2006; REPO, 1989; WANG, 1998).

Apesar de sua importância e dos diversos estudos desenvolvidos para melhor compreendê-la, os conceitos em torno da qualidade da informação apresentam alguns problemas relacionados à sua formulação, como afirmam Paim et al. (1996) e Oleto (2006), segundo os quais o conceito é problemático, pois a qualidade por si só é considerada uma das categorias fundamentais do pensamento e elas são as mais difíceis de serem definidas, porquanto geralmente, são utilizadas para definir outras. Afirmam, nesse sentido, que as dimensões são parâmetros ou atributos relacionados ao conceito e que quantificá-los é uma forma de contornar os problemas inerentes ao conceito:

Qualquer critério de avaliação da qualidade da informação é, por natureza, subjetivo. É praticamente impossível encontrar um critério de mensuração simples, preciso e satisfatório [...]; a informação nunca será exata porque depende do contexto; nunca está isolada, tem vida própria e sua qualidade depende da visão, do nível de conhecimento, da interpretação de seu receptor. A busca da qualidade total da informação é similar à busca do eldorado (PAIM, NEHMY e GUIMARÃES, 1996, p. 114). 
Problemas de qualidade da informação são comumente relatados na literatura e conhecidos pelos profissionais de sistemas de informação. Porém, segundo Oleto (2006), são desconhecidos da maioria dos usuários da informação. No entanto, a percepção de qualidade dos usuários está alicerçada mais na experiência de uso do que nos conceitos ou dimensões relacionados à informação. Essa percepção se deve, segundo o autor, provavelmente ao fato de a teoria não especificar uma forma de atribuir valor à informação, pois ela apenas orienta a apuração de sua qualidade, suficiente para a obtenção de resultados significantes para as instituições, em termos de qualidade dos processos de gestão e de tomada de decisão.

Os conceitos relativos à qualidade da informação, termo geralmente empregado pela ciência da informação e qualidade de dados, comumente usado pela ciência da computação, são utilizados como sinônimos neste estudo. Porém, em determinadas situações, um ou outro termo poderão ser aplicado, especialmente para expressar ideias ou contextos tratados pelos autores, preservando a forma de origem, reproduzidos como os autores os utilizaram. Justifica-se a opção, pelo fato de alguns estudos usarem ambos os termos com significados específicos. O estudo de Silva e Favaretto (2008), por exemplo, no qual as dimensões são utilizadas tanto para aferição da qualidade dos dados em uma base de dados, quanto para aferição da qualidade das informações em processos organizacionais.

\subsubsection{Categorias da qualidade da Informação}

Wang e Strong (1996) entendem que a qualidade de dados é considerada um conceito intrínseco, independente do contexto no qual o dado é produzido ou usado. Para prover dados de qualidade é necessário entender seu significado para os usuários, aqueles que usarão os dados no exercício de suas atividades, a quem os autores denominaram de consumidores de dados. Nessa perspectiva, definem qualidade de dados como a adequação para uso pelos consumidores e afirmam que a gestão eficiente da qualidade de dados maximiza a eficácia das informações nos processos de tomada de decisão ou de gestão. 
Para justificar tais afirmações, os autores realizaram um estudo para identificar as dimensões da qualidade da informação mais importantes na visão dos usuários. Em seus estudos, Wang e Strong (1996) recorrem aos resultados de um relatório em que, de 500 empresas, cujas vendas anuais giravam em torno de U\$20 milhões ao ano (à época), participantes de uma pesquisa, 60\% delas apresentavam problemas de qualidade de dados.

A fim de compreender as necessidades dos consumidores, os autores utilizaram técnicas de marketing para identificar a estrutura hierárquica de necessidades dos consumidores e medir a importância de cada uma. Para tanto, procuraram identificar atributos da qualidade de dados considerados importantes para os usuários. $O$ estudo identificou a taxa de importância desses atributos e estruturou a taxa de importância e os atributos em uma hierarquia representada de acordo com as necessidades dos consumidores.

Alguns critérios foram estabelecidos pelos autores, com o objetivo de garantir o sucesso do estudo e para que os consumidores pudessem participar, tais como:

a) Acessibilidade: 0 dado precisa estar acessível para o consumidor. Por exemplo, saber como recuperar o dado.

b) Interpretabilidade: o consumidor deve ser capaz de interpretar o dado, ou seja, o dado não estar representado em uma língua estrangeira.

c) Precisão: o consumidor deve encontrar o dado preciso. Por exemplo, os dados devem ser corretos, objetivos e de fontes confiáveis.

d) Relevância: o dado precisa ser relevante para o consumidor. Os dados são relevantes e oportunos para uso pelos usuários em processo de tomada de decisão.

Destaca-se como resultado do estudo de Wang e Strong (1996) o desenvolvimento de um framework (Figura 6) que possibilitou capturar aspectos da qualidade de dados importantes para os consumidores. Foram coletados junto aos consumidores 
118 atributos da qualidade de dados, compilados em 20 dimensões, agrupados em 4 categorias: intrínseca, contextual, representacional e acessibilidade.

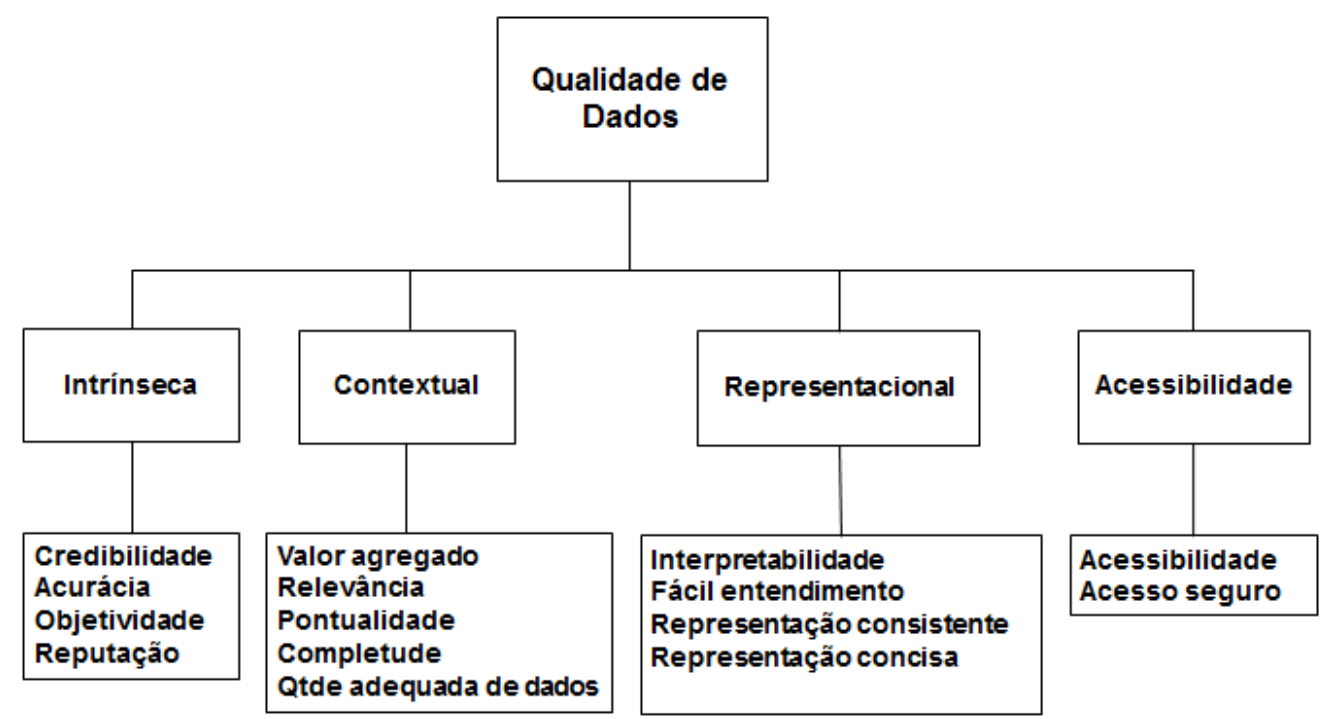

Figura 6 - Framework Conceitual da Qualidade de Dados (WANG e STRONG, 1996)

Segundo Wang e Strong (1996), usando este framework, os profissionais de sistemas de informação serão capazes de entender melhor e encontrar as qualidades de dados necessárias para os consumidores.

As quatro categorias da qualidade identificadas no processo, descritas na sequência, representam a percepção das dimensões na visão dos usuários.

\subsubsection{Categoria Intrínseca}

A Categoria Intrínseca denota que os dados têm qualidade por direito próprio. Relatam que, ao contrário da visão tradicional de desenvolvimento, na visão dos consumidores, a credibilidade e reputação são partes intrínsecas da qualidade e que a acurácia e a objetividade, sozinhas, não são consideradas suficientemente de alta 
qualidade. Esses conceitos estão em acordo com alguns aspectos da qualidade de produtos, em que as dimensões da qualidade enfatizadas pelos consumidores são mais amplas do que as enfatizadas pelos produtores. Da mesma forma, são enfatizadas, pelos profissionais de sistemas de informação, as dimensões acurácia e objetividade. Faz parte dessa categoria as dimensões: credibilidade, acurácia, objetividade e reputação.

\subsubsection{Categoria Contextual}

A categoria contextual assinala os requisitos da qualidade de dados que devem ser considerados no contexto de uso das informações. Está relacionada a cinco dimensões, cujas características a tornam dependente do contexto e dos usuários. Isso significa que as tarefas e seus contextos variam através do tempo e dos consumidores.

Além disso, segundo Wang e Strong (1996),os parâmetros dessa categoria mudam para cada dimensão, e o consumidor pode especificar qual tipo de tarefa está sendo realizado e, consequentemente, configurar os parâmetros mais apropriados para a tarefa. As dimensões listadas nesta categoria são as seguintes: completude, pontualidade, quantidade adequada, valor agregado e relevância.

Essa categoria fundamenta os conceitos sobre os quais se desenvolve este estudo.

\subsubsection{Categoria Representacional}

Essa categoria está relacionada aos aspectos do formato dos significados dos dados. Para Wang e Strong (1996), esses aspectos sugerem que, para os consumidores, não basta os dados estarem concisos e consistentemente 
representados, mas também devem ser interpretáveis e de fácil entendimento. Fazem parte dessa categoria as seguintes dimensões: interpretabilidade, fácil entendimento, representação consistente e representação concisa.

\subsubsection{Categoria Acessibilidade}

A última categoria, a acessibilidade, está associada com as necessidades dos usuários no acesso aos dados em computadores, por exemplo. Segundo Wang e Strong (1996), ela é um importante aspecto da qualidade de dados; contudo, existe uma pequena diferença entre o tratamento da acessibilidade como uma categoria geral da qualidade de dados ou se pode separá-la em outras categorias. São dimensões dessa categoria: acessibilidade e o acesso seguro.

Os autores reafirmam que para melhorar a qualidade de dados, é preciso entender o que significa a qualidade de dados para os consumidores de dados. Dessa forma, desenvolveram outros estudos a fim de compreender a importância do usuário na avaliação da qualidade de dados.

Destaca-se, nesse sentido, a identificação de três tipos de papéis desempenhados pelos usuários, denominados por Strong e Wang (1997) de produtores, guardiões e consumidores de dados. No estudo, os autores denominaram o processo de produção da informação como um sistema de manufatura de dados (ver Quadro 4), em que cada papel desempenhado pelos usuários está associado com um processo ou tarefa.

Por exemplo, os produtores estão associados ao processo de produção de dados, enquanto os guardiões estão envolvidos com as tarefas de armazenar, manter e assegurar a segurança dos dados. Os consumidores, por sua vez, são as pessoas ou grupos de pessoas associados aos processos de utilização dos dados. Desse estudo surgiram padrões relacionados aos problemas da qualidade de dados envolvendo cada um dos papéis. Os resultados demonstraram a importância da 
estruturação das dimensões nas quatro categorias da qualidade identificadas no estudo anterior (Figura 6).

Para chegar a esses resultados, Strong e Wang (1997) analisaram aproximadamente 42 projetos sobre qualidade de dados em três organizações com experiência em qualidade de dados. Todas possuíam setores responsáveis pela gestão dos problemas associados à qualidade de dados, entretanto, apontaram que, apesar dos processos de acompanhamento, os erros persistiam. Por causa desses resultados os autores definiram problemas de qualidade de dados como "qualquer dificuldade encontrada ao longo de uma ou mais dimensões que tornem os dados impróprios para uso" (idem, p. 104).

\subsubsection{Relação entre as abordagens da qualidade e a percepção nos negócios}

Marchand (1990, p. 9) relata a coexistência de cinco abordagens (transcendente, baseada no usuário, baseada no produto, baseada na produção e a baseada no valor) diferentes da qualidade da informação nos negócios das organizações e ressalta que, devido à improvável comunicação entre usuários e fornecedores da informação, cada uma destas abordagens compartilha um problema comum: elas oferecem somente uma parte e, por vezes, uma visão vaga dos elementos básicos da qualidade da informação.

Para a primeira delas, a abordagem transcendente, a qualidade da informação é absoluta e universalmente reconhecida. A qualidade da informação é tida como sinônimo de excelência e é, ao mesmo tempo, atemporal e permanente, ou seja, se mantém apesar de mudanças de gostos e estilos. Marchand (1990) conclui que a universalidade da excelência e do valor duradouro é relativa ao usuário e, portanto, está muitas vezes nos olhos de quem vê, o que demonstraria, em tese, a ambiguidade de tal abordagem para a qualidade. 
Já a segunda abordagem, a baseada no usuário, trata-se de uma visão subjetiva da informação, pois se baseia na visão dos usuários sobre a informação e esses, individualmente, têm necessidades e estilos cognitivos diferentes e, portanto, querem coisas diferentes e optarão por fontes de informação ou tipos de informação que apresentem melhores qualidades, no sentido de atender suas necessidades.

Marchand (1990) aponta dois problemas dessa abordagem. Primeiro, ela agrega a diversidade de preferências individuais que podem conduzir a definições da qualidade em termos de design e de produtos e serviços de informação; segundo, é difícil distinguir entre os atributos da informação que conotam qualidade e aqueles que simplesmente maximizam a satisfação do consumidor.

Wagner (1990), por outro lado, afirma que esta é uma abordagem consistente e salienta que nela, o valor da informação depende do usuário e do contexto em que ela é vista e utilizada. Dessa forma, o usuário, quer individual quer coletivo, faz o julgamento da qualidade ou valor da informação baseada na sua percepção e preferências.

A terceira abordagem, a baseada no produto, vê a qualidade da informação em termos precisos e identificáveis. A qualidade da informação está diretamente relacionada com as características de produtos da informação. Essas características são, portanto, passíveis de serem mensuradas e quantificadas, ou seja, trata a informação como coisa. Nesse contexto, o termo informação é utilizado como atributo de objetos, tais como dados, textos e documentos, mencionados como informação. Procura-se atribuir valor a "coisas pelas quais alguém se torna informado", sendo, portanto, possíveis de serem mensuradas, já que tangíveis (MARCHAND, 1990, p.9). O problema dessa abordagem é que geralmente não existe correspondência de um para um, entre os atributos informação e qualidade.

Quanto à abordagem baseada na produção, ela é focada no atendimento de requisitos estabelecidos para o processo (do consumidor), ou seja, observa-se uma tendência de adequação às necessidades de informação do consumidor. Por exemplo, "fazer os trabalhos direito na primeira vez, dentro do orçamento e no tempo" (MARCHAND, 1990, p.9-10). 
As necessidades do cliente são definidas e documentadas e qualquer desvio da especificação implica na perda de qualidade. Para esse autor, essa abordagem tem pouca base teórica e trata-se de um caráter mais operacional para a administração de serviços de informação.

A última abordagem, a baseada no valor, define a qualidade da informação utilizando como referência as trocas entre critérios concorrentes de valor da informação, em que apenas um é a qualidade da informação. O foco dessa abordagem é o conceito de uso da informação, equilibrado com a facilidade de uso, redução de ruídos, adaptabilidade, economia de tempo e, é claro, a qualidade da informação.

Por fim, Marchand (1990, p.10-12) propõe desagregar o conceito de qualidade da informação em oito dimensões inter-relacionadas, sendo: valor real, características, confiança, relevância, temporalidade (significado ao longo do tempo), validade, estética (formato) e valor percebido. Para ele, existe uma inter-relação entre as dimensões e a necessidade de compreender, que são próprias do produto informação, porém, por vezes, a busca da melhoria em uma dimensão pode incorrer em prejuízos para outra ou outras.

No presente estudo, a proposta prioriza, dentre essas dimensões, a relevância e o valor percebido, por estarem alinhadas conceitualmente aos objetivos do estudo. $\mathrm{O}$ conceito de relevância está associado às diferenças na percepção da informação entre projetistas de sistemas e agentes da tomada de decisão. Pode também estar relacionada com seu significado no tempo, ou ainda associada com a conformidade às especificações, ou seja, as informações são percebidas pelos usuários como relevantes em um momento anterior, mas podem não ser relevantes no momento atual, ou ainda, relevantes em determinados contextos, mas não em outro.

Já o conceito de valor percebido está relacionado com à percepção de valor que pode ser atribuída à informação, pelo usuário de sistemas de informação, após o uso efetivo de determinada informação. Para Marchand (1990), essa dimensão refere-se à irracionalidade da atribuição de reputação pelo usuário a sistemas de informação. Relata que, por vezes, o usuário não possui informações completas 
sobre atributos de produtos ou serviços de informação e depende de medidas indiretas para comparação de serviços de informação. Às vezes, a reputação de um produto ou serviço de informação pode legitimar a confiança que um usuário coloca no seu uso em função de deficiências de outras dimensões, como acurácia ou confiança.

A clareza de entendimento das dimensões da qualidade da informação resulta em melhores bases para avaliação das transações envolvidas no gerenciamento estratégico de informações nos negócios, porém, existe certa dificuldade de descrever ou mensurar a qualidade da informação (MARCHAND, 1990). Em sua visão, a percepção de gerenciamento da qualidade da informação tem sido vista historicamente, como um misto das abordagens transcendental e baseada na produção, focadas nos aspectos físicos de acesso e entrega de informações e documentos eletrônicos. Afirma, no entanto, que no contexto de gerenciamento de tecnologias da informação, o foco tem sido na eficiência técnica, enfatizando as abordagens baseada no produto e baseada no usuário.

A respeito da relação da qualidade da informação com lucratividade, Marchand (1990) lembra que é muito comum olhar para esta relação pelo lado do custo, em que baixo custo de produção de serviços e produtos da informação certamente pode conduzir a lucros, especialmente em instituições que possuem base de produção intensiva de informação, como bancos, seguradoras, dentre outras. Se os custos envolvidos na produção de informação resultar em aumento na contribuição dos serviços e produtos da informação na organização, então, altos lucros poderão advir. Porém, nesse sentido, sugere é importante considerar, obviamente, as variações de tipo de mercado, como indústrias, bancos, dentre outros.

Desse modo, existe relação entre qualidade da informação e custos, pois altos custos investidos na melhoria da qualidade da informação podem conduzir a melhores usos da informação em processos de tomadas de decisão, por exemplo. Essa relação pode ser vista também como um resultado dos custos nas fontes de informação de sistemas e serviços, como avaliação de seu uso e valor real, pelos tomadores de decisão. Os custos de manutenção de fontes de informação confiáveis e precisas são considerados custos de qualidade, as quais a gestão deve suportar 
após a avaliação de custo/benefício ser realizada (MARCHAND, 1990). Por fim, o autor conclui que:

este desafio vai empurrar-nos para ir bem além de nossa visão aceita de qualidade da informação em um contexto de gestão, e, talvez, levar-nos a novas e inovadoras formas de definir nossos papéis e responsabilidades em um mundo cada vez mais cercado por sobrecarga de informação e ansiedade. (Idem, p. 16)

Essas visões da qualidade da informação sugerem que os gestores acreditam que os processos de melhoria da qualidade de informação são necessários e, portanto, que os investimentos se justificam. Por fim, sugere que o gerenciamento de informações estratégicas em uma empresa requer uma avaliação mais estreita, mais próxima entre qualidade da informação e o aprimoramento do valor do negócio.

Os estudos de Marchand (1990) possibilitaram uma reflexão a respeito das dimensões da qualidade e dos efeitos da qualidade associadas com conceitos de custos e valor da informação na organização. Além disso, dentre as abordagens apresentadas, as abordagens baseadas no usuário e baseadas no valor, bem como as dimensões que as compõem, estão alinhadas com os objetivos deste estudo e são melhor detalhadas no capítulo 4 .

\subsection{GESTÃo TECNOLÓGICA dA INFORMAÇÃo}

Os estudos em torno dos efeitos da informação na organização têm sido relatados como de extrema relevância. Na verdade, o papel da informação no cenário atual nunca foi tão evidente, muito mais devido à facilidade de acesso e transformação propiciada pelas novas tecnologias do que propriamente pelas características intrínsecas da informação.

Oliveira (2007) faz uma reflexão sobre as tecnologias de informação no início dos anos 2000 e entende que foram momentos importantes na história da sociedade, 
mas em especial das organizações, que tiveram que se adaptar muito rapidamente para se manterem competitivas. As empresas passaram por um turbulento processo de transformação influenciado pela competição que, apesar de ter gerado oportunidades sem precedentes, extrapolou os limites tradicionalmente conhecidos até então, como regionalização ou atividade econômica.

Esse cenário era composto por empresas estreantes em diferentes setores industriais e econômicos e ampliados pela quebra de barreiras de acesso a novos mercados. Tudo isso fez com que as empresas procurassem alternativas para fora de sua zona de conforto, buscando novos clientes e novos negócios. Houve ruptura na forma tradicional de comportamento das empresas. Os bancos passaram a oferecer serviços de outras naturezas como seguros, corretagem, cartões de créditos. Da mesma forma, as operadoras de cartões de créditos entraram em território originalmente dominado pelos bancos, e passaram a oferecer serviços financeiros, anteriormente oferecidos apenas pelos bancos (OLIVEIRA, 2007).

$\mathrm{Na}$ verdade, as transformações às quais as empresas se viram obrigadas a se adaptar foram bem maiores e mais impactantes do que as expressas nesta síntese. Um dos principais fatores que influenciou essa onda de transformações certamente foi a tecnologia da informação. Observa Oliveira (2007, p. 68) que "a reestruturação das economias nacionais tem sido implacável, sendo em grande parte impulsionada por avanços em tecnologia da informação".

Os motivos de tamanha importância atribuída à tecnologia da informação no cenário organizacional, como impulsionadora de transformações de tal magnitude, são a sua capacidade de penetração em, praticamente, todos os segmentos da sociedade, corporativos ou não, e o atendimento às exigências das especificidades de cada um deles.

Para entender essa capacidade da tecnologia da informação, basta observar como ela se encontra atualmente. Ela está presente e embarcada tanto em um automóvel de brinquedo operado por controle remoto quanto em um automóvel de alto desempenho; em complexos e modernos processos de automação industrial ou na 
automação residencial, que, mesmo em escalas reduzidas, utilizam aparatos tecnológicos semelhantes.

Esses aspectos da tecnologia da informação conduziram naturalmente à evolução, ao crescimento e ao desenvolvimento das organizações ao longo do último século. Conforme ressalta Oliveira (2007), na era industrial, o capital e a tecnologia da informação estiveram focados na produtividade industrial, mas na era da informação, o capital e a tecnologia estão focalizados na produtividade do trabalhador da informação e no prestador de serviços. A positividade dessa relação da tecnologia da informação com as estratégicas organizacionais está na capacidade de reação que proporciona para as organizações, reduzindo dependências de tempo e de espaço.

A tecnologia aliada à globalização dos mercados causou forte impacto na forma como as organizações utilizavam ou valorizavam a tecnologia. Num curto espaço de tempo, surgiram novos concorrentes situados ou não do outro lado do mundo, entrando em seus territórios, disputando o mercado 24 horas por dia e 7 dias por semana. Essa realidade somente se tornou possível com a evolução tecnológica dos computadores, juntamente com o advento da internet e das redes de comunicação.

$\mathrm{Na}$ atualidade, a informação por meio das tecnologias sustenta os processos de gestão organizacional, promovendo a integração dos processos de negócio entre os os níveis operacional, tático e estratégico (AUDY, ANDRADE e CIDRAL, 2005). Laudon \& Laudon (2007) entendem também a existência de um quarto nível, o do conhecimento, em que se situam os serviços relativos à administração e os especialistas, como engenheiros, advogados, dentre outros.

Neste sentido é importante considerar os seguintes pressupostos:

a) Conceitualmente, as instituições são estruturadas em três níveis organizacionais - o operacional, o tático e o estratégico (AUDY, ANDRADE e CIDRAL, 2005); 
b) A operacionalização das funções administrativas, direção, planejamento, controle e organização é embasada em informações provenientes em sua maioria dos sistemas de informações, em seus níveis operacional, tático e estratégico.

c) A gestão da informação nas organizaões envolve o uso de informações provenientes tanto de sistemas internos quanto de sistemas externos.

Os sistemas internos são geralmente alimentados por informações provenientes dos diversos processos de negócio da instituição, como compras, vendas, pagamentos, recebimentos, dentre outros. Os dados inseridos por esses sistemas possuem formatos diversos e normalmente necessitam de algum tratamento para que sejam adequados ao uso ou padrão da instituição. Os tratamentos são realizados em diversas etapas, conforme descreve a cadeia de valor da informação, dada por Schwolow e Jungfalk (2009).

Os dados, em sua maioria, são inseridos nas instituições pelo nível operacional utilizando ou não a intervenção humana. Nesse nível existem poucas atividades relacionadas ao tratamento das informações. Geralmente os sistemas de informação acabam realizando as filtragens necessárias e garantem a qualidade das informações utilizadas. Falhas nesses processos podem influenciar toda a cadeia de valor da informação.

$\mathrm{Na}$ sequência, os dados são processados, estruturados e armazenados, e posteriormente transferidos de forma sintética para os sistemas de apoio aos níveis táticos e estratégicos (Figura 7), nos quais geralmente são recebidos, tratados e utilizados por outros sistemas, como data warehouses ou outros softwares denominados para os ambientes de $\mathrm{BI}$ (Business Intelligence), dentre outros.

No nível tático e especialmente no nível estratégico, as informações ganham novos formatos. Não interessam informações pontuais sobre determinada transação, mas sim o montante de transações realizadas em determinado período para um grupo específico de produtos ou clientes, por exemplo. Em tal cenário, as informações são apresentadas geralmente na forma de gráficos, relatórios e/ou demonstrativos sintéticos (O'BRIEN, 2004). 


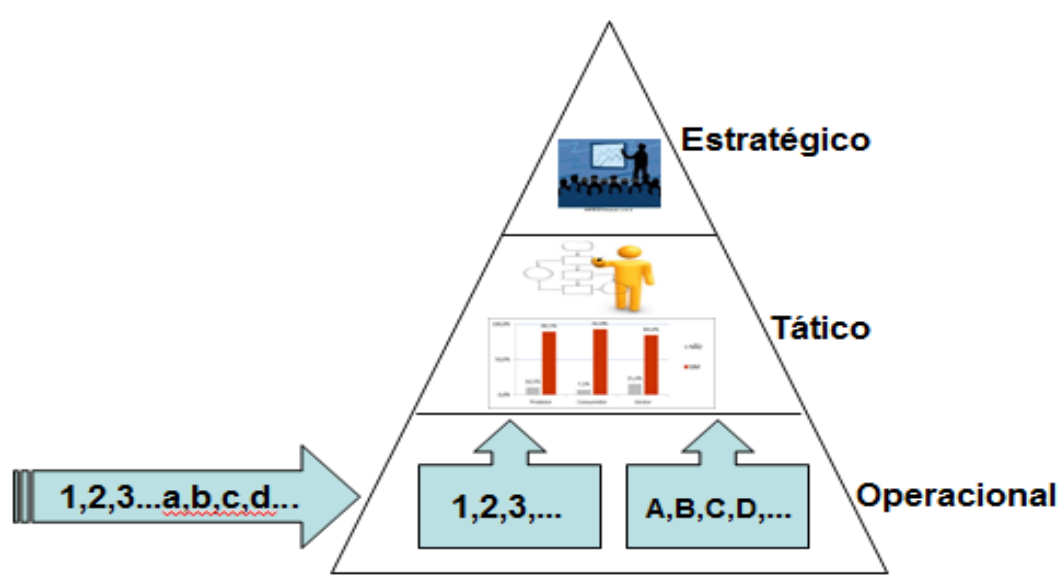

Figura 7 - Fluxo das informações através dos níveis organizacionais Fonte: O próprio autor

O nível organizacional estratégico também coleta informações do ambiente externo, entretanto, elas são pontuais ( $a d$ hoc), geralmente não estruturadas, ao contrário das informações que abastecem a base operacional, oriundas em sua maioria dos sistemas de informações vigentes na instituição, que dialogam com o mercado por meio das transações (CORTES, 2008; FOINA, 2010).

Por isso os processos de entrada, tratamento e distribuição da informação no ambiente organizacional são relevantes para o presente estudo. Eles são componentes da cadeia de valor da informação (LAUDON e LAUDON, 2007; SCHWOLOW e JUNGFALK, 2009) e podem ser utilizados como exemplos de cenários em que será realizada a investigação sobre a percepção da informação, pelos usuários e profissionais da informação, neste estudo.

\subsection{CARACTERÍSticas do PROFISSIONAL dA INFORMAÇÃo}

Dentre os inúmeros estudos sobre qualidade da informação disponibilizados pela literatura nas últimas décadas, os realizados por Marchand (1990), Repo (1986, 1989), Strong e Wang (1997), Wang (1998), Wang e Strong (1996), dentre outros, 
relatam a importância da qualidade da informação de acordo com a percepção dos seus usuários. Os autores entendem que a qualidade da informação é fundamental nos processos de gestão organizacional e que a baixa qualidade da informação pode implicar prejuízos significativos para as instituições.

Salientam, porém, que o impacto da qualidade da informação nas organizações é mais evidente quando os usuários adotam-nas em suas práticas. Isso ocorre porque a relação do usuário com a informação é unica e independente de métodos, portanto, a avaliação da informação é subjetiva.

A subjetividade da avaliação está associada com a percepção que se tem da informação, como se observa em Casanova (1990, p. 50):

Informação nunca será exata, porque a informação é um elemento dentro
de um contexto. Ela nunca é isolada, ela não fica por si só. A informação
tem uma causa e uma consequência e esta causa e esta consequência são
tão variadas quanto as pessoas na terra.

Significa, em síntese, que a informação está associada a um contexto e sua avaliação depende, portanto, da percepção de cada indivíduo sobre a informação e dos elementos que compõem o contexto em si. Torna-se importante, dessa forma, para este estudo, entender os diferentes perfis dos usuários da informação, descritos por Santos (1996, p. 5) como profissionais da informação, pois:

[...] de uma forma ou outra, fazem da informação o seu objeto de trabalho, entre os quais, arquivistas, museólogos, administradores, analistas de sistemas, comunicadores, documentalistas e bibliotecários, além dos profissionais ligados à informática e às tecnologias da informação e das telecomunicações.

De acordo com a Classificação Brasileira de Ocupações CBO (2002) os profissionais da informação são conhecidos como:

a) Bibliotecário: biblioteconomista, bibliógrafo, cientista de informação, consultor de informação, especialista de informação, gerente de informação, gestor de informação.

b) Documentalista: analista de documentação, especialista de documentação, gerente de documentação, supervisor de controle de processos documentais, 
supervisor de controle documental, técnico de documentação, técnico em suporte de documentação.

c) Analista de informações: pesquisador de informações de rede.

Existem outras denominações utilizadas como sinônimos de bibliotecário, segundo a CBO (2002), como cientistas da informação, consultor de informação, especialista de informação, gerente de informação e gestor de informação.

Dentre as funções exercidas pelos profissionais da informação, citadas por Beluzzo (2011), destacam-se:

a) Disponibilizar informação em qualquer suporte;

b) Gerenciar unidades como bibliotecas, centros de documentação, centros de informação e correlatos, além de redes e sistemas de informação;

c) Tratar tecnicamente e desenvolver recursos informacionais;

d) Disseminar informação com o objetivo de facilitar o acesso e geração do conhecimento;

e) Desenvolver estudos e pesquisas;

f) Realizar a difusão cultural e desenvolver ações educativas;

g) Prestar serviços de assessoria e consultoria.

Beluzzo (2011, p. 69) entende que "o contexto onde o profissional da informação desenvolve seu trabalho tem variado substancialmente, mudando com ele os conteúdos e as formas do exercício profissional". Recomenda, por isso, atenção especial "no design do perfil do profissional da informação".

A análise do perfil desse profissional remete a reflexões que extrapolam os limites de abrangência de sua atuação. Até pouco tempo, a maioria dos funcionários, com 
exceção das gerências e chefias de uma organização, realizavam atividades de forma monótona e repetitiva, quase mecânica.

O cenário atual, ao contrário, é composto por funcionários mais ativos e criativos, incentivados pelas organizações a tomarem mais iniciativas e a proporem melhorias nos processos de trabalho (OLIVEIRA, 2007). Nas fábricas, uma parte significativa das tarefas consideradas monótonas, repetitivas ou insalubres e que representavam risco para os trabalhadores foram substituídas pela automação industrial.

Frente às tecnologias implementadas pelas organizações, os trabalhadores viram-se obrigados a buscar especialização e houve, assim, uma mudança significativa no perfil dos trabalhadores quanto ao uso da informação, em relação há poucas décadas passadas.

A informação passou a ser utilizada também nesse contexto como um recurso inerente ao desenvolvimento dessas atividades. Além das máquinas e equipamentos, que passaram a realizar as atividades mais monótonas, repetitivas e insalubres, os trabalhadores passaram a utilizar também a informação como ferramenta de trabalho e, nesse sentido, desenvolveram novas habilidades e competências. Surgiram, com isso, novos perfis de usuários ou profissionais da informação.

Como se percebe, os canais que criam, processam e disseminam as informações se multiplicaram. Paralelamente, à medida que novas formas de coleta, armazenamento, processamento, disseminação, recuperação e uso das informações são implementadas, os usuários ou profissionais que lidam com a informação também buscam adaptação e desenvolvem novas habilidades e especialidades a fim de garantir, primeiramente, sua permanência no mercado de trabalho e, por conseguinte, a qualidade para os processos em que estão envolvidos.

Em síntese, independentemente da denominação utilizada, esses trabalhadores, profissionais ou agentes, utilizam a informação e o conhecimento apenas como um recurso necessário para a realização de suas atividades, a fim de atingir objetivos específicos e determinados, de interesse pessoal ou organizacional. 
Nesse contexto, as características dos papéis desempenhados pelos profissionais estão conectadas com a posição ocupada nas organizações, com o tipo de trabalho e hierarquia, além da estrutura organizacional com os sistemas de informação, situação econômica, tecnologia, cultura, tradição, dentre outros.

As informações deixaram de transitar em blocos de papéis e formulários, transformaram-se em informações digitais e trafegam pelas redes de computadores, nas organizações. Influenciadas e impactadas pela automação, houve a necessidade de adaptação tanto das organizações como dos indivíduos para a realidade, exigindo o desenvolvimento constante de novas habilidades e especialidades.

O profissional da informação, nesse cenário, circula livremente pelas organizações e centros de informação. Da mesma forma que seu objeto de trabalho, a informação, deixou a sobriedade das bibliotecas e chegou ao mundo digital, da virtualização, das redes de computadores, o perfil do profissional da informação também se transforma, adaptando-se às modernidades tecnológicas, sociais e produtivas.

Dessa forma, considerando as funções descritas na CBO (2002), pode-se afirmar que os profissionais envolvidos com os processos de análise, desenvolvimento e gestão e manutenção de sistemas de informação são também profissionais da informação, classificados em duas categorias:

a) Analistas de tecnologia da informação: Tecnólogo em sistema para internet, Analista de Comunicação (teleprocessamento), Analista de desenvolvimento de sistemas, Analista de rede, Analista de redes e de comunicação de dados, Analista de sistemas (informática), Analista de sistemas de automação, Analista de sistemas para internet, Analista de sistemas web (webmaster), Analista de suporte computacional, Analista de suporte de banco de dados, Analista de suporte de sistema, Analista de suporte técnico, Analista de telecomunicação, Consultor de tecnologia da informação, Tecnólogo em análise de desenvolvimento de sistema; 
b) Administradores de Tecnologia da Informação: Analista de aplicativo básico (software), Analista em segurança da informação, Administradores de bancos de dados, Especialista em segurança da informação, Tecnólogo em banco de dados, Tecnólogo em redes de computadores, Tecnólogo em segurança da informação, Administrador de banco de dados, Administrador de rede e de sistemas computacionais, Administrador de redes, Administrador de sistema operacional de rede, Administrador de sistemas computacionais, Administrador de sistemas operacionais, Administrador de sistemas operacionais de rede, Administrador em segurança da informação.

No cenário organizacional, a maioria, senão a totalidade das informações geradas e disponibilizadas, passa por sistemas de informação, criados, mantidos, estruturados e gerenciados por esses profissionais. Portanto, qualquer iniciativa para implementar a qualidade da informação nas organizações deve considerar a sua efetiva participação.

Alguns estudos buscaram identificar e classificar os papéis envolvidos com a informação. Wang e Strong (1996) identificaram três tipos de papéis ou perfis envolvidos no que eles denominaram de sistema de manufatura de dados: os produtores, os guardiões e os consumidores de dados, já descritos no trabalho.

Em um segundo estudo, Wang (1998) propôs a metodologia TDQM (Total Data Quality Management), um método para avaliar a qualidade total da informação e elencou quatro perfis relacionados ao produto informação:

a) Fornecedores: são aqueles que criam ou coletam dados para o produto informação. Coletam dos clientes os dados necessários para a abertura de contas e execução de transações, como criação e abertura de contas em uma instituição financeira, por exemplo;

b) Produtores: são aqueles envolvidos com o desenvolvimento de sistemas de informação. Desenham, desenvolvem ou mantêm os dados e infraestrutura dos sistemas para o IP (Information Product); 
c) Consumidores: são aqueles que utilizam o produto informação em suas atividades, como os clientes ou agentes de controle;

d) Gerentes: são os responsáveis pelo gerenciamento de todo o processo de produção do IP, envolvendo todo o seu ciclo de vida, desde a coleta até a entrega dos dados ao cliente.

Os perfis identificados e definidos por Wang \& Strong (1996) e Wang (1998) retratam, de forma genérica, os diversos tipos de usuários da informação, os que produzem, consomem e administram as informações. Cada qual em sua especificidade, eles determinam a demanda de informações nas instituições.

Existem outras denominações para os profissionais envolvidos com a informação no dia a dia das instituições. Por exemplo, Rezende (2002) propôs a denominação de agentes do conhecimento, descritos como:

a) Agentes criativos - profissionais que utilizam a informação para a solução de problemas e cujas ações culminam em estratégias competitivas. Alimentam as organizações de todo tipo de informação, tanto interna quanto externa, originada pelos sistemas ou pela mídia;

b) Agentes intérpretes - profissionais que analisam e interpretam o contexto de atuação da instituição. As informações são utilizadas como ferramenta de prospecção e identificação de novos negócios, mercados e tecnologias. Os sistemas especialistas são, geralmente, o meio de disponibilização das informações para tais agentes, cuja missão é identificar ameaças e oportunidades;

c) Agentes intermediários - profissionais especializados em mediar o acesso à informação, cuja função é identificar e interpretar as demandas e as fontes de informação do negócio e disponibilizá-las para os agentes do conhecimento da empresa;

d) Agentes gestores do conhecimento - uma nova categoria de profissionais, cuja função é administrar o capital intelectual da instituição como um dos 
princípios geradores de sua riqueza. A gestão do capital intelectual perpassa pela gestão do conhecimento e da informação.

Lidar com a informação na prática, nas organizações, nos dias atuais, já não é mais uma tarefa exclusiva de profissionais com perfil desenvolvido para esse fim. Há uma demanda significativa por profissionais com essa competência, em diferentes segmentos organizacionais, em detrimento de profissionais braçais, por exemplo.

Outras denominações como Radical Knowledges Workers (trabalhadores radicais do conhecimento), Knowledge Worker (Trabalhadores do conhecimento), Information Workers (Trabalhadores da Informação) têm sido também utilizadas para conceituar os profissionais que lidam com a informação e com o conhecimento. Os trabalhadores da informação e os trabalhadores do conhecimento, denominações utilizada por outros estudos, representarão até 2014 cinquenta por cento da força de trabalho dos EUA, segundo estimativas realizadas pelo censo daquele país. As organizações já experimentam certa carência de mão de obra especializada nesses segmentos (DE SORDI, 2008).

Em função disso e por causa da dinâmica de suas atividades, as próprias organizações acabam formando mão de obra para lidar com as suas informações e, muitas vezes, sem a especialização necessária. As pessoas adquirem conhecimentos e habilidades específicas para a realização das operações inerentes às suas funções nas organizações, e a informação é apenas mais um recurso que compõe o cenário das atividades.

Entretanto, diversos autores, dentre eles Marchand (1990), Repo (1986, 1989), Strong e Wang (1997), Wang (1998), são enfáticos ao atribuírem ao usuário ou profissional da informação o papel principal nos processos de avaliação da qualidade da informação e afirmam que, somente por meio da sua percepção e observação, se pode avaliar a qualidade da informação.

As mudanças não são mais decorrentes apenas dos aspectos tecnológicos; a globalização, por exemplo, tornou o ambiente organizacional mais complexo, com 
transformações permanentes. A organização deve se adequar a isso a fim de assegurar a competitividade (FARIA et al, 2005).

Nesse sentido, é importante entender os diferentes perfis dos usuários da informação, nas organizações, tanto daqueles envolvidos com os processos de criação da informação quanto daqueles que trabalham para garantir a manutenção e a gestão da informação.

Dentre os vários perfis de usuários ou profissionais descritos na literatura, serão adotados no estudo, os perfis identificados por Wang e Strong (1996), referentes a três tipos de papéis envolvidos com a criação, gestão e uso da informação: os produtores, os consumidores e os gestores ou guardiões da informação.

Esses perfis foram escolhidos por terem sido utilizados de forma consistente nos estudos de Wang e Strong (1996) e pela associação com os processos de uso e desenvolvimento de sistemas de informação. Cada perfil ou papel está associado a um processo ou tarefa que tem a informação como principal recurso.

\subsubsection{Produtores de Informação}

Os profissionais que se enquadram nesse perfil são envolvidos diretamente com os processos de desenvolvimento de sistemas de informação. As funções relacionadas com esse perfil, neste estudo, são Analistas de sistemas, Programadores e Analistas funcionais, dentre outros. Eles identificam e levantam junto aos usuários (consumidores) os requisitos básicos para 0 atendimento das necessidades de informação que os sistemas deverão controlar.

Os profissionais desse perfil são os responsáveis pelo desenvolvimento dos sistemas, que desenham e desenvolvem a infraestrutura necessária para manter os dados dos sistemas de informação, cujo objetivo é garantir a saída do produto informação (WANG, 1998) para as partes interessadas. 
No ambiente organizacional, nem sempre é possível monitorar todas as informações, no entanto é possível monitorar os veículos pelos quais as informações são transportadas para dentro do ambiente e que possibilitam o trâmite interno da informação. Destacam-se, nesse sentido, os sistemas de informação como veículos coletores, processadores e disseminadores das informações por todo o ambiente organizacional. Eles promovem, dessa forma, integração entre os setores e níveis organizacionais, suprindo-os de informações necessárias para a realização dos processos de negócio. São, nesse sentido, as ferramentas mais eficientes para promover a garantia da qualidade das informações nas organizações.

Alinhado com os conceitos explorados por Marchand (1990), Repo (1989), Wang e Strong (1996), assume-se, aqui, que a qualidade da informação é mais bem avaliada quando é realizada por indivíduos contextualizados com a informação, ou seja, que conhecem a informação, que sabem para o que e por quem, onde e quando ela será utilizada.

Nesse sentido, considerando os papéis identificados por Wang e Strong (1996) como os principais atores nos processos de controle da qualidade da informação, é fundamental que os profissionais deste perfil conheçam, compreendam e apliquem os conceitos da qualidade da informação no desenvolvimento dos sistemas, pois:

- São eles que criam, em tese, as estruturas de armazenamento dos dados que resultarão nas informações utilizadas pela organização na realização de suas atividades.

- Além disso, é fundamental que conheçam tais conceitos e os coloquem em prática, nos processos de coleta, armazenamento, processamento e distribuição da informação. Isso é uma garantia significativa de que as informações disponibilizadas pelos sistemas tenham qualidade.

$\mathrm{Na}$ ausência de conhecimento de tais conceitos é possível que a qualidade das informações produzidas pelos sistemas seja prejudicada. Por essas razões, a visão deste profissional sobre a qualidade da informação é uma fonte importante de conhecimentos que podem orientar a busca de melhorias das práticas da Qualidade 
da Informação. E, se necessário, orientar estudos que ajudem a ampliar a sua formação no sentido de perceber a importância da QI para as organizações.

\subsubsection{Gestores de Informação}

Os profissionais desse perfil são geralmente envolvidos com a gestão das informações e que, portanto, compreendem a importância dos processos de armazenamento, manutenção e segurança dos dados da organização. Eles são também responsáveis pelo gerenciamento de todo o processo de produção do produto informação na organização, envolvendo todo o seu ciclo de vida, desde a coleta dos dados até a entrega da informação (WANG e STRONG, 1996).

O papel desempenhado por esse profissional é talvez o mais impactante na qualidade final da informação. Dentre os profissionais que se encaixam neste perfil, situam-se os Administradores de bancos de dados (DBAs), Analistas de negócios, Gerentes de TI, Gerentes de suporte, dentre outros.

É fundamental para esse perfil, entender o contexto de uso das informações nas organizações. Por isso, os gestores de informação precisam compreender o papel de cada usuário dos sistemas nas organizações; conhecer os processos de negócios organizacionais, com suas entradas e respectivas saídas; identificar os canais pelos quais as informações serão geradas, armazenadas e disseminadas e documentar as estruturas das informações, para que possam ser realizadas as manutenções corretivas e preventivas nos sistemas.

\subsubsection{Consumidores de Informação}

São consumidores de informação todas as pessoas ou grupos de pessoas associados com os processos de utilização dos dados, nas organizações, que 
utilizam o produto informação em suas atividades, como os clientes ou agentes de controle.

Os usuários que se encaixam nesse perfil são os mais variados e estão geralmente alinhados com o ramo ou tipo de negócio da instituição. Ao contrário dos dois perfis anteriores, o consumidor não tem em sua formação, traços ou características específicas quanto ao trato da informação.

Podem ser administradores, médicos, advogados ou quaisquer outras categorias profissionais que utilizam informações no desenvolvimento de suas atividades, nas instituições onde atuam. Eles não têm, necessariamente, formação específica correlata aos processos de produção e/ou gestão/manutenção da informação, mas utilizam as informações disponibilizadas pelos sistemas ou pela organização para a realização de suas atividades.

\subsection{CaRacterísticas Contextuais da InFormaÇão}

Para o pleno entendimento da importância das informações nas organizações é necessário compreender o ambiente onde se insere a própria organização. Isto é, o macroambiente, onde a organizações sobrevivem em função da sua capacidade de aprendizagem e adaptação. Segundo Choo (2003a), essa capacidade é dependente da habilidade da organização em processar as informações tanto do ambiente externo como do ambiente interno e transforma-las em conhecimento.

Da mesma forma, Nonaka e Takeuchi (1997) afirmam, baseados nas experiências das empresas japonesas, que entender e desenvolver essa capacidade de gerar conhecimentos do mercado e da própria organização para a organização é um fator determinante de competitividade organizacional.

Desse modo, alinhado com esses pressupostos descritos por Choo (2003a) e Nonaka e Takeuchi (1997), este estudo busca compreender os aspectos que 
impactam a qualidade da informação no ambiente em que ela é gerada. Por isso, é importante considerar o contexto onde a informação é obtida, processada e necessária, onde o trabalho é realizado. O contexto da informação é complexo e subjetivo, pois envolve o ambiente com os indivíduos e sua cultura e formação, a organização e suas políticas, situação econômica e tradição.

Nesse sentido, Miranda (2006, p. 103) salienta que existe uma associação entre as características dos papéis profissionais com a posição ocupada, com o tipo de trabalho e hierarquia profissional, além da estrutura organizacional incluindo os sistemas e serviços de informação, situação econômica, tecnologia, cultura, tradição, dentre outros. Nesse sentido, a autora afirma que as "estruturas mentais preexistentes nas quais uma informação toma forma estão ligadas ao mundo social e organizacional no qual está inserido o usuário e que lhe fornecem condições para a construção de significados".

Observa-se, dessa forma, que características contextuais envolvem e configuram o ambiente de coleta, processamento, uso e disseminação da informação. Elas são de significativa relevância para as organizações e complementam outras formas, competências e habilidades organizacionais no trato e na qualidade das informações, sejam internas ou externas.

Assim, este capítulo da Tese apresentou as teorias, os conceitos e os principais elementos que fundamentam o contexto da informação na organização, como a qualidade e o valor da informação, os aspectos da gestão tecnológica da informação, o perfil e as características dos profissionais da informação envolvidos com os processos de desenvolvimento de sistemas de informação e, por fim, as características contextuais, que influenciam a gestão da informação organizacional.

Por isso, a abordagem de contexto, que será apresentada e proposta no próximo capítulo, considera estes elementos juntamente com as variáveis ambientais como determinantes para os processos de valorização e avaliação da qualidade das informações nas organizações. 


\section{PROPOSTA PARA AVALIAÇÃo DA IMPORTÂNCIA E VALORIZAÇÃO DA INFORMAÇÃO}

O procedimento metodológico descrito traduz o delineamento de técnicas utilizadas, neste estudo, para avaliar a relação dos profissionais da informação com a qualidade da informação. O processo descrito está direcionado para atender aos objetivos específicos deste trabalho e foi feito, em parte, pelo método indutivo, que segundo Cervo, Bervian e Silva (2007) envolve o estudo de várias partes ou elementos componentes, para ter uma ideia do todo.

Foi realizado um levantamento na literatura, sobre estudos e pesquisas relacionados às formas de valor da informação, porque inicialmente as palavras-chave "valor da informação"; "gestão da informação" e "impacto da informação nas organizações" nortearam a linha de pensamento desta pesquisa.

Tais conceitos induziram a adição, nesta pesquisa, dos conceitos de qualidade da informação como forma de agregar valor à informação e ampliaram o seu escopo. $O$ levantamento bibliográfico realizado, nesta etapa, utilizou como foco as palavraschave "qualidade da informação"; "qualidade de dados" e "qualidade e valor da informação".

Após análise da revisão da literatura, duas questões suscitaram questionamentos relevantes para a proposta. Primeiramente, sobre a importância de identificar junto aos profissionais envolvidos com os processos de desenvolvimento de sistemas, as práticas de uso dos conceitos associados com a qualidade da informação em suas atividades. E, por segundo, sobre a importância e a influência do contexto de uso da informação na avaliação da qualidade da informação, nas organizações e nos sistemas de informações. Assim, foram estabelecidas duas proposições para o presente estudo, sendo: 
Proposição 1: Os profissionais de sistemas de informação e usuários de sistemas podem ser vistos como agentes transformadores, como canais de implementação da qualidade da informação nas organizações.

Proposição 2: Dimensões da qualidade da informação alinhadas com o contexto dos usuários são mais fáceis de serem incorporadas e implementadas tanto por profissionais como por usuários da informação.

Como observa Cervo e Bervian (2002, p. 34) ao contrário da indução, "a dedução é a argumentação que torna explicitas verdades particulares contidas em verdades universais [...] Assim, admitindo-se as premissas, deve-se admitir também as conclusões".

Para atender às proposições, foi necessário ampliar o escopo de investigação, realizando um novo levantamento na literatura, a fim de compreender o perfil dos profissionais e usuários envolvidos com os processos de criação, desenvolvimento, gestão e uso das informações nas organizações. As palavras-chave "profissionais da informação"; "perfil do profissional da Informação" e "trabalhadores da informação" delinearam a pesquisa.

O corpo de conhecimento identificado e obtido sobre informação, qualidade da informação, valor da informação e da relação dos profissionais da informação com os usuários da informação, por meio de ampla revisão bibliográfica, orientou o desenvolvimento desta pesquisa, tendo como referência os estudos de Marchand (1990), Repo (1989) e Wang e Strong (1996) e Wang (1998), os quais apontaram os aspectos contextuais da informação (ambiente e usuários) como indicadores inequívocos para avaliar a qualidade da informação.

Surgiram desses estudos 12 dimensões da qualidade da informação relacionadas ao contexto de uso da informação. Assim, uma pesquisa de campo foi elaborada para identificar, junto aos profissionais da informação, a sua percepção da qualidade e do valor da informação associada com as atividades realizadas no dia a dia das organizações, denominadas "contextuais". 


\subsection{Dimensões PROPOSTAS NO ESTUdO}

A classificação das dimensões propostas na pesquisa é fundamentada nos estudos de Marchand (1990), Repo (1989), Wang e Strong (1996), entre outros. A escolha destas se deve fundamentalmente à sua essência, ou seja, nos processos de avaliação da qualidade da informação essas dimensões, geralmente, estão associadas com as necessidades e características dos usuários.

Dessa forma, elas compõem a classificação das dimensões baseadas no contexto de uso e do usuário (Tabela 1). É possível que dentre as dimensões, algumas possam se enquadrar e serem utilizadas em outras categorias ou abordagens, por conta de sua amplitude conceitual. Porém, a sua avaliação é geralmente dependente das necessidades e características dos usuários (MARCHAND, 1990; REPO, 1989; WANG e STRONG, 1996), o que possibilita que elas sejam enquadradas na abordagem baseada no contexto de uso e do usuário.

Tabela 1 - Dimensões da Qualidade baseadas no contexto de uso

\begin{tabular}{lccc}
\hline Dimensões da Q & Repo & Wang & Marchand \\
\hline Eficácia da recuperação & $\mathbf{X}$ & & $\mathbf{X}$ \\
Utilidade & & & $\mathbf{X}$ \\
Valor de uso & $\mathbf{X}$ & $\mathbf{X}$ & \\
Completude & & $\mathbf{X}$ & \\
Quantidade adequada & $\mathbf{X}$ & & \\
$\begin{array}{l}\text { Adequação da } \\
\text { Indexação e Classificação }\end{array}$ & $\mathbf{X}$ & & $\mathbf{X}$ \\
Relevância & $\mathbf{X}$ & $\mathbf{X}$ & \\
Valor esperado & $\mathbf{X}$ & & $\mathbf{X}$ \\
Valor percebido & $\mathbf{X}$ & & \\
Valor agregado & & $\mathbf{X}$ & \\
Impacto & $\mathbf{X}$ & & $\mathbf{X}$ \\
Pontualidade & & $\mathbf{X}$ & \\
\hline
\end{tabular}


Além disso, essas dimensões são geralmente muito utilizadas no dia a dia de profissionais e usuários envolvidos com as informações nas organizações, independentemente de conhecerem ou não os conceitos que as sustentam.

\subsubsection{Adequação da indexação e classificação}

A dimensão Adequação da Indexação e Classificação está relacionada com as atividades dos processos de obtenção ou aquisição da informação. Refere-se à forma de acesso às informações. Por exemplo, a correta identificação de palavraschave facilita a identificação das informações desejadas pelos usuários. Para as organizações, a informação de qualidade deve estar corretamente indexada, caso contrário não poderá ser considerada uma informação já obtida e que esteja pronta para distribuição e compartilhamento. Além disso, a correta indexação e classificação das informações é um dos recursos mais importantes no processo de compartilhamento das informações, nas organizações (DE SORDI, 2008).

Para Oleto (2006, p. 60) essa dimensão é vista como um atributo dos sistemas de informação e é "associada à qualidade da informação quando considerada uma relevância objetiva", ou seja, segundo Nehmy e Paim (1998, p. 42) "[...] em tal perspectiva a relevância é a medida da adequação entre uma fonte e um destinatário".

Os sistemas de informação, os processos de indexação e classificação da informação são essenciais para a qualidade do sistema. Esses processos garantem o armazenamento eficiente da informação, além de facilitar o seu acesso, quando necessário. 


\subsubsection{Relevância}

Relevância significa a utilidade da informação para a organização e suas partes interessadas como um meio de construção de conhecimento e formação de opiniões, assim como suporte à tomada de decisão. Representa a importância da informação para as partes interessadas ou nas palavras de Saracevic (1970, apud PAIM, NEHMI e GUIMARÃES, 1996, p. 116) ela é a "medida do contato eficaz entre uma fonte e um destinatário".

Para Marchand (1990), a relevância pode estar relacionada com seu significado no tempo ou associada com a conformidade às especificações, ou seja, as informações são percebidas pelos usuários como relevantes em um momento anterior, mas podem não ser relevantes no momento atual, ou ainda, relevantes em determinados contextos, mas não em outros.

\subsubsection{Eficácia da recuperação}

Essa dimensão está relacionada com atributos de sistemas de informação referentes à eficácia da recuperação da informação dentro de um sistema. Significa recuperar informações que serão úteis para as atividades em mãos, a fim de evitar desperdícios de recursos e esforços na obtenção ou aquisição de informações desnecessárias, que não proporcionam resultados positivos para as atividades correntes. A dimensão é dependente do acesso realizado pelo usuário e está também relacionada com os processos de indexação e classificação da informação para fins de documentação. Para Paim, Nehmi e Guimarães (1996, p. 116):

Eficácia significa o grau de adequação da informação na solução do problema do sujeito-usuário da informação. A Eficácia decorre do uso da informação, isto é, a informação é eficaz se contribui para algum resultado positivo para o sujeito da ação, como por exemplo, tomada de decisão adequada. 
Nos sistemas de informação, essa dimensão está associada com os processos de busca e recuperação da informação e, sobretudo, com 0 atendimento às necessidades em tempo e formatos desejados.

\subsubsection{Impacto}

Esta dimensão representa a influência positiva ou negativa da informação nas atividades em que está envolvida e sua capacidade de resolução. Johnson (2003) analisando a relação da tecnologia da informação com o contexto salienta que ela representa a capacidade de impactar e ser impactada pelo ambiente.

É, portanto, uma dimensão associada ao contexto. Para Marchand (1990), sua capacidade de impactar ou não determinado evento depende das características contextuais, inserindo-se os indivíduos e o ambiente de uso da informação.

\subsubsection{Valor esperado}

Representa a expectativa de valor que se tem de uma informação antes do seu uso. Ou seja, antes de utilizar uma informação, na fase de planejamento, é comum criar expectativas de que a informação possa resolver determinado problema, ou acrescentar algo em determinada situação.

Nesse sentido, o valor esperado é uma espécie de valor que se atribui à informação na certeza de que ela é útil para determinado problema. A expectativa, nesse momento, é que seu valor é alto ou baixo, caso não haja a convicção de resolução por meio da informação (REPO, 2009).

Além disso, o autor afirma que esse valor é importante, pois o uso ou não de determinada informação é quase sempre decidido pelas expectativas dos indivíduos. 


\subsubsection{Valor percebido}

Essa dimensão descreve a real experiência e uso da informação em determinadas situações. Repo (1989) a destaca como uma decomposição do valor de uso da informação..

Para Marchand (1990), os usuários raramente dispõem de informações completas sobre um produto ou serviço de informação e, por isso, eles precisam confiar em medidas indiretas para realizar comparações entre serviços de Informação. Por vezes, o valor percebido pode ser associado à reputação de um produto ou serviço, legitimado pela confiança que o usuário deposita em seu uso.

Paim, Nehmy e Guimarães (1996) entendem que o valor percebido refere-se à compreensão que o sujeito tem do valor da Informação. Representa o valor que se atribui para a informação em função de sua importância percebida.

\subsubsection{Valor Agregado}

Agregar valor à informação é o processo de transformar dados sem significado algum em informação. Kielgast e Hubbard (1997) indicam quatro etapas para a realização do processo de agregar valor a informação. São elas:

a) Organização da informação: criação de índices, mapeamentos, etc.;

b) Análise da informação: análise focada nos dados e análise focada no problema. Quando focada nos dados, o objetivo é valorizar o conteúdo, valorizar a legitimidade, a qualidade e a precisão dos dados. Na análise focada no problema, objetiva-se atender ao usuário a fim de resolver um problema; 
c) Síntese: agrupamento da informação de interesse, aglomerando-a em blocos, com a classificação do produto de acordo com a pertinência do assunto, elaboração de resumos executivos e a padronização da informação;

d) Julgamento: processo que depende, em essência, da capacidade do indivíduo que vai utilizar a informação.

A agregação de valor à informação tem sido uma alternativa utilizada e que significa uma forma de valorizar os benefícios adicionais obtidos pelo uso da informação (ALMEIDA e VARVAKIS, 2005). Para agregar valor à informação é necessário identificar suas características ou atributos que permitam sua avaliação e utilização, geralmente expressos como dimensões da qualidade da informação.

\subsubsection{Valor de uso}

Esta dimensão refere-se ao valor atribuído para a informação pelas partes interessadas em função do seu uso, ou seja, um valor não monetário que o usuário atribui para a informação pelo seu uso, como uma representação da sua importância.

Alguns autores sugerem que ele seja dividido em valor esperado e valor percebido (REPO, 1989), nomenclatura que também será adotada neste estudo. Dessa forma, nesta proposta, o Valor de uso será considerado como a análise do valor esperado e valor percebido.

\subsubsection{Quantidade adequada}

Refere-se ao volume de dados necessários para que a informação se torne eficaz. Nem muito nem pouco (PAIM, NEHMY E GUIMARÃES, 1996). É a extensão em que a 
quantidade ou volume de dados disponibilizados são adequados para uso, independente do formato em que se apresenta.

Por exemplo, é mais eficiente analisar dados sumarizados do que um relatório com 100 páginas. Relatórios, formulários, consultas e gráficos devem conter somente as informações realmente necessárias à sua análise, pois em excesso podem causar confusões e dificultar uma análise objetiva. Em outras palavras, informação em excesso ou sua escassez prejudica a qualidade das atividades em que são necessárias.

\subsubsection{Completude}

Refere-se à extensão na qual os dados são de amplitude suficiente, profundidade e alcance para a tarefa em mãos. Está relacionada com a completeza da informação e diz respeito ao conteúdo da informação, o qual deve ser suficientemente claro e composto de tudo o que se deseja informar ou comunicar, para que não restem dúvidas, para os seus usuários sobre o que pretende comunicar (WANG e STRONG, 1996).

Informações completas tendem a evitar a dupla interpretação. Por exemplo, quando são representadas por siglas, sem a correta descrição do seu significado podem levar a interpretações equivocadas. A informação comunicada pela sigla DER tratase de uma informação que pode ser entendida de acordo com seu contexto de uso: Diagrama de Entidades e Relacionamentos para um desenvolvedor de sistemas de informação, Departamento de Estradas e Rodagem para usuários não familiarizados com termos correlatos a sistemas.

Essa dimensão originalmente pode ser atribuída a outras categorias, como a representacional por exemplo. Porém, Wang e Strong (1996) salientam que ela está associada ao contexto de uso e trata da completude da informação, ou seja, que a 
informação esteja completa, com todos os elementos necessários para o seu pleno entendimento pelo usuário.

\subsubsection{Pontualidade}

A dimensão pontualidade está relacionada à disponibilidade da informação, ou seja, a informação deve estar disponível no momento em que é necessária, pois pouco valor terá uma informação disponibilizada tardiamente, quando já não é mais necessária e, portanto, sem valor para determinada situação.

Marchand (1990) salienta que a importância da informação está associada à sua disponibilidade ao longo do tempo e, como é baseada no contexto, seu uso dependente das necessidades dos usuários e das circunstâncias de uso. No ambiente dos sistemas, ela está associada também com a capacidade de disponibilização dos sistemas, ou seja, da saída da informação para os usuários.

\subsubsection{Utilidade}

Essa dimensão está relacionada à utilidade da informação em determinadas situações ou quão útil é a informação para a composição de conhecimentos sobre determinado assunto. Para Cooney (1991 apud OLETO, 2006), a utilidade da informação está relacionada à análise e perpectiva de quem ou para que ela será útil. Para as organizações, segundo 0 autor, a utilidade está relacionada essencialmente à sua contribuição para decisões lucrativas. 


\subsection{Pesquisa-PILOTO: IDENTIFICAÇÃo dA PERCEPÇÃo de VALOR DA INFORMAÇÃO}

O instrumento utilizado nesta pesquisa foi desenvolvido a partir dos resultados apontados pelos estudos de Marchand (1990), Repo (1989), Wang e Strong (1996) e Wang (1998), ou seja, do ambiente e dos usuários da informação. Desse modo, foi elaborado um instrumento, denominado IPVI - Inventário de Percepção de Valor das Informações (Anexo 1), para identificar junto a profissionais de Tecnologia da infomação, a percepção do valor da informação associada com as dimensões da proposta, conforme expõe a tabela 1, associadas com os autores que as indicam para esse contexto.

O instrumento foi composto de duas partes:

- Parte I - trata da identificação do participante e da sua relação com a informação no ambiente de trabalho.

- Parte II: refere-se à percepção que os participantes têm da informação. Foram elaboradas 20 questões e cada uma foi composta pelos grupos:

a) Uso da informação: verificou a associação entre 0 uso e o valor da informação. As questões buscaram coletar como os participantes percebem os aspectos de valor nas informações que utilizam. A configuração das questões foi contextualizada e adaptada dos instrumentos (IQA Survey e IQK Survey) desenvolvidos e utilizados por Huang, Lee e Wang. (1999 p. 8789, 105-108).

b) Qualidade da informação: buscou identificar as dimensões da qualidade (dimensões da proposta, na tabela 1), relacionadas ao uso das informações, estabelecendo uma associação entre ambas, ou seja, das dimensões mais utilizadas pelos usuários no seu cotidiano, no ambiente de trabalho. 
Para cada questão, o participante deveria fazer uma associação entre a sua resposta e a importância percebida de cada dimensão (dentre as 12 dimensões da proposta) para a resposta assinalada.

Todas as respostas foram estruturadas em escala Likert de 7 pontos (sendo: 1 nada importante e 7 - muito importante), em que o participante assinalava tanto a resposta à questão, como ao grau de importância que atribuía para cada dimensão.

A escala Likert é uma escala psicométrica. Ela mede atitudes e comportamentos, utilizando opções de resposta que variam de um extremo a outro, por exemplo, de nada provável para extremamente provável em que $1=$ nada provável e $7=$ extremamente provável. Ao contrário de questões de resposta diretas e simples como "sim ou não", a Escala Likert permite obter informações sobre o nível de concordância sobre determinado assunto, o que garante maior liberdade de escolha ao participante da pesquisa, que não precisam ficar restritos ao simples concordo/discordo, geralmente utilizados em outras escalas como a de Thurstone, por exemplo. Recomenda-se, porém, que as Escalas de Likert sejam utilizadas com um número ímpar de opções, por exemplo, de 1 a 7, de 1 a 9 ou de 0 a 4, dentre outros (ALEXANDRE et al., 2003; OLIVEIRA, 2001).

Neste estudo, por conta da subjetividade dos elementos pesquisados, como a percepção dos profissionais sobre a qualidade da informação, optou-se pela escala com 7 pontos. Objetivou-se, assim, ampliar as possibilidades de respostas para que os respondentes pudessem assinalar com exatidão a sua percepção. As escalas mais utilizadas nas pesquisas são geralmente as de 5 e 7 pontos (ALEXANDRE et al, 2003; OLIVEIRA, 2001).

O instrumento foi enviado via e-mail para 150 profissionais de $\mathrm{TI}$ e aplicado in loco para 15 usuários. Todos os participantes atuam em processos de criação, desenvolvimento e gestão de sistemas de informação, estão em acordo com as especificações definidas pela CBO e se enquadram como analistas de tecnologia da informação ou administradores de tecnologia da Informação. 
A escolha desta amostra foi motivada pela formação acadêmica dos profissionais, todos egressos de cursos de Bacharelado em Ciência da Computação e de Análise e Desenvolvimento de Sistemas de uma instituição de ensino superior no interior do Estado de São Paulo. Todos os participantes atuam em atividades relacionadas com suas formações e têm a informação como principal recurso de suas atividades.

Dos 150 instrumentos enviados eletronicamente, retornaram apenas 77 , ou seja, $51 \%$. A análise dos dados demonstrou:

a) Conflitos entre as dimensões utilidade e relevância: $25 \%$ dos respondentes entenderam que as dimensões são idênticas, consideraram-nas equivalentes em uma mesma dimensão. Esses conflitos estão em acordo com os estudos de Harter e Hooten (1992), citados por Oleto (2006, p. 60).

b) Conflitos entre valor de uso e utilidade: $31 \%$ assinalaram de forma semelhante, o que leva a crer que os respondentes consideraram-nas equivalentes ou pode indicar que não houve entendimento dos conceitos.

c) Constatou-se, de forma geral, um alto nível de dificuldade de entendimento e preenchimento do instrumento pelos participantes (29\%) que responderam eletronicamente (via e-mail).

d) Já os participantes que responderam in loco, relataram dificuldades parciais para associar cada uma das dimensões da qualidade da informação com o desenvolvimento de suas atividades. É possível que o mesmo tenha ocorrido também com os participantes que responderam eletronicamente, mas, por não haver a troca com o aplicador in loco, a dificuldade não foi relatada. Por isso, não foi possível assegurar que os resultados tratam de fato de uma associação da importância das dimensões da qualidade com as atividades de uso, valor ou impacto das informações.

e) Contudo, foi possível coletar a importância atribuída às dimensões da qualidade, sem associá-las às atividades do seu dia a dia. É possível que os usuários entendam os conceitos em torno das dimensões da qualidade da 
informação, mas, na prática, não os associam à realização de suas atividades.

A partir dessas análises, optou-se pela realização de uma segunda pesquisa, complementando, desta forma, as lacunas observadas na pesquisa-piloto. Esta nova pesquisa, descrita na sequência, teve o foco na percepção dos profissionais e usuários sobre a qualidade da informação, especificamente sobre as dimensões da qualidade da informação que compõem a abordagem contextual, propostas no estudo.

\subsection{Pesquisa Principal: IdentificaÇÃoda PERCEPÇÃo da QUALIDADE dA INFORMAÇÃO}

Esta pesquisa objetivou identificar a percepção da qualidade da informação entre os profissionais e usuários da informação. Assim, optou-se pela inclusão, entre os perfis, do Consumidor da informação, identificado por Strong e Wang (1997), ampliando o escopo da pesquisa.

O instrumento utilizado foi denominado de IPQI - Inventário de Percepção da Qualidade das Informações (Anexo 2). Da mesma forma que o anterior, foi composto de duas partes, sendo uma referente à identificação do participante e outra referente à percepção da qualidade da informação.

\subsubsection{Identificação do participante}

Esta parte do instrumento objetivou colher dados referentes à relação do participante com a informação no ambiente de trabalho, considerando as três funções ou papéis definidas por (WANG e STRONG,1996), de Produtor, Consumidor e Gestor. 
Os papéis estão associados com processos ou tarefas para a produção da informação, ao que o autor denominou de sistema de manufatura de dados. Assim, os produtores estão associados com o processo de produção de dados; os gestores com processos de administrar, armazenar, manter e garantir a segurança dos dados; e os consumidores, por sua vez, estão associados com os processos de utilização dos dados.

\subsubsection{Percepção da qualidade da informação}

A segunda parte do instrumento buscou identificar os fatores relacionados à informação no ambiente em que é utilizada, de acordo com a percepção dos usuários, identificados na primeira parte desse instrumento - consumidor, produtor e gestor (guardião) da informação.

No ambiente organizacional, as informações são os insumos necessários para que os usuários desenvolvam suas atividades, e os sistemas de informação por meio de seus processos de coleta, armazenamento, processamento e distribuição, fornecem a maioria das informações necessárias. Os sistemas realizam também as primeiras filtragens dos dados a fim de garantir a qualidade das informações, mas são os usuários os principais responsáveis pela qualidade das informações inseridas nos sistemas.

Daí a importância de coletar, por meio do instrumento, a percepção sobre a qualidade das informações tanto de quem desenvolve e mantém os sistemas quanto daqueles que utilizam e alimentam as informações dos sistemas. 


\subsubsection{Práticas da qualidade da informação}

As questões do número 1 ao número 5 (Anexo 2) avaliam a relação dos participantes com os conceitos da qualidade da informação, especialmente no seu ambiente de trabalho e estão estruturadas da seguinte forma:

a) Conceitos da qualidade da informação: identifica se os participantes conhecem ou não os conceitos da qualidade da informação e os utilizam no dia a dia, na realização de suas atividades (questões 1 e 2).

b) Prática da qualidade da informação: verifica se a empresa em que o participante trabalha, incentiva e pratica os conceitos disseminados sobre a qualidade da informação (questão 3).

c) Valor da informação: coleta a percepção dos participantes sobre a relação da qualidade da informação com a valorização da informação (questão 4 e 5).

\subsubsection{Dimensões Investigadas}

As análises dos resultados obtidos por intermédio da pesquisa-piloto apontaram a necessidade de efetuar alterações no conjunto das dimensões propostas, listadas no tem 4.1. Assim, decidiu-se por excluir da classificação as dimensões utilidade e valor de uso, pelos seguintes motivos:

- Utilidade: apresentou-se redundante conceitualmente em relação à dimensão relevância e valor de uso.

- Valor de uso: apresentou redundância conceitual com as dimensões utilidade e relevância. 
Por fim, a classificação proposta ficou composta por 10 dimensões relacionadas ao contexto e ao perfil dos usuários, apresentadas na Tabela 2.

Tabela 2 - Dimensões da proposta

\begin{tabular}{lccc}
\hline Dimensões da QI & Repo & Wang & Marchand \\
\hline Eficácia da recuperação & $\mathbf{X}$ & & \\
Completude & & $\mathbf{X}$ & \\
Quantidade adequada & $\mathbf{X}$ & $\mathbf{X}$ & \\
$\begin{array}{l}\text { Adequação da Indexação } \\
\text { e Classificação }\end{array}$ & $\mathbf{X}$ & & \\
Relevância & $\mathbf{X}$ & $\mathbf{X}$ & $\mathbf{X}$ \\
Valor esperado & $\mathbf{X}$ & & \\
Valor percebido & $\mathbf{X}$ & & $\mathbf{X}$ \\
Valor agregado & & $\mathbf{X}$ & \\
Impacto & $\mathbf{X}$ & & $\mathbf{X}$ \\
Pontualidade & & $\mathbf{X}$ & $\mathbf{X}$ \\
\hline
\end{tabular}

As dimensões que compõem a proposta são fundamentadas nos estudos de Marchand (1990), Repo (1989), Strong e Wang (1997), Wang e Strong (1996), Wang (1998), dentre outros, que afirmam ser o usuário, no ambiente corporativo, o principal agente no processo de avaliação da qualidade da informação. Além disso, de acordo com os autores, as dimensões da qualidade associadas ao contexto de uso são as mais difíceis de serem identificadas e mensuradas, devido à subjetividade tanto do ambiente corporativo quanto do próprio usuário e das informações.

$\mathrm{Na}$ verdade, as dificuldades inerentes à identificação e mensuração dessas dimensões foram também os principais motivadores que levaram à escolha dessa abordagem para este estudo. Ao contrário da realidade das abordagens que tratam a informação como produto, sobre as quais há abundante literatura, nessa abordagem há evidente carência de estudos. Nesse sentido, a classificação proposta, bem como os resultados do estudo, podem ser considerados contribuições 
efetivas no sentido de ampliar o corpo de conhecimentos sobre o contexto de uso das informações.

A abordagem orientada ao contexto e uso, representada neste estudo pela Figura 8, tem como seus elementos as dimensões da qualidade da informação fundamentadas nos estudos de Marchand (1990), Repo (1989), Wang e Strong (1996); os perfis - produtor, consumidor e gestor - identificados por Strong e Wang (1997), Wang (1998), denominados, no estudo, de profissionais da informação; e o contexto, que representa o ambiente onde se reúne e influencia nos demais elementos.

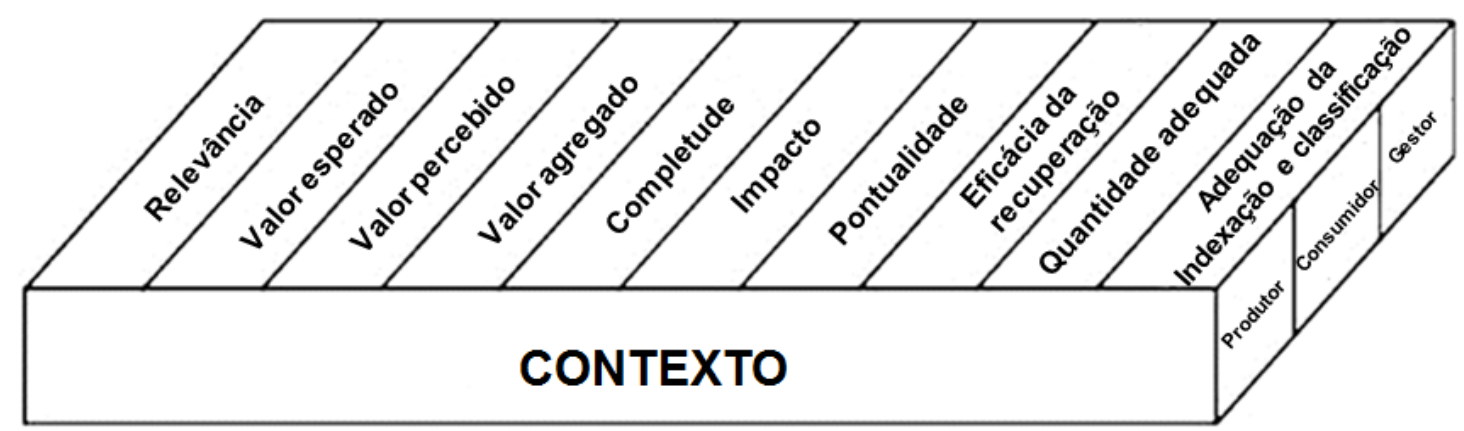

Figura 8 - Visão tridimensional da abordagem de Contexto

Fonte: O próprio autor

O contexto representa 0 ambiente de uso da informação, sendo qualquer organização, repartição ou local onde a informação é utilizada e avaliada. É considerado o principal elemento dessa abordagem, pois sobre ele incidem diversos fatores como a política, a cultura, as crenças, a formação dos indivíduos e da própria organização, denominados por Calazans (2008) como características contextuais, que afetam e são afetados pelo ambiente. 


\subsubsection{Inventário de Percepção da Qualidade da Informação - IPQI}

O instrumento utilizado (IPQI - Anexo 2) permite que sejam assinaladas a importância e a correspondente valorização de cada dimensão da proposta, na realização das atividades da organização, na visão do usuário, conforme exemplifica o quadro 3.

Questão 6 - Relevância

\begin{tabular}{|l|l|l|l|l|l|}
\hline 1 & 2 & 3 & 4 & 5 & $\begin{array}{l}\text { Importância desta dimensão para a realização das minhas } \\
\text { atividades. }\end{array}$ \\
\hline 1 & 2 & 3 & 4 & 5 & $\begin{array}{l}\text { As informações de maior relevância, na minha opinião, têm mais } \\
\text { valor para a organização. }\end{array}$ \\
\hline
\end{tabular}

Quadro 3 - Escala Likert das dimensões do IPQI

Nesse instrumento optou-se pela escala Likert de 5 pontos. Para pesquisas desse tipo, que visam identificar comportamentos e percepções dos indivíduos, Oliveira (2001) recomenda que as escalas sejam utilizadas com um número impar de opções, independente da quantidade de pontos. A opção pela escala com 5 pontos buscou concentrar a respostas tornando-as mais objetivas, sendo que quanto mais próximo do número um, menor é o grau de importância ou valorização atribuídas ao item avaliado e, quanto mais próximo do número cinco, maior é o grau de importância ou valorização atribuídas ao item avaliado.

O instrumento possibilitou coletar também a percepção de Importância e a percepção de valor (Valorização) da dimensão. Alguns autores, como Marchand (1990) e Repo (1989) sugerem que as informações mais valorizadas são, geralmente, de boa qualidade. Ressaltam, no entanto as dificuldades inerentes ao processo de valorização da informação, por conta principalmente da subjetividade expressa no termo valor da informação. 
Por isso, o estudo buscou associar os conceitos da qualidade expressos nas dimensões da abordagem de contexto com a percepção de valor da informação, segundo a visão dos usuários. É possível que a atribuição de importância e de valorização para as dimensões atuem de forma distinta na mente dos participantes.

Geralmente, o que é importante para o indivíduo possui uma forma de valor, seja afetiva, seja de estima, seja cultural ou mesmo material. Entretanto, nem tudo o que tem valor para o indivíduo têm, necessariamente, importância. Assim é possível que os participantes do estudo atribuam escores diferentes para a importância e valorização das dimensões. Os resultados dessa associação podem ser úteis para a compreensão do valor da informação, conforme sintetiza a figura 9.

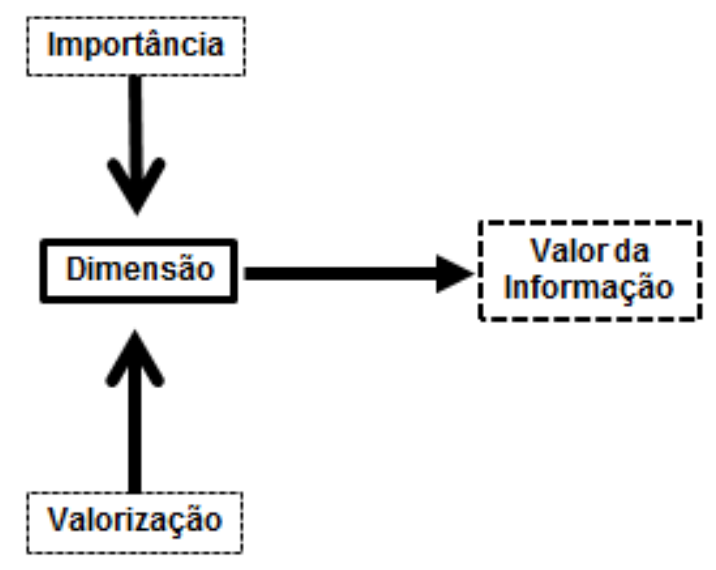

Figura 9 - Perspectiva de valor da informação na abordagem de contexto

Fonte: O próprio autor

Importância da qualidade da informação: essa escala procura representar o grau de importância que o participante atribui para cada dimensão da qualidade da informação. Não se encontrou na literatura uma medida para o que seja Importância da dimensão. Porém, como o foco do estudo está em avaliar a percepção dos indivíduos associadas à qualidade da informação baseadas no contexto, decidiu-se por definir a escala Importância como um elemento de avaliação das dimensões. É, 
portanto, um parâmetro de avaliação da dimensão, uma escala para a medida da qualidade da informação.

Valorização da informação: essa escala objetiva avaliar a existência ou não de relação entre a dimensão e a valorização das informações na organização, pela visão do participante. Portanto, no estudo, a valorização é uma escala que está associada com a percepção de valor da informação, atribuída para cada dimensão da qualidade da informação.

\subsubsection{Amostra}

Os participantes denominados produtores e gestores da informação atuam em processos de criação, desenvolvimento e gestão de sistemas de informação, em acordo com as especificações definidas pela CBO (2002) e se enquadram como analistas de tecnologia da informação ou administradores de tecnologia da Informação, alinhados com as especificações referenciados na CBO. Foram enviados 80 instrumentos, via e-mail, para esses profissionais, não participantes da pesquisa-piloto.

Além desses oitenta, foram enviados, também por e-mail e/ou redes sociais, 50 instrumentos para profissionais denominados como consumidores da informação. De forma semelhante aos outros perfis, a seleção dessa amostra utilizou critérios técnicos, por isso, o requisito de graduação em cursos de Administração, Ciência da Computação ou Análise e Desenvolvimento de sistemas. Todos os participantes desse perfil atuam como usuários de sistemas de informação, na iniciativa privada, em diversos estados brasileiros.

O instrumento, também foi aplicado in loco para 20 profissionais (não participantes da pesquisa-piloto) a fim de avaliar problemas relacionados à interpretação das questões e medição do tempo médio das respostas. 
Considerando as avaliações realizadas, o método classifica-se como descritivo. De acordo com Cervo e Bervian (2002, p.66) "a fase descritiva observa, registra, analisa e correlaciona fatos ou fenômenos (variáveis) sem manipulá-los". Pode se afirmar ainda, que a pesquisa classifica-se também como exploratória, considerando que Cervo, Bervian e Silva (2007) justificam esse método como adequado para explorar as áreas a serem estudadas e descobrir a relação existente entre elas, explorando ângulos de visão - percepção dos usuários - e conhecimento obtidos, nesse caso, por meio da aplicação da pesquisa-piloto e da pesquisa principal.

A aplicação do instrumento foi realizada pelo método denominado auto aplicação no qual o instrumento é enviado ao participante por e-mail ou correio e os próprios participantes os preenchem (VIEIRA, 2009).

Espera-se, desse modo, que a proposta traga contribuições significativas, agregando informações e conceitos para o conjunto de conhecimentos relacionados às abordagens de contexto e uso das informações nas organizações, especialmente das vinculadas aos sistemas de informação.

\subsection{ESTUDOS RELACIONADOS}

\subsubsection{Valor da informação na área da saúde}

$\mathrm{Na}$ área da Saúde um modelo que tem sido utilizado especialmente para determinar o valor da informação é o VOI (Value of Information). O VOI é assinalado como um valor numérico para obter uma forma particular de novo conhecimento. Na maioria das vezes, o valor tem sido entendido, não necessariamente, como uma medida econômica de VOI. Mäntyniemi et al. (2009) afirmam que qualquer medida quantitativa pode ser utilizada. Como um exemplo hipotético, citam o número de peixes desembarcados ou a percepção de felicidade em uma escala de 0-100. Na área médica, esse conceito tem levado a resultados significativos e tem sido 
utilizado geralmente para auxiliar em processos decisórios relacionados a situações de risco à saúde ou nos momentos em que determinadas decisões podem acarretar custos demasiados.

\subsubsection{Gerenciamento Total da Qualidade de Dados}

Dentre os estudos que vislumbram a informação como um ativo possível de ser mensurado e avaliado, destaca-se o estudo de Wang (1998, p. 59). Na visão desse autor, os dados podem ser tratados como um produto e considera essa perspectiva apropriada porque "a produção da informação pode ser visto como um sistema de processamento agindo sobre dados crus para produzir o produto informação". Inspirado nos modelos tradicionais de gestão da qualidade total (TQM), Wang (1998) propôs o TDQM - Total Data Quality Management (Gerenciamento Total da Qualidade de Dados) - Figura 10 - uma metodologia cujo objetivo é entregar alta qualidade aos consumidores do que o autor denominou produto informação. Ele compara os processos tradicionais de qualidade com o processo de qualidade na manufatura do produto informação. Os processos tradicionais de manufatura podem ser vistos como um sistema de processamento em que entram materiais (matéria prima) para a produção de um produto físico. O quadro 4 e a figura 10 expõem o processo de produção da informação, como um sistema de processamento para a manufatura do produto informação (IP).

Entretanto, o autor salienta que existem diferenças substanciais na natureza de cada um dos processos, o que ele denominou como limitações em relação à natureza da linha de materiais usados na produção da informação: os dados. 


\begin{tabular}{|l|l|l|}
\hline & \multicolumn{1}{|c|}{$\begin{array}{c}\text { Manufatura de } \\
\text { Produtos }\end{array}$} & \multicolumn{1}{c|}{$\begin{array}{c}\text { Manufatura de } \\
\text { Informação }\end{array}$} \\
\hline Entrada & Linha de materiais & Linha de Dados \\
\hline Processo & Linha de montagem & Sistemas de Informação \\
\hline Saída & Produtos acabados & Produto Informação \\
\hline
\end{tabular}

Quadro 4 - Manufatura de produtos vs manufatura de informação Fonte: WANG (1998)

Enquanto os materiais da linha de manufatura tradicional são utilizados para a produção de um único produto, os dados, por sua vez, podem ser utilizados por múltiplos consumidores e para produção de diversas informações.

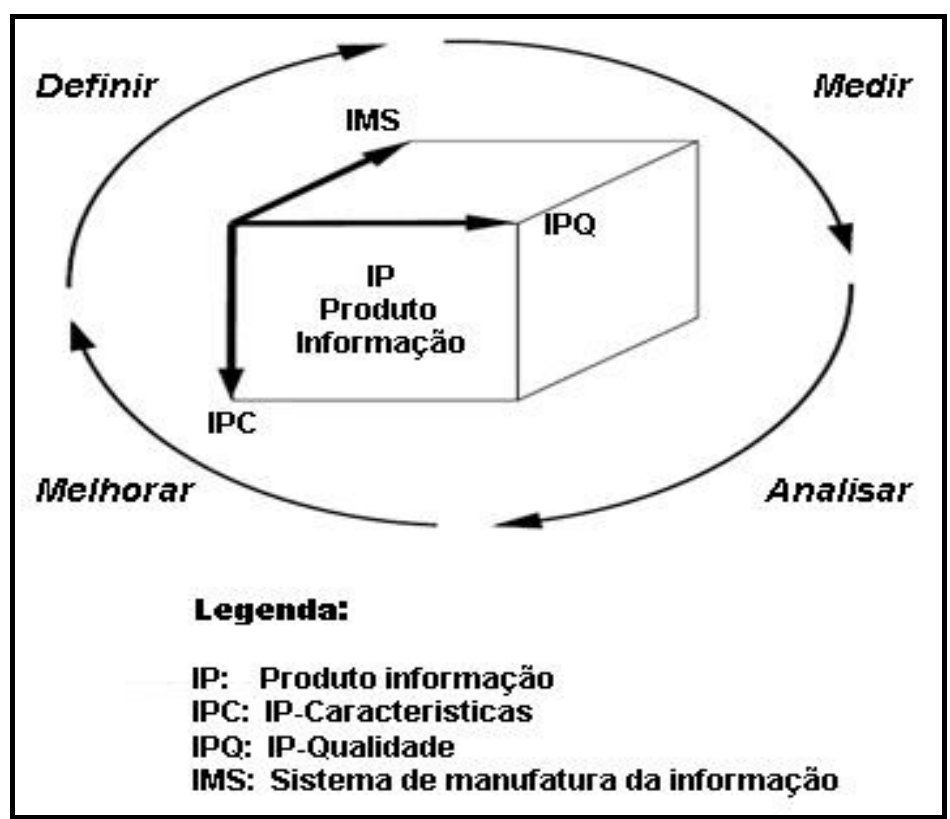

Figura 10 - Esquema da metodologia TDQM Fonte: WANG (1998)

O conceito de produto informação obtido por meio desse sistema de manufatura da informação enfatiza o fato de que a informação de saída em um sistema de manufatura tem valor que é transferido para o consumidor. 


\subsubsection{Cadeia de Valor da Informação}

Para Schwolow e Jungfalk (2009), a cadeia de valor da informação (Figura 11) pode contribuir para que as instituições obtenham vantagem competitiva por meio do gerenciamento de informações.

O modelo incorpora alguns conceitos do ciclo de gerenciamento da informação, tais como identificação de informações necessárias, aquisição de informação, organização e armazenamento de informações, produtos e serviços de informação, distribuição e uso das informações.

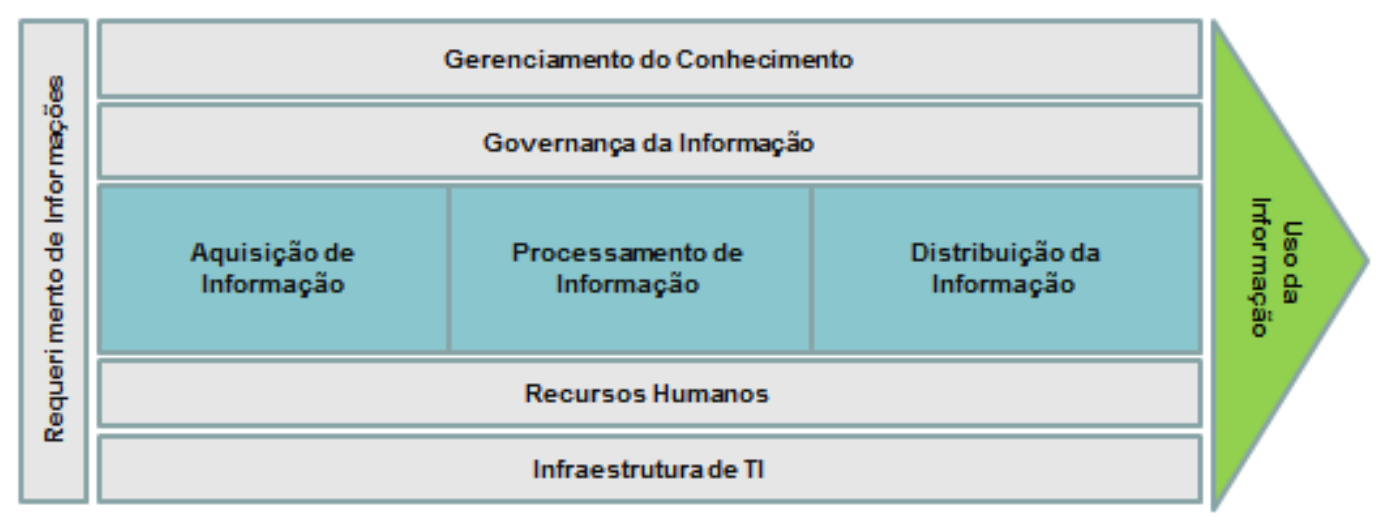

Figura 11 - Cadeia de valor da informação

Fonte: Schwolow e Jungfalk (2009)

De forma semelhante ao modelo de Porter (1989), a cadeia de valor das informações considera as atividades primárias e de suporte como estrutura da cadeia. As atividades primárias são relacionadas à aquisição, processamento e distribuição da informação. Já as atividades de suporte garantem a continuidade e eficiência das atividades primárias e são compostas pelas atividades relacionadas aos recursos humanos e infraestrutura de TI. 
O modelo adiciona ainda duas atividades: gerenciamento do conhecimento e gestão da informação, que, segundo os autores, têm como foco garantir a execução, de forma mais eficiente, da própria cadeia. As atividades primárias são as principais atividades da cadeia, as quais agregam valor ao recurso informação (SCHWOLOW e JUNGFALK, 2009) e é composta pelas seguintes atividades:

Aquisição de Informação: compreende explorar atividades do ambiente interno e externo, a fim de atender às exigências e necessidades de informações da instituição. Existem duas formas de explorar a variedade de informações: na primeira, as instituições podem aumentar a variedade de canais para aquisição de informação sobre o ambiente, que se configura como amplificação da variedade; na segunda, elas podem filtrar o influxo de informação e se ajustar para atender às necessidades individuais dos membros da instituição, o que se caracteriza como atenuação da variedade. O correto balanceamento entre amplificação e atenuação da informação pode resultar em redução de custo e melhorar a qualidade da informação.

Processamento da Informação: consiste nas ações que modificam e sintetizam as informações. As etapas subsequentes ao processo de aquisição adicionam valor às informações por meio da aplicação de filtragens, amostragem e redução de inconsistências, dentre outros.

Distribuição da Informação: se caracteriza por atividades relacionadas ao compartilhamento e à disseminação das informações. Para Choo (2003b) esta se configura como a etapa que mais aumenta o valor do recurso informação. É a etapa em que a informação é disponibilizada para os usuários e compartilhada com eles, a fim de atender às necessidades organizacionais de informação.

As atividades secundárias, da mesma forma que a Cadeia de Valor de Porter (1989), objetivam dar suporte e garantir que as atividades primárias sejam executadas com eficiência e efetividade. Esta categoria é composta por seis atividades:

Gerenciamento do conhecimento: diz respeito aos processos cujos objetivos são identificar, externar, representar e distribuir o recurso da informação, que existe tanto 
na forma de informação como conhecimento. São exemplos desse item as informações sobre consumidores, processos e competidores (concorrentes).

Governança da informação: compreende as políticas e normas internas da organização para manuseio do recurso informação, como aquisição, processamento, distribuição, armazenamento, segurança, manutenção e disponibilidade.

Recursos humanos: incluem atividades como recrutamento, seleção, pagamentos, treinamentos e desenvolvimento, gerenciamento de carreira, dentre outros. Elas contribuem e adicionam valor à cadeia, selecionando e recrutando membros que concebem a importância da informação e se ajustam à cultura da instituição.

Infraestrutura de TI: consiste em todos os aplicativos de front-end e back-end, incluindo os dispositivos de armazenamento, estrutura de redes e hardware e sistemas de software. Além disso, a estrutura de TI pode reduzir erros humanos e gerar economia de tempo em relação às mesmas operações realizadas manualmente. Ela adiciona valor à cadeia por meio da automação de processos, melhoria da velocidade de processamento das informações e maior qualidade.

Requerimentos de informação: como se observa na figura 11, a necessidade de informação precede qualquer atividade de gerenciamento da informação, primárias ou de suporte. Segundo os autores, ela define o cenário para o gerenciamento da informação e deve ser continuamente revisada durante a sua execução. Uma vez definida a necessidade da informação, a instituição pode determinar qual informação tem valor para ela. $O$ foco pode estar na redução de custo ou redução de incertezas e, dependendo de como a informação é valorizada pela instituição, a estratégia para se obter a vantagem dependente do seu valor, poderá ser diferente. Além disso, a descrição correta das necessidades de informação é considerada um pré-requisito para a gestão da informação. (SCHWOLOW e JUNGFALK, 2009).

Uso da informação: configura-se no emprego efetivo da informação, seja para uma melhor compreensão do ambiente organizacional, seja para a tomada de decisões.

As atividades primárias da Cadeia de Valor da Informação respondem pelas principais atividades da cadeia, pois envolvem a operacionalização direta do recurso 
informação e aumentam o seu valor. Por outro lado, a sustentação adequada proporcionada pelas atividades de suporte garante o funcionamento da cadeia.

Por fim, é importante ressaltar, quanto às atividades, a necessidade de informação (information requirements) e o uso da informação (information use), que constituem a margem da cadeia, mas, como afirmam os autores, nem por isso são consideradas de menor importância dentre os elementos da cadeia. Não existem atividades isoladas na cadeia; há uma relação de interdependência entre as atividades, pois cada atividade depende dos elementos afins e os impacta (SCHWOLOW e JUNGFALK, 2009).

O conceito de cadeia de valor proposto por Porter (1989) trouxe contribuições significativas para compreensão e gestão das instituições ao possibilitam a auto avaliação e identificação das atividades que mais impactam as instituições em termos de produtividade e competitividade.

Da mesma forma, a cadeia de valor da Informação contribui para a gestão das informações institucionais, ao possibilitar uma macrovisão de como se processa a integração das informações entre as atividades primárias e as de suporte. Além disso, ela considera a informação como um recurso institucional.

A cadeia de valor, por tratar-se de um conceito já consolidado e utilizado no ambiente corporativo e incorporado à área de gestão das informações, como uma metodologia para compreensão e gestão do recurso informação, é um conceito significativo para este estudo, pois é um método concreto e viável de gestão das informações.

O diferencial, entre a cadeia de valor de Porter (1989) e da Informação, é que os custos envolvidos na produção da informação podem ser expressos monetariamente, mas isso não é suficiente para expressar o seu valor real. Esse tem sido um tópico recorrente na literatura relacionada às possibilidades de se atribuir ou não valor para a informação, viabilizando, assim, a sua mensuração, avaliação e consequente comercialização. 


\section{RESULTADOS E DISCUSSÕES}

Os resultados da pesquisa principal, obtidos pela aplicação do IPQI (Anexo 2), serão apresentados e discutidos na seguinte sequência:

I. Contexto da pesquisa;

II. Relação entre a qualidade da informação e o perfil do profissional da informação no estudo;

III. Análise da classificação proposta;

IV. Análise dos resultados da relação entre profissionais da informação e dimensões da QI.

\subsection{CONTEXTO DA PESQUISA}

Os participantes desta pesquisa, denominados produtores e gestores, são profissionais da área de Tecnologia da Informação, alocados em empresas consolidadas no mercado na área de desenvolvimento de sistemas de informação. Com exceção da empresa número 2, as demais possuem cada uma acima de 200 clientes. Todas atuam nos seus ramos de atividade há pelo menos 15 anos. As informações listadas abaixo foram obtidas nos sítios eletrônicos das empresas, disponibilizados na internet.

\begin{tabular}{|c|c|}
\hline Empresa 1: & Área de atuação: mercado de varejo \\
\hline $\begin{array}{l}\text { № Clientes } \\
\text { Região de atuação } \\
\text { Início das atividades }\end{array}$ & $\begin{array}{l}600 \text { clientes } \\
\text { Brasil } \\
2001\end{array}$ \\
\hline Empresa 2: & Área de atuação: Educação \\
\hline $\begin{array}{l}\text { № Clientes } \\
\text { Região de atuação } \\
\text { Início das atividades }\end{array}$ & $\begin{array}{l}35 \\
\text { Estado de São Paulo. } \\
1989\end{array}$ \\
\hline
\end{tabular}




\begin{tabular}{ll}
\hline Empresa 3: & Área de atuação: Cartografia Digital \\
$\begin{array}{l}\text { № Clientes } \\
\text { Região de atuação }\end{array}$ & 200 \\
Início das atividades & Brasil \\
& \\
\hline & \\
\hline Empresa 4: & Área de atuação: Energia \\
№ Clientes & 300 \\
Região de atuação & São Paulo, Paraná, Mato Grosso do Sul, Mato Grosso, \\
& Tocantins, Goiás e Minas Gerais \\
Início das atividades & 1992 \\
\hline & \\
\hline Empresa 5: & Área de atuação: mercado sucroalcooleiro \\
№ Clientes & 225 \\
Região de atuação & Brasil, Colômbia, Peru, México, Guatemala, Nicarágua e \\
& Honduras. Aproximadamente 8.000 usuários finais. \\
Início das atividades & 1989 \\
\hline
\end{tabular}

Esperava-se, inicialmente, uma participação em torno de $70 \%$ dos instrumentos enviados, entretanto somente $46 \%$ dos instrumentos retornaram preenchidos. As empresas justificaram que o volume de trabalho no período de aplicação da pesquisa, nos meses de dezembro e janeiro inviabilizou a participação de um número maior de colaboradores.

Os profissionais, distribuídos entre produtores, gestores e consumidores de informação, foram organizados em dois grupos:

a) Produtores e Gestores: formado por profissionais das áreas de TI, sendo:produtores de informação - programadores e analistas de sistemas, designers; e gestores - gestores da área de $\mathrm{TI}$, analistas de suporte, DBAs. Todos os profissionais são egressos de cursos superiores em Tecnologia em Processamento de Dados, Análise e Desenvolvimento de Sistemas e Bacharelado em Ciência da Computação.

b) Consumidores: são profissionais que utilizam a informação de sistemas de informação em seu dia a dia, como administradores, gerentes, supervisores, implantadores de sistemas, alocados em empresas de vários segmentos, como comércio, indústrias, serviços, educação, dentre outros. 
Os participantes estão lotados em diversos cargos e níveis hierárquicos. São gerentes, supervisores, operacionais, consultores, dentre outros, como mostra a tabela 3.

Tabela 3 - Demonstrativo de participantes por cargo

\begin{tabular}{lcccccc}
\hline Função & $\begin{array}{c}\text { Gerência } \\
(\%)\end{array}$ & $\begin{array}{c}\text { Supervisão } \\
(\%)\end{array}$ & $\begin{array}{c}\text { Operacional } \\
(\%)\end{array}$ & $\begin{array}{c}\text { Consultor } \\
(\%)\end{array}$ & $\begin{array}{c}\text { Outros } \\
(\%)\end{array}$ & $\begin{array}{c}\text { Total } \\
(\%)\end{array}$ \\
\hline Produtor & 0,0 & 10,5 & 57,9 & 21,1 & 10,5 & 100,0 \\
Consumidor & 28,6 & 14,3 & 57,1 & 0,0 & 0,0 & 100,0 \\
Gestor & 38,5 & 23,1 & 30,8 & 7,7 & 0,0 & 100,0 \\
\hline
\end{tabular}

A tabela 4 mostra a distribuição dos participantes por perfil e como se observa, houve um equilibrio entre os três perfis.

Tabela 4 - Demonstrativo de participantes por perfil

\begin{tabular}{ccccc}
\hline Tipo Participante & $\begin{array}{c}\text { Produtores } \\
(\%)\end{array}$ & $\begin{array}{c}\text { Consumidores } \\
(\%)\end{array}$ & $\begin{array}{c}\text { Gestores } \\
(\%)\end{array}$ & $\begin{array}{c}\text { Total } \\
(\%)\end{array}$ \\
\hline$\%$ & 41,3 & 30,4 & 28,3 & 100,0 \\
\hline
\end{tabular}

Os processos de tabulação e análise dos dados foram realizados por meio de planilhas eletrônicas e do aplicativo IBM SPSS Statistics ${ }^{1}$, como ferramenta de apoio para as análises estatísticas.

\subsubsection{Relação dos profissionais com as dimensões da Qualidade da Informação}

Esta seção apresenta e discute os resultados apurados na pesquisa a respeito da relação dos participantes com a qualidade da informação. Em outras palavras, visa a

\footnotetext{
${ }^{1}$ IBM® Software SPSS - Software estatístico desenvolvido pela IBM.
} 
identificar se os participantes conhecem e praticam os conceitos da qualidade da informação no desempenho de suas atividades profissionais.

Foram elaboradas cinco questões, listadas na sequência com os respectivos resultados.

\section{Questão 1 - Eu conheço os conceitos da qualidade da informação.}

Com relação à qualidade da informação, 10,9\% dos participantes assinalaram não ter conhecimento do conceito, enquanto $89,1 \%$ assinalaram conhecer os conceitos da qualidade da informação: $41,5 \%$ produtores, $31,7 \%$ Consumidores e $26,8 \%$ gestores.

Entre os perfis, os consumidores foram os que mais assinalaram possuir conhecimento da qualidade da informação, seguidos pelos produtores e gestores, como se observa no gráfico 1.

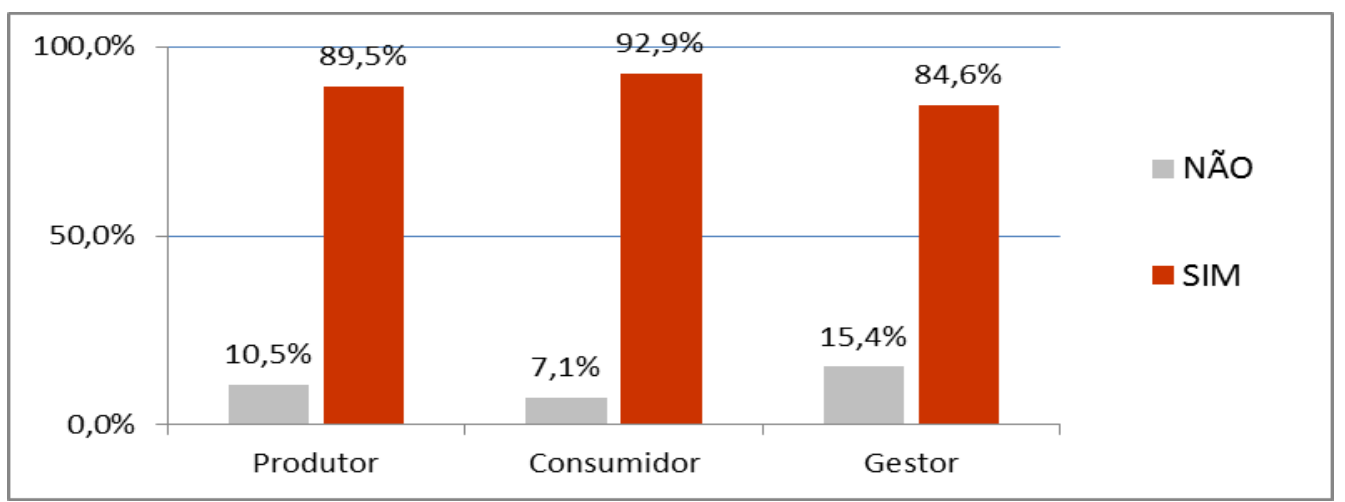

Gráfico 1 - Demonstrativo de participantes que conhecem os conceitos da Ql

\section{Questão 2 - Eu geralmente utilizo os conceitos da qualidade da informação nas atividades do meu trabalho.}

Nesta questão, sobre utilizar ou não os conceitos da qualidade da informação nas organizações, $15,2 \%$ dos participantes responderam que não os utilizam, ao passo que $84,8 \%$ afirmaram utilizar tais conceitos em suas atividades, sendo: $41,0 \%$ produtores, 33,3\% Consumidores e $25,6 \%$ gestores. 
Os resultados por perfil, no entanto, demonstrados no gráfico 2, mostram que os consumidores são os participantes que mais assinalaram que utilizam os conceitos da qualidade da informação.

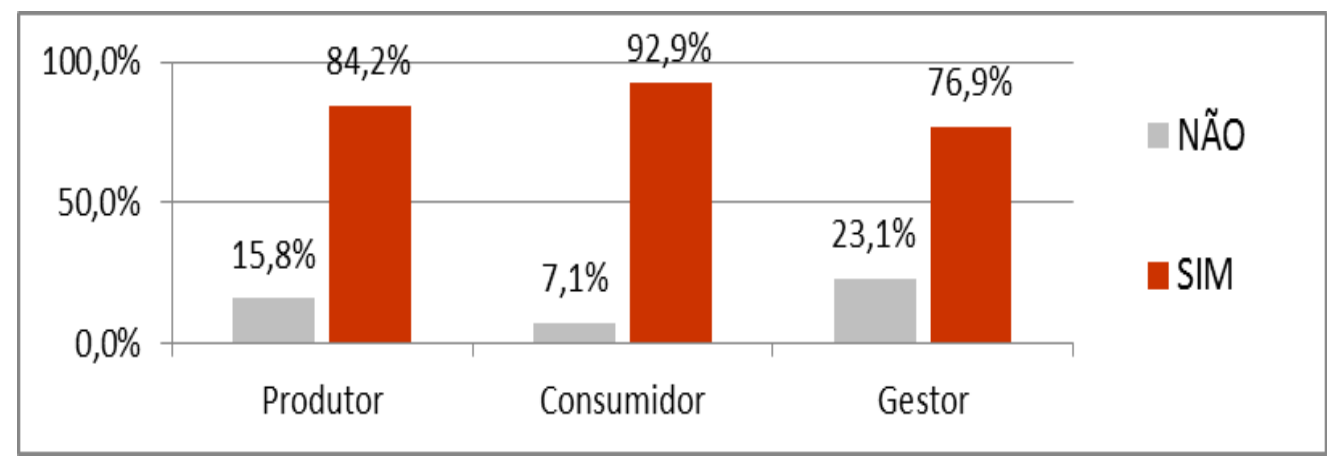

Gráfico 2 - Demonstrativo dos participantes que usam os conceitos da Ql

\section{Questão 3- A empresa onde trabalho incentiva as práticas da qualidade da informação.}

Os resultados apontaram que $21,7 \%$ dos participantes assinalaram que as empresas não incentivam a prática da qualidade, enquanto $78,3 \%$ dos participantes declararam que a prática da qualidade da informação é incentivada pelas empresas.

O gráfico 3 demonstra os resultados apurados entre os perfis e como se observa, os produtores estão alocados nas empresas que mais incentivam tais práticas.

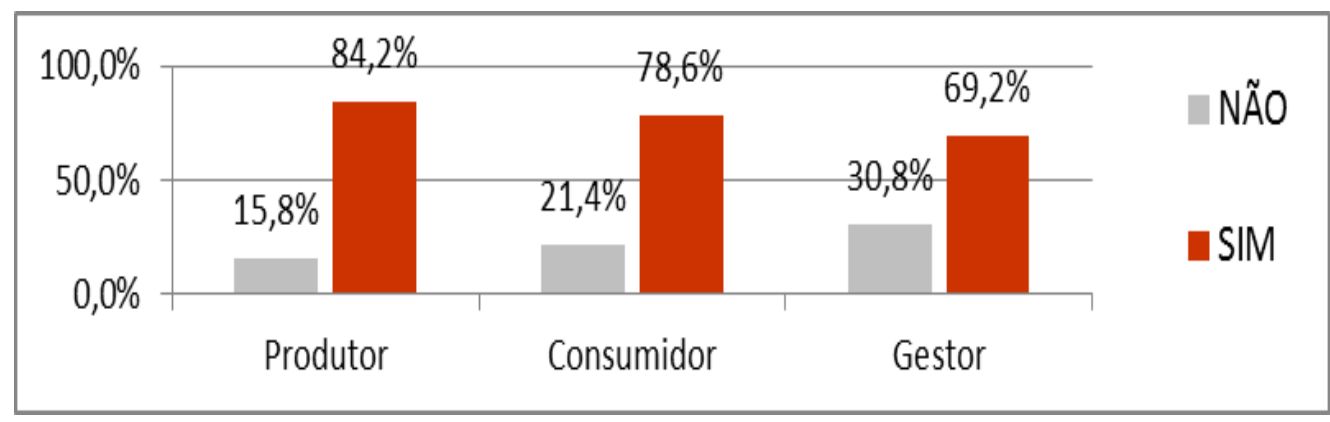

Gráfico 3 - Demonstrativo das empresas que incentivam as práticas da Ql 
Questões 4 e 5: Nas questões de número 4 - Acredito que as informações têm valor para as organizações, e de número 5 - Entendo que o valor da informação depende da qualidade da informação, a totalidade dos participantes assinalou de forma positiva, conforme se observa no gráfico 4 .

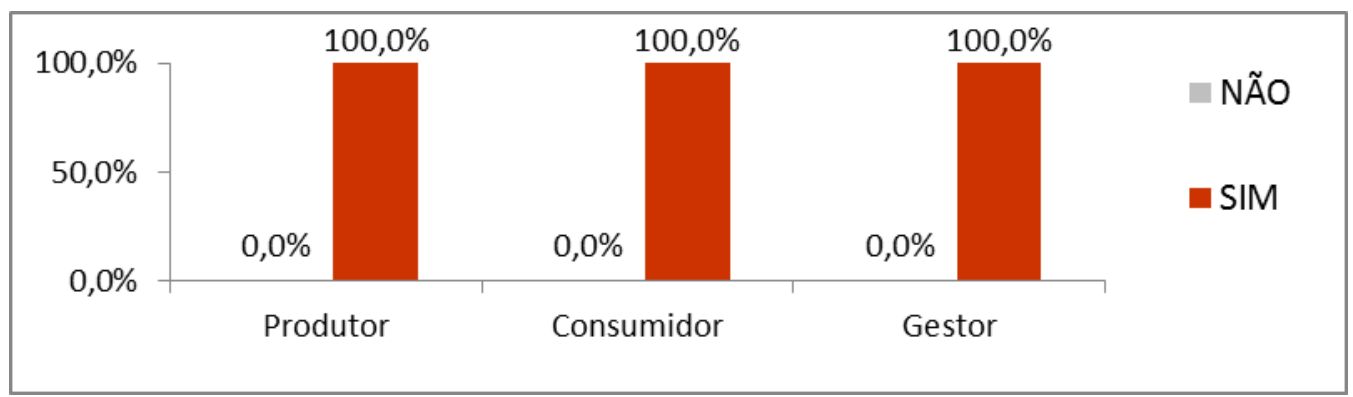

Gráfico 4 - Demonstrativo das questões 4 e 5

Como se observa, houve equidade de valores entre as questões, sinalizando que os participantes associam a qualidade da informação com o valor da informação. Conforme sinalizam Marchand (1990) e Repo (1989), existe certa relação da qualidade como um critério de valor para a informação, na visão dos participantes. Ou seja, as informações mais valorizadas nas organizações são geralmente as de melhor qualidade.

\subsection{PROFISSIONAIS dA INFORMAÇÃOX DIMENSÕES DA QUALIDADE DE DADOS}

Para assinalar sua percepção sobre a Importância e a Valorização da dimensão, os participantes preencheram as opções em escala Likert de 5 pontos, sendo: 1 - Nada Importante e 5 - Muito importante. Entretanto, a análise dos resultados apontou que a maioria dos escores ficou concentrada nos itens 3, 4 e 5. Assim, optou-se por organizar os dados em tres grupos, sendo: Baixa (itens 1 e 2), Média (item 3) e Alta 
(itens 4 e 5); tanto para a escala Importância quanto para Valorização, como se observa na Figura 12.

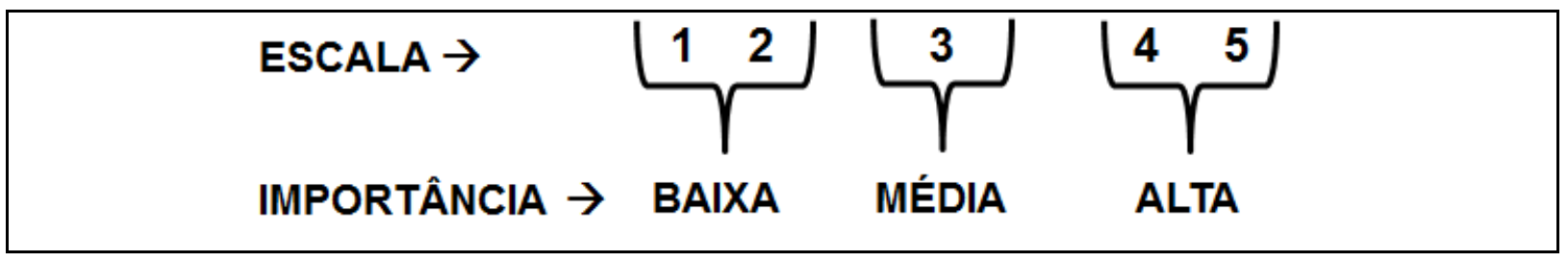

Figura 12 - Agrupamento da escala Likert na proposta Fonte: O próprio autor

Dessa forma, os resultados serão apresentados assinalando os escores obtidos para a Importância e para a Valorização atribuída a cada dimensão, expostos em duas visões:

a) Média geral: trata-se do percentual de participantes que assinalaram a dimensão em baixa, média e alta importância e Valorização, considerando todos os participantes, ou seja, $\mathrm{N}=46$.

b) Média do perfil: trata-se do percentual de participantes que assinalaram a dimensão em baixa, média e alta Importância e Valorização, considerando o número de participantes em cada perfil, sendo: 19 produtores, 14 Consumidores e 13 Gestores.

Os resultados apontados pelas médias gerais $(\mathrm{N}=46)$ representam uma visão dos escores dos participantes, em cada dimensão e distribuídos entre os perfis. Como se trata de um estudo exploratório, em que não existem medidas ou padrões para comparação dos resultados, foi importante traçar um parâmetro (média geral) para avaliar o comportamento de cada perfil, em cada dimensão. 


\subsubsection{Relevância}

As diferenças dos escores entre os perfis foram discretos, porém indicam associação entre Importância e Valorização atribuída à dimensão. Dentre os perfis, como se observa na tabela 5 , os produtores foram os que mais assinalaram Importância e Valorização da dimensão.

Tabela 5 - Relevância: Médias gerais

\begin{tabular}{|c|c|c|c|c|c|c|}
\hline & \multicolumn{3}{|c|}{$\begin{array}{l}\text { Importância da } \\
\text { dimensão }\end{array}$} & \multicolumn{3}{|c|}{$\begin{array}{l}\text { Valorização da } \\
\text { Dimensão }\end{array}$} \\
\hline Perfis & $\begin{array}{c}\text { Baixa } \\
(\%)\end{array}$ & $\begin{array}{c}\text { Média } \\
(\%)\end{array}$ & $\begin{array}{l}\text { Alta } \\
(\%)\end{array}$ & $\begin{array}{c}\text { Baixa } \\
(\%)\end{array}$ & $\begin{array}{l}\text { Média } \\
(\%)\end{array}$ & $\begin{array}{l}\text { Alta } \\
\text { (\%) }\end{array}$ \\
\hline Produtor & 2,2 & 6,5 & 32,6 & 4,3 & 10,9 & 26,1 \\
\hline Consumidor & 0,0 & 2,2 & 28,3 & 2,2 & 6,5 & 21,7 \\
\hline Gestor & 4,3 & 6,5 & 17,4 & 4,3 & 6,5 & 17,4 \\
\hline
\end{tabular}

Considerando as médias por perfil, apresentadas na tabela 6, em cada perfil, os consumidores foram os que mais atribuíram Importância e Valorização à dimensão.

Tabela 6 - Relevância: Médias por perfil

\begin{tabular}{l|cccccc}
\hline & \multicolumn{3}{c}{$\begin{array}{c}\text { Importância da } \\
\text { dimensão }\end{array}$} & \multicolumn{3}{c}{ Valorização da } \\
& \multicolumn{3}{c}{ Dimensão } \\
\hline \multicolumn{1}{c|}{ Perfis } & $\begin{array}{c}\text { Baixa } \\
\text { (\%) }\end{array}$ & $\begin{array}{c}\text { Média } \\
(\%)\end{array}$ & Alta & Baixa & Média & Alta \\
Produtor & 5,3 & 15,8 & 78,9 & $(\%)$ & $(\%)$ & $(\%)$ \\
Consumidor & 0,0 & 7,1 & 92,9 & 7,1 & 26,3 & 63,2 \\
Gestor & 15,4 & 23,1 & 61,5 & 15,4 & 23,1 & 61,5 \\
\hline \multicolumn{2}{r}{ Produtor (N): 19} & Consumidor $(\mathrm{N}): 14$ & \multicolumn{3}{c}{ Gestor $(\mathrm{N}): 13$}
\end{tabular}

Hjørland (2010), citando experimentos de Cranfield sobre a relevância, observa os perfis dos participantes listados como usuários reais e experts (o autor não denomina a especialidade desses participantes). Na perspectiva orientada ao usuário, os experts se enquadram na visão "objetiva"; e os usuários reais, na visão 
"subjetiva" de relevância. Ambos são subjetivos em seus julgamentos, porém os julgamentos dos experts são geralmente mais bem fundamentados e tendem a ter menos variação conceitual.

É possível estabelecer uma associação entre os perfis em ambos os estudos: os experts equivalem aos produtores e gestores da informação, enquanto os usuários reais equivalem ao perfil dos consumidores.

Estabelecendo uma relação dos estudos citados por Hjørland (2010), com os resultados apurados pelo IPQI, é possível tecer as seguintes considerações:

a) Considerando os produtores e gestores como experts, espera-se que seus julgamentos sejam os de melhor embasamento teórico em cada dimensão. Entretanto, tanto os produtores (78,9\% - 63,2\%) quanto os Gestores (61,5\% $61,5 \%)$ foram os perfis que atribuíram os menores escores para alta Importância e alta Valorização da dimensão. E, consequentemente, são os que mais assinalaram Baixa e Média Importância e Valorização da dimensão.

Pode se inferir, portanto, que na visão de $15 \%$ dos produtores, não existe, necessariamente, associação entre a Importância e Valorização da dimensão.

Os gestores, por sua vez, assinalaram de forma idêntica as opções, o que pode indicar que Importância e Valorização, na sua visão, são equivalentes.

b) Os consumidores, equivalentes ao "usuário real", do estudo de Hjørland (2010), fornecem uma visão subjetiva em seus julgamentos por não dominarem plenamente os conceitos. Entretanto, no estudo, foram os que mais atribuíram Importância e Valorização à dimensão relevância.

Complementando, Hørland (2010), baseado na subjetividade da dimensão, afirma que usuários de sistemas de informação não são competentes para julgar a dimensão relevância da informação. Por outro lado, é possivel justificar os resultados ao se considerar que os consumidores na prática de suas atividades estão focados na utilização das informações dos sistemas, ao 
passo que produtores e gestores conhecem os conceitos, mas não os vivenciam, na prática, como os consumidores.

Os resultados apurados neste estudo demonstraram que os participantes, em sua maioria, percebem a dimensão relevância de forma significativa em suas atividades.

\subsubsection{Valor Esperado}

Os escores na média geral ( $\mathrm{N}=46)$, conforme tabela 7 , sugerem que os três perfis atribuem maior Importância do que Valorização para essa dimensão. Os resultados apontam que os gestores atribuíram os menores escores para Importância e para Valorização.

Tabela 7 - Valor Esperado: Médias gerais

\begin{tabular}{l|cccccc}
\hline \multicolumn{1}{c|}{ Dimensão } & \multicolumn{3}{|c}{ Importância } & \multicolumn{3}{c}{ Valorização } \\
\hline \multicolumn{1}{c}{ Perfis } & Baixa & Média & Alta & Baixa & Média & Alta \\
& $(\%)$ & $(\%)$ & $(\%)$ & $(\%)$ & $(\%)$ & $(\%)$ \\
Produtor & 2,2 & 8,7 & 30,4 & 4,3 & 10,9 & 26,1 \\
Consumidor & 0,0 & 2,2 & 28,3 & 0 & 8,7 & 21,7 \\
Gestor & 10,9 & 2,2 & 15,2 & 4,3 & 4,3 & 19,6 \\
\hline \multicolumn{4}{c}{ Participantes (N): 46}
\end{tabular}

Os resultados obtidos por meio das análises dos perfis, apresentados na tabela 8 , nesta dimensão, demonstraram que a maioria dos participantes atribuiu alta Importância e alta Valorização. Além disso, chamam a atenção os resultados apurados pelos consumidores, que atribuíram alta Importância e alta Valorização. Nenhum participante desse perfil assinalou baixa Importância ou baixa Valorização, situando todas as respostas entre média e alta Importância e Valorização. 
Observou-se um resultado importante entre os produtores, mesmo a maioria tendo atribuído alta Importância e Valorização os escores para média Importância e média Valorização também foram elevados.

Os gestores assinalaram os escores mais significativos para alta e baixa Importância, entretanto assinalaram altos escores para alta Valorização. Os consumidores, porém, representaram o perfil que mais assinalou alta Importância e Valorização.

Tabela 8 - Valor Esperado: Médias por perfil

\begin{tabular}{l|cccccc}
\hline \multicolumn{1}{c|}{ Dimensão } & \multicolumn{3}{c}{ Importância } & \multicolumn{3}{c}{ Valorização } \\
& Baixa & Média & Alta & Baixa & Média & Alta \\
\multicolumn{1}{c}{ Perfis } & $(\%)$ & $(\%)$ & $(\%)$ & $(\%)$ & $(\%)$ & $(\%)$ \\
& 5,3 & 21,1 & 73,7 & 10,5 & 26,3 & 63,2 \\
Produtor & 0,0 & 7,1 & 92,9 & 0,0 & 28,6 & 71,4 \\
Consumidor & 38,5 & 7,7 & 53,8 & 15,4 & 15,4 & 69,2 \\
\multicolumn{2}{c}{ Gestor } & \multicolumn{3}{c}{ Produtor $(\mathrm{N}): 19$} & Consumidor $(\mathrm{N}): 14$ & Gestor $(\mathrm{N}): 13$
\end{tabular}

Mesmo não tendo encontrado na literatura referências em termos de parâmetros para essa dimensão, havia a expectativa de que os gestores atribuíssem os maiores escores tanto para Importância quanto para Valorização.

Tal expectativa justifica-se pela ocupação dos participantes deste perfil. Haja vista que $61,5 \%$ dos participantes atuam em cargos de gerenciamento $(38,5 \%)$ e supervisão $(23,1 \%)$, ou seja, geralmente são os cargos responsáveis por garantir as melhores práticas de gestão tanto para os sistemas como para os ambientes em que estão lotados.

Por outro lado, os resultados apurados pelos produtores e consumidores, que atribuíram os maiores escores - Importância e Valorização - à dimensão, podem ser explicados pelo fato desses perfis estarem diretamente envolvidos em processos que envolvem atividades de criação e uso das informações. Em ambos os perfis, $57 \%$ aproximadamente dos participantes, realizam atividades operacionais. São, portanto, mais propensos de realizarem melhores avaliações da qualidade da 
informação, conforme justificam Repo (1989) e Wang (1998). Além disso, esta dimensão carrega aspectos conceituais da dimensão valor de uso, o que possibilita associar esses resultados com os conceitos implícitos na dimensão.

\subsubsection{Valor Percebido}

Os resultados apontados pela análise geral $(\mathrm{N}=46)$, na tabela 9, nesta dimensão, indicam um padrão com as outras dimensões, em que os produtores assinalam os maiores escores, seguidos dos consumidores e dos gestores.

Tabela 9 - Valor Percebido: Médias Gerais

\begin{tabular}{lcccccc}
\hline \multicolumn{1}{c}{ Dimensão } & \multicolumn{3}{c}{ Importância } & \multicolumn{3}{c}{ Valorização } \\
\hline \multicolumn{1}{c}{ Perfis } & $\begin{array}{c}\text { Baixa } \\
(\%)\end{array}$ & $\begin{array}{c}\text { Média } \\
(\%)\end{array}$ & $\begin{array}{c}\text { Alta } \\
(\%)\end{array}$ & $\begin{array}{c}\text { Baixa } \\
(\%)\end{array}$ & $\begin{array}{c}\text { Média } \\
(\%)\end{array}$ & $\begin{array}{c}\text { Alta } \\
(\%)\end{array}$ \\
\hline Produtor & 0,0 & 2,2 & 39,1 & 4,3 & 6,5 & 30,4 \\
Consumidor & 0,0 & 0,0 & 30,4 & 0 & 2,2 & 28,3 \\
Gestor & 4,3 & 4,3 & 19,6 & 2,2 & 2,2 & 23,9 \\
\hline
\end{tabular}

Participantes (N): 46

A análise por perfil, conforme se apresenta na tabela 10, ressalta os resultados dos consumidores. A totalidade dos participantes deste perfil atribuiu alta Importância à dimensão e 92,9\%, para alta Valorização. Além disso, o perfil não assinalou em baixa Valorização, ficando as respostas centralizadas em média e alta Valorização.

Dentre os perfis, os gestores foram o que atribuíram menor Importância à dimensão, porém, assinalaram alta Valorização, com maiores escores do que o apontado pelos produtores.

Tabela 10 - Valor Percebido: Médias por perfil

\begin{tabular}{lcccccc}
\hline \multicolumn{1}{c}{ Dimensão } & \multicolumn{3}{c}{ Importância } & \multicolumn{3}{c}{ Valorização } \\
\hline \multicolumn{1}{c}{ Perfis } & $\begin{array}{c}\text { Baixa } \\
(\%)\end{array}$ & $\begin{array}{c}\text { Média } \\
(\%)\end{array}$ & $\begin{array}{c}\text { Alta } \\
(\%)\end{array}$ & $\begin{array}{c}\text { Baixa } \\
(\%)\end{array}$ & $\begin{array}{c}\text { Média } \\
(\%)\end{array}$ & $\begin{array}{c}\text { Alta } \\
(\%)\end{array}$ \\
\hline Produtor & 0,0 & 5,3 & 94,7 & 10,5 & 15,87 & 73,7 \\
Consumidor & 0,0 & 0,0 & 100,0 & 0,0 & 7,1 & 92,9 \\
Gestor & 15,4 & 15,4 & 69,2 & 7,7 & 7,7 & 84,6 \\
\hline
\end{tabular}

Produtor $(\mathrm{N}): 19 \quad$ Consumidor $(\mathrm{N}): 14 \quad$ Gestor $(\mathrm{N}): 13$ 
A afirmação de Repo (1989, p. 80) de que os "indivíduos dão valores diferentes para a mesma informação dependendo do contexto [...]" explica, em parte, os resultados assinalados pelos gestores. Cada dimensão, das expostas neste estudo, está associada na mente dos participantes a contextos diversos e, por isso, pode ter influenciado a percepção de valorização.

$\mathrm{Na}$ literatura não foi possível identificar parâmetros sobre os resultados assinalados pelos consumidores. Porém, considerando que 42,9\% dos participantes do perfil ocupam cargos de gestão - gerência $(28,6 \%)$ e supervisão $(14,3 \%)$ - e que $57,1 \%$ exercem atividades operacionais, esperava-se uma melhor distribuição entre média e alta Importância. Todavia, em relação aos consumidores lotados em cargos operacionais, a maioria do perfil, os resultados podem indicar que eles têm uma percepção mais aguçada da qualidade da informação. Da mesma forma que a dimensão valor esperado, a dimensão valor percebido carrega aspectos conceituais da dimensão valor de uso, o que em tese justifica esses resultados.

\subsubsection{Valor Agregado}

Os resultados apontados na tabela 11, da análise geral $(\mathrm{N}=46)$, demonstram altos escores tanto para alta Importância como para Valorização. O padrão observado nas outras dimensões é mantido, já que os produtores assinalam os maiores escores, seguidos dos consumidores e dos gestores.

Tabela 11 - Valor Agregado: Médias Gerais

\begin{tabular}{lcccccc}
\hline & \multicolumn{3}{c}{$\begin{array}{c}\text { Importância da } \\
\text { dimensão }\end{array}$} & \multicolumn{3}{c}{$\begin{array}{c}\text { Valorização da } \\
\text { Dimensão }\end{array}$} \\
\hline \multicolumn{1}{c}{ Perfis } & $\begin{array}{c}\text { Baixa } \\
(\%)\end{array}$ & $\begin{array}{c}\text { Média } \\
(\%)\end{array}$ & $\begin{array}{c}\text { Alta } \\
(\%)\end{array}$ & $\begin{array}{c}\text { Baixa } \\
(\%)\end{array}$ & $\begin{array}{c}\text { Média } \\
(\%)\end{array}$ & $\begin{array}{c}\text { Alta } \\
(\%)\end{array}$ \\
\hline Produtor & 0,0 & 6,5 & 34,8 & 4,3 & 10,9 & 26,1 \\
Consumidor & 0,0 & 2,2 & 28,3 & 0 & 4,3 & 26,1 \\
Gestor & 2,2 & 4,3 & 21,7 & 4,3 & 4,3 & 19,6 \\
\hline
\end{tabular}

Participantes (N): 46 
$\mathrm{Na}$ tabela 12 ficou demonstrado que produtores e gestores têm percepção similar nessa dimensão, assinalando alta Importância e escores menores à Valorização. Já os consumidores, assinalaram os maiores escores tanto para Importância quanto para a Valorização da dimensão.

Tabela 12 - Valor Agregado: Médias por perfil

\begin{tabular}{ccccccc}
\hline \multicolumn{1}{c}{ Dimensão } & \multicolumn{3}{c}{ Importância } & \multicolumn{3}{c}{ Valorização } \\
\hline \multicolumn{1}{c}{ Perfis } & $\begin{array}{c}\text { Baixa } \\
(\%)\end{array}$ & $\begin{array}{c}\text { Média } \\
(\%)\end{array}$ & $\begin{array}{c}\text { Alta } \\
(\%)\end{array}$ & $\begin{array}{c}\text { Baixa } \\
(\%)\end{array}$ & $\begin{array}{c}\text { Média } \\
(\%)\end{array}$ & $\begin{array}{c}\text { Alta } \\
(\%)\end{array}$ \\
\hline Produtor & 0,0 & 15,8 & 84,2 & 10,5 & 26,3 & 63,2 \\
Consumidor & 0,0 & 7,1 & 92,9 & 0,0 & 14,3 & 85,7 \\
Gestor & 7,7 & 15,4 & 76,9 & 15,4 & 15,4 & 69,2 \\
\hline \multicolumn{2}{c}{ Produtor (N): 19} & Consumidor $(\mathrm{N}): 14$ & \multicolumn{3}{c}{ Gestor $(\mathrm{N}): 13$}
\end{tabular}

Mensurar o valor agregado da informação não é uma tarefa fácil, pois é a dimensão mais associada com os processos de tomada de decisão, alinhados, portanto, com cargos referentes à gestão das organizações. De Sordi (2008, p. 81), afirma que "quanto mais estratégica for a informação, ou seja, quanto maior for a capacidade de sustentar e apoiar as estratégias da empresa, maior será sua capacidade ou potencial de agregar valor ao negócio".

Nesse sentido, esperava-se que os gestores assinalassem os maiores escores para essa dimensão, pois $61,5 \%$ dos participantes desse perfil atuam em cargos de gerenciamento $(38,5 \%)$ e supervisão $(23,1 \%)$. Os consumidores, por outro lado, $42,9 \%$ estão relacionados aos cargos de gerenciamento e supervisão.

\subsubsection{Completude}

A análise geral $(\mathrm{N}=46)$ nesta dimensão, demonstrada na tabela 13, mostra que a maioria dos produtores e consumidores assinalou em alta Importância e alta Valorização. Os gestores assinalaram os menores escores em ambas as escalas. 
Tabela 13 - Completude: Médias Gerais

\begin{tabular}{lcccccc}
\hline & \multicolumn{3}{c}{$\begin{array}{c}\text { Importância da } \\
\text { dimensão }\end{array}$} & \multicolumn{3}{c}{ Valorização da } \\
Dimensão
\end{tabular}

Participantes $(\mathrm{N}): 46$

A tabela 14 apresenta a análise dos perfis. Observa-se que os consumidores assinalaram os maiores escores para alta Importância e Valorização. Merecem atenção os resultados assinalados pelos gestores tanto para alta Importância quanto para alta Valorização, visto que eles assinalaram na maioria das dimensões os menores escores entre os perfis.

Chamou a atenção ainda, os escores apontados pelos produtores em média Importância e média Valorização.

Tabela 14 - Completude: Médias por perfil

\begin{tabular}{lcccccc}
\hline \multicolumn{1}{c}{ Dimensão } & \multicolumn{3}{c}{ Importância } & \multicolumn{3}{c}{ Valorização } \\
\hline \multicolumn{1}{c}{ Perfis } & Baixa & Média & Alta & Baixa & Média & Alta \\
& $(\%)$ & $(\%)$ & $(\%)$ & $(\%)$ & $(\%)$ & $(\%)$ \\
\hline Produtor & 5,3 & 26,3 & 68,4 & 15,8 & 21,1 & 63,2 \\
Consumidor & 0,0 & 7,1 & 92,9 & 0,0 & 14,3 & 85,7 \\
Gestor & 0,0 & 15,4 & 84,6 & 7,7 & 7,7 & 84,6 \\
\hline${ }^{*}$ Produtor (N): 19 & \multicolumn{2}{c}{ Consumidor (N): 14} & Gestor (N): 13 &
\end{tabular}

${ }^{*}$ Produtor $(\mathrm{N}): 19 \quad$ Consumidor $(\mathrm{N}): 14 \quad$ Gestor $(\mathrm{N}): 13$

Os resultados se justificam caso sejam associados com os cargos ocupados pelos participantes, pois a maioria, entre os gestores e consumidores, exercem atividades relacionadas às áreas de gestão (gerência e supervisão). É uma tendência natural desses cargos avaliar com mais critério a qualidade das informações que utilizam. Por outro lado, a maioria dos produtores exerce atividades operacionais e por isso, não atribui Importância e Valorização na mesma proporção que os outros perfis. 
Além disso, essa dimensão, segundo Lee (2003) apresenta certa dificuldade em sua conceituação, pois os conceitos oscilam entre as categorias intrínseca e contextual. Em ambas as categorias, ela pode ser definida em termos de ausência de valor, porém, na categoria contextual, a ausência de valor refere-se somente para os valores usados ou realmente necessários para os consumidores da informação. Isto justifica os resultados apurados nessa dimensão em relação aos consumidores, mas não explica os resultados apontados para produtores e especialmente para os gestores.

\subsubsection{Impacto}

Os resultados da análise geral ( $\mathrm{N}=46)$, demonstrados na tabela 15, mostram que produtores e consumidores foram os perfis que atribuíram maior Importância e Valorização a essa dimensão.

Tabela 15 - Impacto: Médias gerais

\begin{tabular}{lcccccc}
\hline & \multicolumn{3}{c}{ Importância da } & \multicolumn{3}{c}{ Valorização da } \\
dimensão & Dimensão \\
\hline \multicolumn{1}{c}{ Perfis } & $\begin{array}{c}\text { Baixa } \\
\text { (\%) }\end{array}$ & $\begin{array}{c}\text { Média } \\
(\%)\end{array}$ & $\begin{array}{c}\text { Alta } \\
(\%)\end{array}$ & $\begin{array}{c}\text { Baixa } \\
(\%)\end{array}$ & $\begin{array}{c}\text { Média } \\
(\%)\end{array}$ & $\begin{array}{c}\text { Alta } \\
(\%)\end{array}$ \\
\hline Produtor & 0,0 & 0,0 & 41,3 & 2,2 & 8,7 & 30,4 \\
Consumidor & 0,0 & 0,0 & 30,4 & 0 & 2,2 & 28,3 \\
Gestor & 2,2 & 0,0 & 26,1 & 0 & 2,2 & 26,1 \\
\hline
\end{tabular}

Participantes (N): 46

A análise dos perfis, exposta na tabela 16, indica que a totalidade dos produtores e dos consumidores atribuiu alta Importância e apenas 7,7\% dos gestores deixaram de assinalar alta Importância para a dimensão. Quanto à Valorização, os escores foram também significativos, principalmente entre os consumidores e gestores, já os produtores assinalaram escores distribuídos entre alta e média Valorização. 
Tabela 16 - Impacto: Médias por perfil

\begin{tabular}{lcccccc}
\hline \multicolumn{1}{c}{ Dimensão } & \multicolumn{3}{c}{ Importância } & \multicolumn{3}{c}{ Valorização } \\
\hline \multicolumn{1}{c}{ Perfis } & $\begin{array}{c}\text { Baixa } \\
(\%)\end{array}$ & $\begin{array}{c}\text { Média } \\
(\%)\end{array}$ & $\begin{array}{c}\text { Alta } \\
(\%)\end{array}$ & $\begin{array}{c}\text { Baixa } \\
(\%)\end{array}$ & $\begin{array}{c}\text { Média } \\
(\%)\end{array}$ & $\begin{array}{c}\text { Alta } \\
(\%)\end{array}$ \\
\hline Produtor & 0,0 & 0,0 & 100,0 & 5,3 & 21,1 & 73,7 \\
Consumidor & 0,0 & 0,0 & 100,0 & 0,0 & 7,1 & 92,9 \\
Gestor & 7,7 & 0,0 & 92,3 & 0,0 & 7,7 & 92,3 \\
\hline \multicolumn{2}{c}{ Produtor (N): 19} & Consumidor $(\mathrm{N}): 14$ & \multicolumn{3}{c}{ Gestor $(\mathrm{N}): 13$}
\end{tabular}

Wang e Strong (1996) explicam que existem três abordagens, na literatura, utilizadas para estudar a qualidade de dados: a intuitiva, a teórica - baseadas nas teorias - e a empírica - baseada na experiência. A abordagem intuitiva é percebida quando a seleção de atributos da qualidade de dados para algum evento é embasada na experiência do usuário ou em seu entendimento intuitivo, para saber quais atributos são mais importantes naquele momento.

Isso parece fundamentar os resultados apurados neste estudo. Além disso, mesmo não encontrando parâmetros na literatura que possibilitassem comparações com os resultados obtidos, havia a expectativa de boa avaliação da dimensão pelos participantes, mas não se esperavam resultados tão expressivos.

\subsubsection{Pontualidade}

Considerando os escores observados na tabela 17 , da média geral $(\mathrm{N}=46)$, percebese que os participantes atribuíram alta Importância e alta Valorização para a dimensão. 
Tabela 17 - Pontualidade: Médias gerais

\begin{tabular}{lcccccc}
\hline & \multicolumn{3}{c}{$\begin{array}{l}\text { Importância da } \\
\text { dimensão }\end{array}$} & \multicolumn{3}{c}{$\begin{array}{c}\text { Valorização da } \\
\text { Dimensão }\end{array}$} \\
\hline \multicolumn{1}{c}{ Perfis } & $\begin{array}{c}\text { Baixa } \\
(\%)\end{array}$ & $\begin{array}{c}\text { Média } \\
(\%)\end{array}$ & $\begin{array}{c}\text { Alta } \\
(\%)\end{array}$ & $\begin{array}{c}\text { Baixa } \\
(\%)\end{array}$ & $\begin{array}{c}\text { Média } \\
(\%)\end{array}$ & $\begin{array}{c}\text { Alta } \\
(\%)\end{array}$ \\
\hline Produtor & 2,2 & 2,2 & 37,0 & 0 & 6,5 & 34,8 \\
Consumidor & 0,0 & 2,2 & 28,3 & 0 & 0 & 30,4 \\
Gestor & 2,2 & 0,0 & 26,1 & 0 & 2,2 & 26,1 \\
\hline
\end{tabular}

Da mesma forma, a análise dos perfis, apresentada na tabela 18, apurou que os consumidores foram os que mais atribuíram alta Importância e Valorização à dimensão, sendo também expressivos os resultados apontados pelos gestores, nas duas escalas.

Tabela 18 - Pontualidade: Médias por perfil

\begin{tabular}{lcccccc}
\hline \multicolumn{1}{c}{ Dimensão } & \multicolumn{3}{c}{ Importância } & \multicolumn{3}{c}{ Valorização } \\
\hline \multicolumn{1}{c}{ Perfis } & $\begin{array}{c}\text { Baixa } \\
(\%)\end{array}$ & $\begin{array}{c}\text { Média } \\
(\%)\end{array}$ & $\begin{array}{c}\text { Alta } \\
(\%)\end{array}$ & $\begin{array}{c}\text { Baixa } \\
(\%)\end{array}$ & $\begin{array}{c}\text { Média } \\
(\%)\end{array}$ & $\begin{array}{c}\text { Alta } \\
(\%)\end{array}$ \\
\hline Produtor & 5,3 & 5,3 & 89,5 & 0,0 & 15,8 & 84,2 \\
Consumidor & 0,0 & 7,1 & 92,9 & 0,0 & 0,0 & 100,0 \\
Gestor & 7,7 & 0,0 & 92,3 & 0,0 & 7,7 & 92,3 \\
\hline \multicolumn{2}{c}{ Produtor $(\mathrm{N}): 19$} & Consumidor $(\mathrm{N}): 14$ & \multicolumn{3}{c}{ Gestor $(\mathrm{N}): 13$}
\end{tabular}

A pontualidade está associada à entrega de serviços e produtos da informação. Assim, os resultados indicam que os três perfis analisados consideram a dimensão de forma significativa em suas atividades. Porém, os consumidores e gestores atribuem maior importância e valorização à dimensão. Esses resultados podem ser justificados por conta dos cargos que esses perfis ocupam, isto é, $42,9 \%$ dos consumidores e $61,5 \%$ dos gestores atuam como gerentes e supervisores.

Os produtores, por outro lado, estão associados aos processos de desenvolvimento de software. Esses processos são geralmente, realizados com cronogramas e entregas planejadas, sendo, portanto, alinhados com os conceitos dessa dimensão. Isto justifica, em tese, os resultados apontados pelos produtores para essa 
dimensão. Além disso, é possível associar a dimensão como sendo de caráter técnico, ou seja, ela pode ser planejada e mensurada, pois está associada intrinsecamente à entrega de serviços e produtos, atividades também inerentes à função dos produtores.

\subsubsection{Eficácia da recuperação}

A análise dos perfis $(\mathrm{N}=46)$, conforme tabela 19 , não indicou mudanças do padrão de resposta entre os participantes. Os resultados apurados mostram que produtores, consumidores e gestores assinalaram alta Importância e alta Valorização para a dimensão.

Tabela 19 - Eficácia da Recuperação: Médias gerais

\begin{tabular}{lcccccc}
\hline & \multicolumn{3}{c}{$\begin{array}{c}\text { Importância da } \\
\text { dimensão }\end{array}$} & \multicolumn{3}{c}{$\begin{array}{c}\text { Valorização da } \\
\text { Dimensão }\end{array}$} \\
\hline \multicolumn{1}{c}{ Perfis } & $\begin{array}{c}\text { Baixa } \\
(\%)\end{array}$ & $\begin{array}{c}\text { Média } \\
(\%)\end{array}$ & $\begin{array}{c}\text { Alta } \\
(\%)\end{array}$ & $\begin{array}{c}\text { Baixa } \\
(\%)\end{array}$ & $\begin{array}{c}\text { Média } \\
(\%)\end{array}$ & $\begin{array}{c}\text { Alta } \\
(\%)\end{array}$ \\
\hline Produtor & 0,0 & 4,3 & 37,0 & 2,2 & 6,5 & 32,6 \\
Consumidor & 0,0 & 4,3 & 26,1 & 0 & 2,2 & 28,3 \\
Gestor & 2,2 & 0,0 & 26,1 & 2,2 & 4,3 & 21,7 \\
\hline
\end{tabular}

Participantes (N): 46

Como se observa na tabela 20 , nos resultados por perfil, os gestores atribuíram os maiores escores para alta Importância, enquanto os consumidores assinalaram os menores escores. Porém, para alta Valorização, os maiores escores foram atribuídos pelos consumidores, seguidos dos produtores e gestores.

Tabela 20 - Eficácia da Recuperação: Médias por perfil

\begin{tabular}{lcccccc}
\hline \multicolumn{1}{c}{ Dimensão } & \multicolumn{3}{c}{ Importância } & \multicolumn{3}{c}{ Valorização } \\
\hline \multicolumn{1}{c}{ Perfis } & $\begin{array}{c}\text { Baixa } \\
\text { (\%) }\end{array}$ & $\begin{array}{c}\text { Média } \\
(\%)\end{array}$ & $\begin{array}{c}\text { Alta } \\
(\%)\end{array}$ & $\begin{array}{c}\text { Baixa } \\
(\%)\end{array}$ & $\begin{array}{c}\text { Média } \\
(\%)\end{array}$ & $\begin{array}{c}\text { Alta } \\
(\%)\end{array}$ \\
\hline Produtor & 0,0 & 10,5 & 89,5 & 5,3 & 15,8 & 78,9 \\
Consumidor & 0,0 & 14,3 & 85,7 & 0,0 & 7,1 & 92,9 \\
Gestor & 7,7 & 0,0 & 92,3 & 7,7 & 15,4 & 76,9 \\
\hline
\end{tabular}

Produtor $(\mathrm{N}): 19 \quad$ Consumidor $(\mathrm{N}): 14 \quad$ Gestor $(\mathrm{N}): 13$ 
Os resultados entre os perfis, indicam que todos atribuíram alta Importância, com resultados próximos entre si, oscilando entre 2,8 a 3,8 pontos percentuais.

É possível explicar esses resultados tecendo uma análise das características de cada perfil em relação a essa dimensão. A Eficácia da Recuperação é também uma dimensão mais técnica e, portanto, está mais associada às atividades desenvolvidas pelos profissionais com perfil de gestor e produtor do que as atividades realizadas pelos consumidores. Por isso, os gestores e produtores podem ter atribuído maior importância a ela.

\subsubsection{Quantidade adequada}

Os resultados apontados na tabela 21 , na análise geral $(\mathrm{N}=46)$, demonstraram altos escores tanto para alta Importância como para Valorização, em todos os perfis.

Tabela 21 - Quantidade Adequada: Médias gerais

\begin{tabular}{lcccccc}
\hline & \multicolumn{3}{c}{$\begin{array}{l}\text { Importância da } \\
\text { dimensão }\end{array}$} & \multicolumn{3}{c}{$\begin{array}{c}\text { Valorização da } \\
\text { Dimensão }\end{array}$} \\
\hline \multicolumn{1}{c}{ Perfis } & $\begin{array}{c}\text { Baixa } \\
(\%)\end{array}$ & $\begin{array}{c}\text { Média } \\
(\%)\end{array}$ & $\begin{array}{c}\text { Alta } \\
(\%)\end{array}$ & $\begin{array}{c}\text { Baixa } \\
(\%)\end{array}$ & $\begin{array}{c}\text { Média } \\
(\%)\end{array}$ & $\begin{array}{c}\text { Alta } \\
(\%)\end{array}$ \\
\hline Produtor & 4,3 & 2,2 & 34,8 & 6,5 & 4,3 & 30,4 \\
Consumidor & 2,2 & 4,3 & 23,9 & 0 & 8,7 & 21,7 \\
Gestor & 2,2 & 6,5 & 19,6 & 0 & 4,3 & 23,9 \\
\hline \multicolumn{4}{c}{ Participantes (N): 46 }
\end{tabular}

A tabela 22 apresenta a análise entre os perfis. Ela mostra escores bem distribuídos entre os participantes, tanto na escala Importância como na Valorização. As duas escalas foram bem avaliadas em alta e média Importância, merecendo destaque os resultados em média e baixa Importância dos gestores e média e baixa Valorização dos consumidores. Os produtores, por sua vez, assinalaram altos escores tanto à Importância quanto para Valorização. 
Tabela 22 - Quantidade Adequada: Médias por perfil

\begin{tabular}{lcccccc}
\hline \multicolumn{1}{c}{ Dimensão } & \multicolumn{3}{c}{ Importância } & \multicolumn{3}{c}{ Valorização } \\
\hline \multicolumn{1}{c}{ Perfis } & $\begin{array}{c}\text { Baixa } \\
(\%)\end{array}$ & $\begin{array}{c}\text { Média } \\
(\%)\end{array}$ & $\begin{array}{c}\text { Alta } \\
(\%)\end{array}$ & $\begin{array}{c}\text { Baixa } \\
(\%)\end{array}$ & $\begin{array}{c}\text { Média } \\
(\%)\end{array}$ & $\begin{array}{c}\text { Alta } \\
(\%)\end{array}$ \\
\hline Produtor & 10,5 & 5,3 & 84,2 & 15,8 & 10,5 & 73,7 \\
Consumidor & 7,1 & 14,3 & 78,6 & 0,0 & 28,6 & 71,4 \\
Gestor & 7,7 & 23,1 & 69,2 & 0,0 & 15,4 & 84,6 \\
\hline \multicolumn{2}{c}{ Produtor (N): 19} & Consumidor (N): 14 & \multicolumn{3}{c}{ Gestor (N): 13}
\end{tabular}

Tecendo uma análise dos resultados é possível observar que essa dimensão apresentou resultados bem distribuídos em baixa, média e alta Importância atribuída à dimensão. Entretanto, houve diferenças significativas entre os perfis em média Importância, com ênfase para os resultados apurados para os produtores. Na escala Valorização, os resultados foram bem distribuídos em média e alta Valorização.

Considerando as características dessa dimensão, percebe-se um alinhamento dos resultados com as funções e cargos dos participantes. Ou seja, tanto os consumidores quanto os gestores possuem uma visão mais acurada de uso das informações e interessam-se, portanto, por informações disponibilizadas em quantidade necessária e suficiente para a realização de suas atividades, nem mais, nem menos. O excesso, assim como a escassez, é prejudicial.

Além disso, há que se considerar que uma parcela significativa desses perfis está envolvida com atividades relacionadas à gestão, para a qual as informações em quantidade adequada são essenciais para o sucesso de suas decisões.

Os produtores, por outro lado, criam interfaces (relatórios, consultas) que disponibilizam informações, mas geralmente não utilizam, de fato, as informações dos sistemas que desenvolvem. 


\subsubsection{Adequação da Indexação e Classificação}

Os resultados apurados na análise geral dos perfis $(\mathrm{N}=46)$, mostrados na tabela 23, apontaram que os produtores, em sua maioria, atribuíram alta Importância e Valorização à dimensão, seguidos dos consumidores e dos gestores.

Tabela 23 - Adequação da Indexação e Classificação: Médias Gerais

\begin{tabular}{lcccccc}
\hline & \multicolumn{3}{c}{$\begin{array}{c}\text { Importância da } \\
\text { dimensão }\end{array}$} & \multicolumn{3}{c}{$\begin{array}{c}\text { Valorização da } \\
\text { Dimensão }\end{array}$} \\
\hline \multicolumn{1}{c}{ Perfis } & $\begin{array}{c}\text { Baixa } \\
\text { (\%) }\end{array}$ & $\begin{array}{c}\text { Média } \\
(\%)\end{array}$ & $\begin{array}{c}\text { Alta } \\
(\%)\end{array}$ & $\begin{array}{c}\text { Baixa } \\
(\%)\end{array}$ & $\begin{array}{c}\text { Média } \\
(\%)\end{array}$ & $\begin{array}{c}\text { Alta } \\
(\%)\end{array}$ \\
\hline Produtor & 2,2 & 6,5 & 32,6 & 4,3 & 10,9 & 26,1 \\
Consumidor & 2,2 & 0,0 & 28,3 & 0 & 4,3 & 26,1 \\
Gestor & 4,3 & 4,3 & 19,6 & 0 & 6,5 & 21,7 \\
\hline
\end{tabular}

Participantes $(\mathrm{N}): 46$

Entre os perfis analisados, conforme tabela 24, chamaram a atenção os resultados em alta Importância pelos produtores, os quais assinalaram escores bem distribuídos para Valorização.

Situação contrária foi registrada pelos Gestores, que assinalaram maiores escores para Valorização do que na escala Importância. Os consumidores assinalaram altos escores em ambas as escalas.

Tabela 24 - Adequação da Indexação e Classificação: Médias por perfil

\begin{tabular}{lcccccc}
\hline \multicolumn{1}{c}{ Dimensão } & \multicolumn{3}{c}{ Importância } & \multicolumn{3}{c}{ Valorização } \\
\hline \multicolumn{1}{c}{ Perfis } & $\begin{array}{c}\text { Baixa } \\
(\%)\end{array}$ & $\begin{array}{c}\text { Média } \\
(\%)\end{array}$ & $\begin{array}{c}\text { Alta } \\
(\%)\end{array}$ & $\begin{array}{c}\text { Baixa } \\
(\%)\end{array}$ & $\begin{array}{c}\text { Média } \\
(\%)\end{array}$ & $\begin{array}{c}\text { Alta } \\
(\%)\end{array}$ \\
\hline Produtor & 5,3 & 15,8 & 78,9 & 10,5 & 26,3 & 63,2 \\
Consumidor & 7,1 & 0,0 & 92,9 & 0,0 & 14,3 & 85,7 \\
Gestor & 15,4 & 15,4 & 69,2 & 0,0 & 23,1 & 76,9 \\
\hline \multicolumn{2}{c}{ Produtor $(\mathrm{N}): 19$} & Consumidor $(\mathrm{N}): 14$ & \multicolumn{3}{c}{ Gestor $(\mathrm{N}): 13$}
\end{tabular}


Os resultados apontados nessa dimensão podem ser justificados, em parte, pelas características de cada perfil do estudo. Devido às suas atividades associadas ao desenvolvimento de sistemas, os produtores utilizam com frequência os conceitos dessa dimensão, por isso podem ter atribuído alta Importância a ela. Além disso, a maioria dos participantes desse perfil executam atividades operacionais (57,9\%), o que leva a crer que não tem a percepção de valor dessa dimensão para a organização, por isso justificam-se os escores em alta Valorização deste perfil.

Os gestores, por sua vez, envolvidos diretamente com a gestão por conta dos cargos que exercem, sendo a maioria associados com gerenciamento e supervisão, podem ter maior percepção de valor dessa dimensão.

Os consumidores, por causa das suas atividades possuem certa relação de dependência com esta dimensão, pois os conceitos da Adequação da Indexação e Classificação das informações estão presentes em consultas, relatórios, listagens, dentre outras, utilizadas por eles no dia a dia. Isso pode ter influenciado na sua forma de assinalar a Importância e a Valorização da dimensão.

\subsection{Discussãodos RESULTADOS}

Os resultados apurados apresentam como se processa a percepção da qualidade da informação, em especial das dimensões da abordagem de contexto, entre os profissionais da informação envolvidos com a área de $\mathrm{TI}$, representados no estudo pelos perfis, produtor, consumidor e gestor.

Observou-se que a maioria dos participantes atribuiu altos escores para alta importância e alta Valorização em todas as dimensões. Isso indica que a qualidade da informação é um conceito conhecido e utilizado pelos participantes em suas atividades profissionais.

Entretanto, existem fatores que podem ter influenciado nos resultados, como: 
a) Perfil do participante: $89 \%$ dos participantes assinalaram que já conheciam os conceitos da qualidade da informação. Tratando-se de um estudo dirigido para um público específico, formado por profissionais da área de tecnologia da informação (produtores e gestores) e usuários de sistemas de informação (consumidores), havia inicialmente uma expectativa positiva sobre as percepções dos participantes, porém, os resultados ultrapassaram o esperado.

b) Formação acadêmica: todos os participantes são graduados em cursos de nível superior, nas áreas de tecnologia e gestão, que têm a informação e seus conceitos como recursos a serem gerenciados.

c) O contexto da aplicação: as empresas onde os participantes trabalham incentivam as práticas da qualidade da informação, segundo dados coletados na questão 2 do IPQI. Essas empresas têm como atividade principal a produção de softwares, portanto, estão mais alinhadas com as práticas e conceitos da qualidade da informação.

d) Características das dimensões: as dimensões de contexto, pelas suas características, fazem parte das atividades cotidianas dos participantes no ambiente de trabalho, ainda que eles não conheçam os seus conceitos e práticas.

Esses resultados, na verdade, afirmam os objetivos deste estudo sobre as dimensões baseadas no contexto. Essas são as dimensões mais difíceis de serem identificadas e mensuradas, porém estão mais associadas às atividades e às práticas dos profissionais da informação, no seu dia a dia.

Além disso, conforme se observa no item III, acima descrito, considerando o contexto delimitado no estudo, o perfil das empresas e dos participantes pode ter contribuído para se chegar aos resultados apurados. Neste estudo, o ramo de atividade das empresas analisadas está associado à prestação de serviços de informação, ou seja, existe uma sintonia entre os perfis e as organizações avaliadas. Assim, é possível que a aplicação do instrumento em outros contextos, com 
empresas de diferentes ramos de atividades, por exemplo, os resultados sejam diferentes, mesmo entre os perfis alinhados com a produção e gestão da informação.

\subsubsection{Dimensões e Escalas da proposta}

Observou-se que os participantes conhecem os conceitos das dimensões, haja vista os altos escores assinalados tanto para Importância como para Valorização atribuídas em todas as dimensões.

Considerando esses resultados assinalados entre os perfis, nas escalas Importância (gráfico 5) e escala Valorização (gráfico 6), é possível fazer algumas inferências:

a) Constatou-se que os consumidores assinalaram os maiores escores em sete dimensões na escala Importância, exceto para impacto, eficácia da recuperação e quantidade adequada. Na escala Valorização, eles assinalaram os maiores escores em nove dimensões, exceto para a dimensão quantidade adequada.

b) Os produtores, na escala Importância atribuída, assinalaram os maiores escores para quantidade adequada e assinalaram à frente dos gestores em relevância, valor esperado, valor percebido, valor agregado, impacto e adequação à indexação e classificação. Já na escala Valorização, assinalaram escores maiores do que os gestores apenas para relevância e eficácia da recuperação.

c) Os gestores, na escala Importância, assinalaram os maiores escores apenas em eficácia da recuperação e assinalaram à frente dos produtores em completude, pontualidade. Na escala Valorização, porém, assinalaram os maiores escores para quantidade adequada e assinalaram à frente dos produtores em valor esperado, valor percebido, valor agregado, 
completude, impacto, pontualidade, adequação da indexação e classificação.

Em síntese, os resultados apurados contrariam as expectativas sobre a percepção da qualidade da informação pelos participantes e, sobretudo, das diferenças anotadas entre os perfis.

Sendo a informação um dos principais produtos do trabalho dos gestores e dos produtores e, sendo sua formação profissional, especificamente orientada para os processos de produção de sistemas de informação, era esperado que esses perfis anotassem os maiores escores devido à sua familiaridade com alguns conceitos da qualidade da informação.

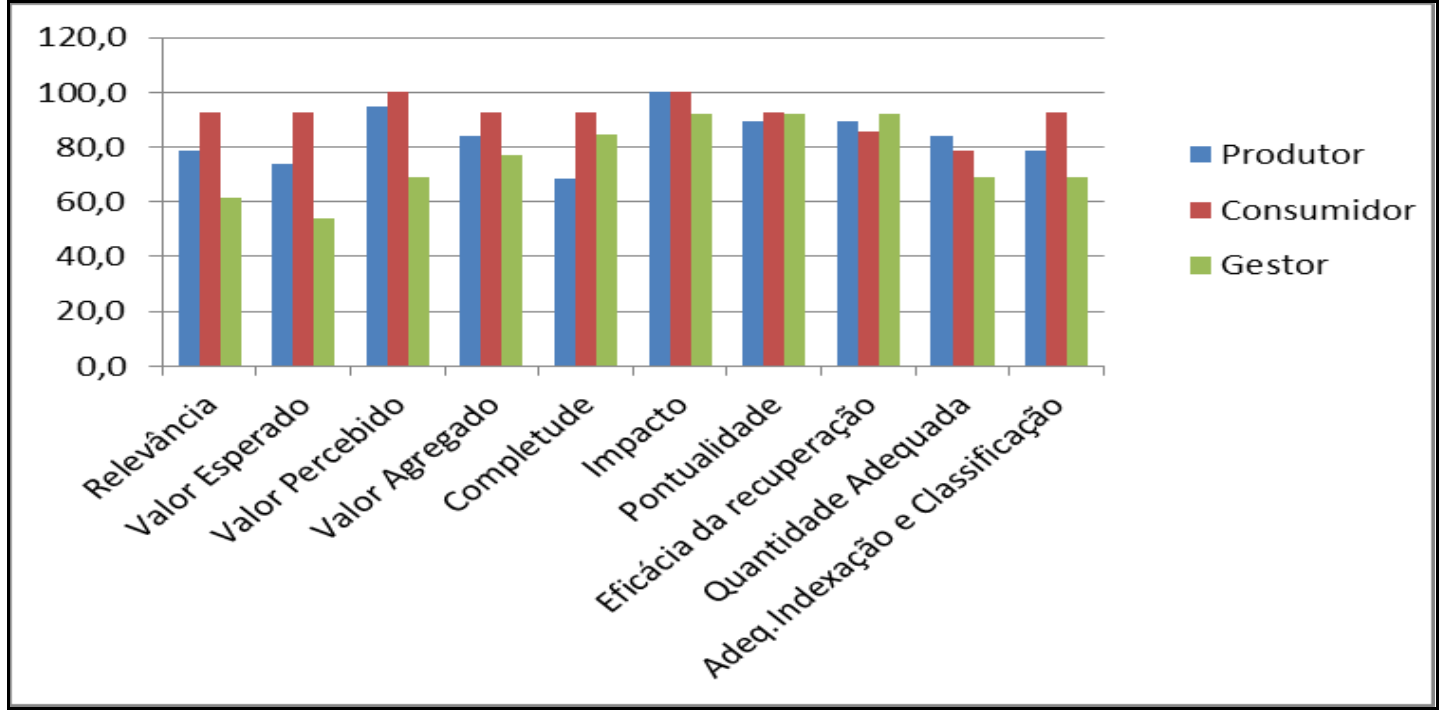

Gráfico 5 - Alta Importância atribuída às dimensões por perfil

Os resultados mais contundentes, entretanto, foram observados entre os perfis de produtor e consumidor, na escala Valorização, como se pode observar no gráfico 6 , em que a média para consumidor é significativamente maior que a média para produtor.

Esses resultados indicam que os usuários (consumidores) de sistemas de informação, com boa formação e alocados em organizações que valorizam as práticas da qualidade da informação, tendem a desenvolver uma boa percepção da 
qualidade, até mesmo superior à de perfis geralmente envolvidos com os conceitos da qualidade, como ficou demonstrado neste estudo.

Lee (2003) já havia identificado que os consumidores têm o entendimento básico da qualidade da informação que necessitam para seus trabalhos. $E$, nesse sentido, Wang (1998, p. 65) assinala que os consumidores "são mais propensos a encontrar problemas com as informações que eles usam [...]”. É importante, porém, observar que em ambos os estudos a informação é tratada como um produto, ou seja, com atributos passíveis de serem quantificados e mensurados.

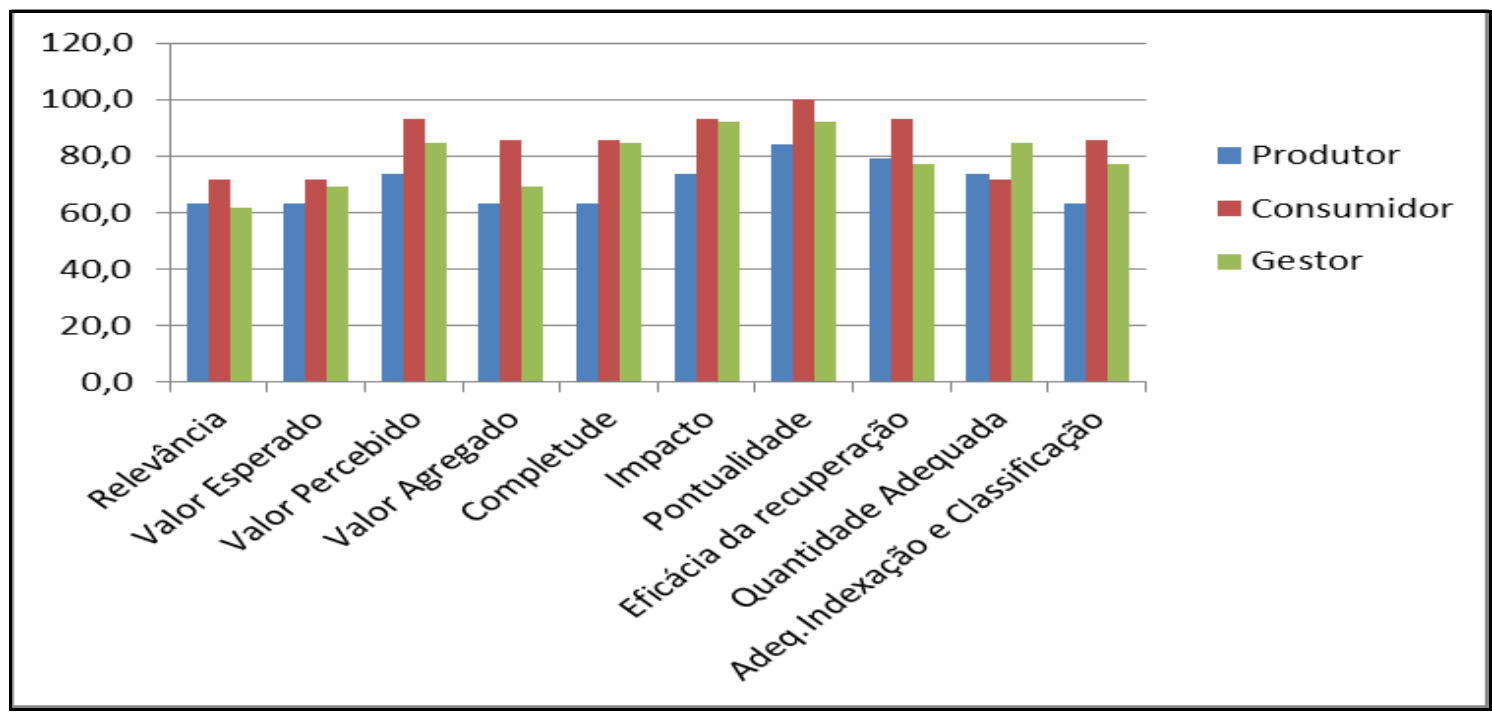

Gráfico 6 - Alta Valorização atribuída às dimensões por perfil

Além disso, não se pode assumir que os usuários de sistemas em geral têm essa percepção acurada sobre os conceitos de cada dimensão da qualidade da informação. Oleto (2006), por exemplo, relata o caso de um estudo em que os participantes tinham dificuldade para entender os conceitos da qualidade de forma distinta, individualizada e que os conceitos se misturavam e eles os utilizavam de forma intuitiva, baseados no senso comum.

Ressalta-se que, no estudo relatado por Oleto (2006), os participantes desconheciam os conceitos da qualidade da informação, mas esses estavam vinculados às práticas cotidianas do trabalho dos participantes, entretanto o autor 
não revela o tipo de trabalho desempenhado e tampouco a formação acadêmica dos participantes.

\subsubsection{Associação entre escalas e cargos dos participantes}

Ficou evidenciada a existência de forte associação entre as dimensões da abordagem de contexto com os cargos dos participantes. Ou seja, uma mesma dimensão avaliada por indivíduos de cargos diferentes, produz resultados também diferentes.

Esse resultado é uma confirmação da base teórica que sustenta as abordagens de contexto, em que cada indivíduo avalia a qualidade da informação de acordo com suas percepções do contexto de uso. Neste estudo, isso pode ser observado, nas dimensões quantidade adequada, impacto, completude, pontualidade, eficácia da recuperação e adequação a indexação e classificação. Essa última será utilizada como exemplo.

Nessa dimensão, a maioria dos produtores atribuiu alta Importância, porém, atribuiu menores escores à alta Valorização. $57 \%$ dos produtores atuam em cargos operacionais e, portanto, têm uma percepção mais técnica da dimensão, por isso assinalaram alta importância à dimensão, cujas características estão associadas às atividades geralmente desenvolvidas por esse perfil de profissional. Da mesma forma, esses profissionais atribuíram escores menores para alta Valorização, pois, em função de suas atividades, eles não fazem a associação entre a dimensão e a sua influência para os processos de negócios da organização.

De outro lado, a dimensão avaliada pelos gestores apresentou visões diferentes. Sendo a maioria dos participantes do perfil (61,5\%) gerentes e supervisores, atribuíram provavelmente escores menores à Importância do que à Valorização. Em outras palavras, eles consideraram mais significativos os aspectos da dimensão 
associados ao contexto da organização/empresa do que aos aspectos técnicos da dimensão.

\subsubsection{Escalas Importância x Escala Valorização}

As análises dos resultados sobre as escalas Importância e Valorização apontaram que há uma igualdade de variância entre as médias das escalas, significando que são muito próximas e, portanto, não existem diferenças significativas entre elas.

Contudo, mediante a aplicação de testes estatísticos como a ANOVA $^{2}$ (Análise de Variância) usados para verificar o comportamento entre as escalas, constatou-se uma diferença (Quadro 5) na escala Valorização (sig 0,044) entre os grupos. Resultados com sig < 0,05 indicam diferenças entre os grupos testados e o contrário, sig > 0,05, indica normalidade entre os grupos (SOUZA, 2013).

\begin{tabular}{|c|c|c|c|c|c|c|}
\hline & & $\begin{array}{l}\text { Sum of } \\
\text { Squares }\end{array}$ & $\mathrm{df}$ & $\begin{array}{l}\text { Média } \\
\text { Square }\end{array}$ & $\mathrm{F}$ & Sig. \\
\hline \multirow{3}{*}{$\begin{array}{l}\text { Média de importância atribuída } \\
\text { às dimensões }\end{array}$} & Between Groups & 4,397 & 2 & 2,198 & \multirow[t]{3}{*}{1,844} & \multirow[t]{3}{*}{, 171 } \\
\hline & Within Groups & 51,273 & 43 & 1,192 & & \\
\hline & Total & 55,670 & 45 & & & \\
\hline \multirow{3}{*}{$\begin{array}{l}\text { Média de valorização atribuída } \\
\text { às dimensões }\end{array}$} & Between Groups & 6,541 & 2 & 3,271 & \multirow[t]{3}{*}{3,370} & \multirow[t]{3}{*}{,044 } \\
\hline & Within Groups & 41,737 & 43 & ,971 & & \\
\hline & Total & 48,278 & 45 & & & \\
\hline
\end{tabular}

Quadro 5 - Resultados da ANOVA: Escalas X Grupos

Como se observa, o sig. 0,044 para Média de Valorização atribuída às dimensões é menor que 0,05 , portanto indica que há pelo menos uma diferença entre os grupos testados, ou seja entre os produtores, gestores e consumidores.

\footnotetext{
${ }^{2}$ ANOVA: É uma técnica de teste de hipótese utilizada quando se deseja comparar as médias de três ou mais populações (SOUZA, 2013).
} 
Por isso, foram realizados testes como Shapiro $\mathrm{Wilk}^{3}$, para amostras com até 50 casos; e Post Hoc Tests ${ }^{4}$ (Quadro 6), a fim de localizar e identificar a diferença. O teste identificou que a diferença na escala Valorização estava concentrada entre os perfis de consumidor e produtor. Isso significa, em síntese, que produtores e consumidores percebem a Valorização das dimensões de forma diferente.

\begin{tabular}{|c|c|c|c|c|c|c|c|}
\hline \multirow{2}{*}{ 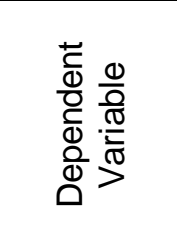 } & \multirow[b]{2}{*}{ (I) Função } & \multirow[b]{2}{*}{ (J) Função } & \multirow{2}{*}{$\begin{array}{c}\text { Diferença } \\
\text { da } \\
\text { Média(I-J) }\end{array}$} & \multirow[b]{2}{*}{$\begin{array}{l}\text { Erro } \\
\text { padrão }\end{array}$} & \multirow[b]{2}{*}{ Sig. } & \multicolumn{2}{|c|}{$\begin{array}{c}\text { Intervalo de } \\
\text { Confiança }\end{array}$} \\
\hline & & & & & & $\begin{array}{l}\text { Limite } \\
\text { inferior }\end{array}$ & $\begin{array}{l}\text { Limite } \\
\text { superior }\end{array}$ \\
\hline \multirow{6}{*}{ 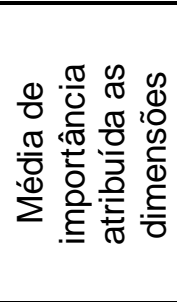 } & Produtor & Consumidor &,- 35639 & ,38461 & ,627 & $\begin{array}{l}-1,2900 \\
\end{array}$ & ,5772 \\
\hline & & Gestor & ,45020 & ,39304 & ,492 &,- 5039 & 1,4043 \\
\hline & Consumidor & Produtor & 35639 & ,38461 & ,627 &,- 5772 & 1,2900 \\
\hline & & Gestor & 80659 & 42059 & 146 &,- 2144 & 1,8275 \\
\hline & Gestor & Produtor &,- 45020 & ,39304 & ,492 & $-1,4043$ & ,5039 \\
\hline & & Consumidor &,- 80659 & 42059 &, 146 & $-1,8275$ & 2144 \\
\hline \multirow{6}{*}{ 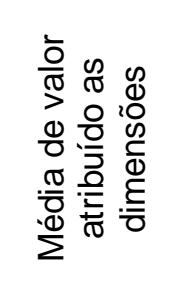 } & Produtor & Consumidor &,$- 85789\left(^{*}\right)$ & ,34701 & ,045 & $-1,7002$ &,- 0155 \\
\hline & & Gestor &,- 61943 & ,35461 & ,200 & $-1,4802$ & ,2414 \\
\hline & Consumidor & Produtor &, $85789\left(^{*}\right)$ & ,34701 &, 045 & ,0155 & 1,7002 \\
\hline & & Gestor & ,23846 & ,37947 & ,805 &,- 6827 & 1,1596 \\
\hline & Gestor & Produtor & ,61943 & ,35461 & ,200 &,- 2414 & 1,4802 \\
\hline & & Consumidor &,- 23846 & 37947 & ,805 & $-1,1596$ & 6827 \\
\hline
\end{tabular}

Quadro 6 - Diferenças entre os grupos Produtor e Consumidor

Essa percepção da Valorização, como nas outras diferenças observadas, pode estar associada aos cargos dos participantes, ou seja, o consumidor está mais envolvido com os resultados das informações na realização das atividades e, por isso, tende a dar maior importância e valorização às dimensões. O produtor, por outro lado, tem a percepção da importância das informações necessárias para atender às necessidades dos consumidores, mas não vivencia, ele próprio os impactos do uso da informação, por isso atribui menor valorização.

Considerando que apenas o sig entre os grupos produtor e consumidor está abaixo de 0,05 , pode-se dizer que estes dois grupos diferem entre si, sendo que o grupo

\footnotetext{
${ }^{3}$ Shapiro Milk - Teste de normalidade, aplicado para amostras com até 50 casos.

${ }^{4}$ Post Hoc Test - Teste aplicado para identificar as diferenças entre as escalas e grupos do estudo.
} 
consumidor atribui maior média ao valor geral das dimensões pesquisadas, visto que a média de pontuação apurada para este grupo foi de 8,9000 enquanto que a média de pontuação do grupo produtor foi 8,0421. Entretanto, não foram encontradas outras diferenças entre as escalas, o que significa que os indivíduos que atribuem alta Importância à determinada dimensão, geralmente atribuem também alta Valorização.

Desse modo, adotou-se neste estudo a perspectiva de que a qualidade da informação é dependente do contexto em que é utilizada, isto é, depende dos indivíduos e das propriedades contextuais e não somente do produto informação: a informação de qualidade é resultado do processo, como se observa na Figura 13. As propriedades contextuais são as vinculadas ao contexto, como a cultura organizacional, social e educacional, entre outras.

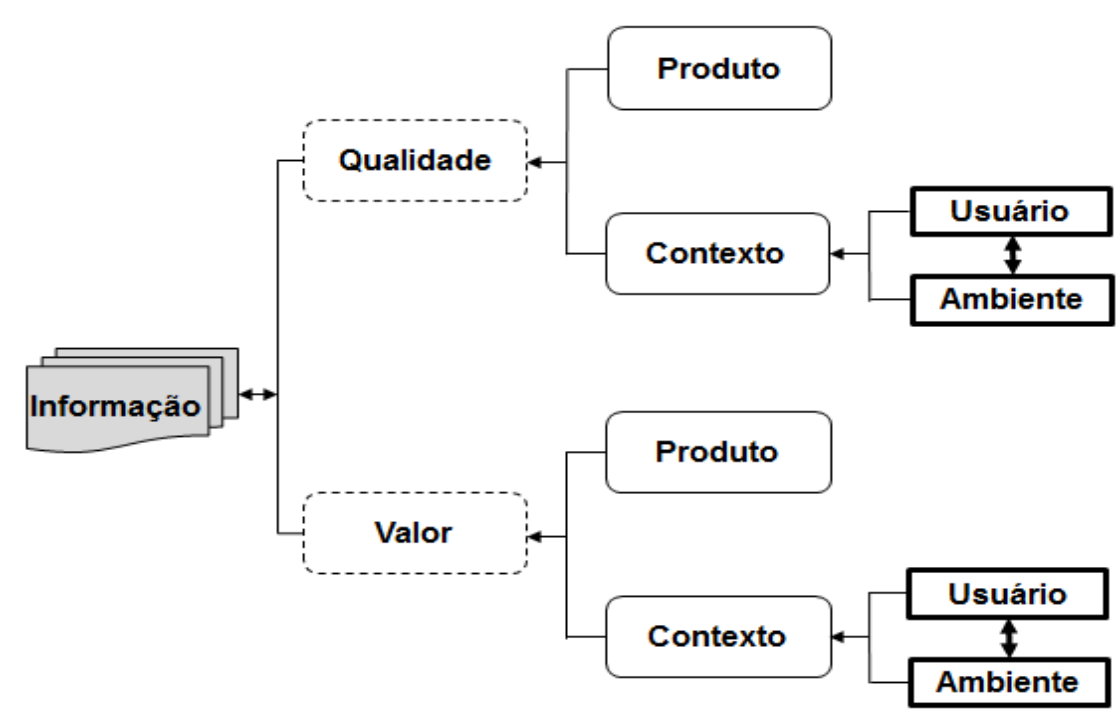

Figura 13 - Configuração do contexto da qualidade das informações Fonte: O próprio autor

A informação possui qualidade e valor. Porém, tanto a qualidade quanto o valor dependem da avaliação da informação como produto e ao mesmo tempo da avaliação das suas características de contexto. Nessa perspectiva, a avaliação plena da informação não se restringe somente às análises das dimensões da 
informação orientadas ao produto e, tampouco, se limitam às dimensões orientadas para o contexto. Na realidade, as duas abordagens se complementam.

As dimensões orientadas para o contexto são as mais difíceis de serem identificadas e mensuradas, porém elas orientam a percepção do usuário para avaliar os demais aspectos da qualidade da informação. Por vezes, o sucesso do processo de avaliação da qualidade da informação depende da perfeita integração de ambas as abordagens. O contexto, neste estudo, é configurado pela própria informação, suas dimensões, pelos usuários e pelo ambiente de uso da informação 


\section{CONCLUSÕES}

O resultado principal deste estudo foi o desenvolvimento de uma classificação de dimensões da qualidade da informação que pode ser utilizada para a melhoria da qualidade da informação, pressupondo, consequentemente, uma melhoria na qualidade dos processos de gestão nas organizações.

Verificou-se, neste estudo, que a teoria em torno dos conceitos da qualidade da informação está bem consolidada na literatura, contudo, tais conceitos são de difícil implementação prática, conforme alertam Calazans (2008) e Oleto (2006), dentre outros. Um dos fatores que dificulta a prática dos conceitos pode estar associado ao perfil do profissional da informação, que tem se alterado continuamente, principalmente em função da rápida evolução das tecnologias, das linguagens e ambientes computacionais, das necessidades das organizações em se manterem competitivas e da própria sociedade, que se torna refém das constantes alterações macroambientais.

Por isso, foram estabelecidas duas proposições relacionadas à participação dos profissionais de tecnologia da informação, como agentes de fomento para a melhoria da qualidade da informação, sendo a primeira:

\section{Os profissionais de sistemas e os usuários podem ser vistos como agentes transformadores, como canais de implementação da qualidade da informação nas organizações.}

Nesse contexto, o estudo demonstrou que os consumidores foram os mais alinhados com os conceitos e prática da qualidade da informação, sendo importante ressaltar que os participantes desse perfil possuem boa formação acadêmica e têm o incentivo das empresas onde trabalham para utilizar tais práticas. Nesse sentido, ficou uma lacuna sobre o perfil de consumidores com menor capacitação e formação; terão eles desempenho semelhante aos demonstrados pelos participantes da amostra? 
Somente estudos futuros sobre o assunto poderão esclarecer essa questão. Assim, há que se investigar a qualidade da informação em grupos mistos, independentes da formação acadêmica dos participantes.

Em relação aos produtores, ficou demonstrado que os participantes consideram importantes e utilizam as abordagens de contexto em suas atividades, porém não as associam aos negócios da organização na mesma intensidade. Esse é um resultado importante e que merece atenção, pois os produtores estão diretamente envolvidos com o desenvolvimento de sistemas de informação. Considerando o impacto dos sistemas de informação nas organizações, esse resultado deixa a sensação de que falta algo a ser complementado na formação desses profissionais.

Como bem salienta Audy, Andrade e Cidral (2005), os conceitos de sistemas de informação estão estruturados em três dimensões, a tecnológica, a humana e a organizacional.

É possível, nesse sentido, constatar que os produtores sejam mais focados na dimensão tecnológica e por isso, valorizam mais os aspectos técnicos em detrimento dos organizacionais ou humanos em suas atividades.

Quanto aos gestores, o estudo demonstrou o contrário, isto é, que esse perfil tem maior percepção dos aspectos organizacionais das dimensões e por isso valoriza tais aspectos em detrimento dos técnicos.

Relacionada à efetividade das dimensões baseadas no contexto na formação dos usuários e profissionais da informação, foi estabelecida a segunda proposição:

Dimensões da qualidade da informação alinhadas com o contexto dos usuários são mais fáceis de serem incorporadas e implementadas tanto por profissionais quanto por usuários da informação.

Em síntese, o fator fundamental das dimensões de contexto é que elas são as mais difíceis de serem mensuradas, porém, são as mais próximas da realidade dos participantes e por isso, podem ser mais facilmente incorporadas pelos usuários ou profissionais da informação. Dessa forma, elas também podem ser utilizadas como 
instrumento de formação e capacitação sobre qualidade da informação, pois uma vez incorporados os seus conceitos, é possível que as demais dimensões sejam também mais facilmente desenvolvidas nos indivíduos.

Este estudo traz contribuições significativas para o entendimento sobre como os profissionais da informação associados com os processos de desenvolvimento de sistemas e os usuários percebem e usam a qualidade da informação no dia a dia, em seu contexto de uso.

Confirma-se, assim, a segunda proposição: as dimensões de contexto podem ser uma forma de implementação dos conceitos da qualidade da informação na prática, no ambiente em que são utilizadas.

Além disso, alguns autores como Marchand (1990), Repo (1989), já haviam sinalizado que geralmente as informações de maior qualidade tendem a ser mais valorizadas pelos usuários e pelo mercado. Ressaltam, no entanto as dificuldades inerentes à valorização da informação, por causa principalmente da subjetividade expressa no termo valor da informação. Pedro (1994), no mesmo sentido, entende que a qualidade da informação pode estar relacionada com os processos de se atribuir valor à informação, como um de seus componentes.

A qualidade, avaliada por meio das dimensões, pode ser uma forma de agregar e atribuir valor às informações. Nonaka e Takeuchi (1997), nesse sentido, afirmam que a inteligência organizacional é construída a partir da proposição de que é possível agregar valor à informação e estruturá-la de forma que passe a ter um valor e uma importância contextual, na organização.

Ressalta-se, entretanto, que o termo valor em si, da informação, nem sempre está relacionado apenas ao valor material (agregado de recursos e esforços) da informação, mas sim às vantagens que podem ser obtidas por intermédio de seu uso. Nesse sentido, vale lembrar também a observação de Navy (2005), de que o valor da informação é, por vezes, percebido mais pela ausência da informação do que por sua disponibilidade. Nos casos de ausência da informação, é até possível 
arriscar um valor para ela, pois foi identificada uma necessidade real e pontual de uso adequado. Parece evidente o valor da informação nesse momento.

Antes, porém, de dar valor à informação é necessário que os métodos e processos para aferição da qualidade da informação sejam incorporados pelos usuários e profissionais envolvidos nos processos de criação da informação, no caso deste estudo, aos profissionais da informação. Dessa forma, o estudo reafirma as sugestões de diversos autores (CAPURRO e HJORLAND, 2007; MARCHAND, 1990; REPO, 1989) sobre a necessidade de novos estudos a fim de investigar com maior profundidade a relação dos usuários e profissionais da informação com a qualidade da informação na prática, no contexto de uso, pois, como afirmam Wang e Strong (1996), são os usuários que conhecem os problemas da qualidade da informação, embora, na maioria dos casos, eles são considerados intrínsecos, ou seja, um efeito natural inerente ao produto informação.

Concluiu-se que, a classificação das dimensões baseadas no contexto, aqui proposta, é um instrumento eficiente e pode ser utilizado, nas organizações, para identificar como se processam os conceitos da qualidade da informação entre os profissionais envolvidos com as informações.

Entretanto, entre as limitações deste estudo, destaca-se a necessidade de se realizar uma análise com maior profundidade na relação das dimensões com os cargos em cada perfil. Além disso, é possível que o instrumento aplicado para uma amostra maior, produza resultados mais significativos e amplie as contribuições do estudo.

A expectativa inicial neste estudo era de que os resultados apontassem falta de conhecimento sobre os conceitos da qualidade da informação dos participantes. Por fim, as expectativas foram superadas. Os resultados apontaram que os conceitos da qualidade fazem parte do cotidiano dos profissionais da informação e que a abordagem de contexto é um conceito a ser estudado e praticado com maior efetividade nas organizações. 
Em termos práticos, a classificação proposta possui uma relação intrínseca com a cadeia de valor da informação. Isto é, em termos gerais a cadeia de valor considera a aquisição, transformação e distribuição da informação na organização em suas atividades primárias. Logo, essa classificação é um método capaz de avaliar não somente a qualidade da informação entrante na cadeia, mas, sobretudo, dos aspectos contextuais de toda a cadeia. Ela pode ser utilizada, portanto, como um método aliado à governaça da informação, propiciando melhorias e qualidade para toda a organização.

Por meio de análise detalhada sobre as referências utilizadas neste estudo, bem como dos resultados apontados por ele, desvendaram-se possibilidades de se aprofundar na investigação sobre o conceito da qualidade da informação, como propostas de trabalhos acadêmicos que podem ser viáveis na busca de conhecimentos e esclarecimentos sobre a temática. Por isso, elencam-se algumas sugestões para futuros estudos sobre o assunto:

I. Investigar como as dimensões de contexto podem influenciar na incorporação de dimensões de outras abordagens e orientações, pelos profissionais da informação;

II. Avaliar como se processa a percepção da abordagem de contexto entre os diferentes cargos exercidos pelos profissionais envolvidos com os processos de desenvolvimento de sistemas de informação;

III. Estudar a relação das dimensões da qualidade como componente de valor das informações;

IV. Investigar como a qualidade da informação é disseminada pelos cursos que formam os profissionais da informação, especialmente dos envolvidos com os processos de desenvolvimento de sistemas de informação;

V. Investigar a associação das dimensões da proposta em público heterogêneo, sem delimitar o perfil dos participantes em empresas de outros ramos de atividades. 
Por fim, espera-se que este estudo possa contribuir e ampliar o uso dos conceitos da qualidade da informação, especialmente pelas áreas envolvidas com a gestão das informações nas organizações. 


\section{REFERÊNCIAS BIBLIOGRÁFICAS}

ABNT NBR ISO 9000. Norma Brasileira: Sistemas de gestão da qualidade Fundamentos e vocabulário. 2. Ed. 2005. Disponível em: <http://qualidadeuniso.files. wordpress.com/2012/09/nbr-iso-9000-2005. pdf. $>$ Acesso em: 29 maio 2013.

ALEXANDRE, J. W. C., ANDRADE, D. F., VASCONCElOS, A. P., ARAUJo, A. M.S., BATISTA, M.J. Análise do número de categorias da escala de Likert aplicada à gestão pela qualidade total através da teoria da resposta ao item. In: XXIII ENCONTRO NACIONAL DE ENGENHARIA DE PRODUÇÃO. 2003, Ouro Preto, MG, Brasil. Disponível em: <http://www.abepro.org.br/biblioteca/ENEGEP2003 _TR0201_0741.pdf>. Acesso em: 15 maio 2013.

ALMEIDA, C. C.; VARVAKIS, G. Valor e ciência da informação: Serviços de Informação baseados na Gestão de Operações de Serviço. Informação \& Sociedade: Estudos, João Pessoa, v. 15, n. 1, 2005. Disponível em: <http://www.lgti.ufsc.br/valor.pdf>. Acesso em: 18 maio 2011.

ALMEIDA Jr., J.R. Segurança em Sistemas Críticos e em Sistemas de Informação - Um estudo Comparativo. Tese (Livre Docência) - Escola Politécnica da Universidade de São Paulo, São Paulo, 2003.

ARAÚJO. C. A. A. Correntes teóricas da ciência da Informação: revisão da literatura. Ciência da Informação, Brasília, DF, v. 38, n. 3, p.192-204, set./dez., 2009. Disponível em: http://www.scielo.br/pdf/ci/v38n3/v38n3a13.pdf. Acesso em: 20 jan. 2012.

ARAÚJO, C. A. A. A ciência da informação como ciência social. Ciência da Informação, Brasília, v.32, n.3, p. 21-27, set./dez. 2003. Disponível em:http://www.scielo.br/pdf/ci/v32n3/19020.pdf . Acesso em: 18 jan. 2011.

AUDY, J. L. N.; ANDRADE, G. K.; CIDRAL, A. Fundamentos de Sistemas de informação. Porto Alegre: Bookman, 2005.

BAPTISTA, D. M. O Impacto dos metadados na representação descritiva. Revista ACB: Biblioteconomia em Santa Catarina, Florianópolis, v.12, n.2, p. 177-190, jul./dez., 2007.

BARRETO, A. A. A Condição da Informação. In: Gestão Estratégica da Informação e Inteligência Competitiva. São Paulo: Saraiva, 2005. P. 3-16.

O comportamento dos custos em serviços de informação. Ciência da Informação, Brasília, v. 13 n. 2, p. 129-135, jul./dez. 1984. 
BELUZZO, R. C. B. As competências do profissional da informação nas organizações contemporâneas. Revista Brasileira de Biblioteconomia e Documentação - RBBD. v.7, n. 1, 2011. Disponível em: <http://rbbd.febab.org.br/rbbd/article/view/180>. Acesso em: 29 dez. 2012.

BRINBERG, H.R.; PINELLI, T.E.; BARCLAY, R.O. Valuing Information in an Interactive Environment. NASA. Langley Research Center. Department of Defense. Indiana University. May, 1995. NASA-TM-110448 - NASA/DoD Aerospace Knowledge Diffusion Research Project.

BUCKLAND, M.K. Information as thing. Journal of the American Society for Information Science (JASIS), v.45, n.5, p.351-360, 1991. Disponível em: http://www.publicpraxis.com/wp-content/uploads/2011/01/informationasthing.pdf. Acesso em: 25 jan. 2011.

CALAZANS, A.T.S. Qualidade da informação: conceitos e aplicações. TransInformação. Campinas, 20(1): p. 29-45. Jan./abr., 2008. Disponível em: <http://www.angelicatoffano.pro.br/upload_arquivos/pt/TR-2006-175.pdf>. Acesso em: 15 set. 2012.

CAPURRO, Rafael and HJØRLAND, Birger, O conceito de informação. Perspectivas em ciência da informação. [online]. 2007, vol.12, n.1, p. 148-207. Disponível em: <http://www.scielo.br/scielo.php?pid=S141399362007000100012 \&script=sci_arttext $>$. Acesso em: 10 fev. 2012.

CARBONE, P.P.; BRANDÃO, H. P; LEITE, J.B.D; VILHENA, R.M.P. Gestão por competências e gestão do conhecimento. 2. ed. Rio de Janeiro: Editora FGV, 2006.

CASANOVA, M.B. Information: the major element for change. In: WORMELL, I. (Ed.). Information quality: definitions and dimensions. London: Taylor Graham, 1990. p.42-53.

CBO-2002. Classificação Brasileira de Ocupações. Disponível em: <http://www. mtecbo.gov.br/cbosite/pages/pesquisas/ResultadoOcupacaoMovimentacao.jsf>.

Acesso em: 29 dez. 2012.

CERVO, A. L; BERVIAN, P. A.; SILVA, R.. Metodologia Científica. 6. ed. São Paulo: Pearson Education do Brasil, 2007.

CERVO, A. L.; BERVIAN, P. A. Metodologia científica. 5. ed. São Paulo: Prentice Hall, 2002.

$\mathrm{CHOO}, \mathrm{C}$. W. A organização do conhecimento: como as organizações usam a informação para criar significado, construir conhecimento e tomar decisões. Tradução Eliana Rocha. - São Paulo: Editora Senac São Paulo, 2003a. 
$\mathrm{CHOO}, \mathrm{C} . \mathrm{W}$. Perspectives on Managing Knowledge in Organizations. The Haworth Press, Inc. 2003b. Disponível em: <http://www.haworthpress.com/store /product.asp?sku=J104>. Acesso em: 17 ago. 2011.

Managing Information for the Competitive Edge. Disponível em: <http://choo.ischool.utoronto.ca/>. Acesso em: 12 maio 2011.

CORTES, Pedro Luiz. Administração de Sistemas de Informação. São Paulo : Saraiva, 2008.

CURRY, Adrienne. Managing information and systems: the business perspective / Adrienne Curry, Peter Flett, and Ivan Hollingsworth. - 1st ed. Taylor \& Francis eLibrary, 2006. Acesso em: 28 jun. 2011.2 Disponível em: <http://moazzen.com/uploads/file/SISEBOOK.pdf>. Acesso em: 25 jul. 2011

DAVENPORT, T.H., PRUSAK, L. Conhecimento empresarial: Como as organizações gerenciam o seu capital intelectual. 15. ed. Rio de Janeiro: Elsevier, 2003.

Ecologia da Informação: Por que só a tecnologia não basta para o sucesso na era da informação. São Paulo: Futura, 1998

NAVY - Department Of The Navy Chief Information Officer. The Value of Information: Measuring Your Impact: Using Evaluation to Demonstrate Value (Tutorial). Information Literacy Toolkit, Version 3.0, Jul. 2005. Disponível em: <http://www.doncio.navy.mil/iltoolkit/default.htm>. Acesso em: 20 ago. 2010.

DE SORDI, J. O. Administração da Informação: fundamentos e práticas para uma nova gestão do conhecimento. - São Paulo : Saraiva, 2008.

Dicionário do pensamento marxista. Rio de Janeiro: Jorge Zahar Editor, 1997.

DODEBEI, V. Memória e conhecimento: oralidade, visualidade e reprodutibilidade no fluxo da informação. In: ENCONTRO NACIONAL DE PESQUISA E PÓSGRADUAÇÃO EM CIÊNCIA DA INFORMAÇÃO. 2009, João Pessoa. Anais... João Pessoa: Ancib, 2009. Disponível em <http://dci2.ccsa.ufpb.br:8080/jspui/bitstream/ 123456789/487/1/GT\%202\%20Txt\%2013-\%20DODEBEl\%2c\%20Vera.pdf>. Acesso em: 30 set. 2011.

DRUCKER, Peter. Post-Capitalist Society. New York: Harper Collins, 1993.

EPSTEIN, Isaac. Teoria da Informação. São Paulo: Ática, 1986.

FARIA, S.; OLIVEIRA, V. F.; FORNER, L.; D'ASTUTO, F. Competências do profissional da informação: uma reflexão a partir da Classificação Brasileira de Ocupações. Ciência da Innformação. Brasília, v. 34, n.2, p. 26-33, maio/ago. 2005. 
Disponível em: <http://www.scielo.br/pdf/ci/v34n2/28552.pdf>. Acesso em: 30 dez. 2012.

FERNANDES, R.M.S.; AZEVEDO, T.S. Teoria da informação e suas aplicações em compressão e aleatoriedade. Projeto do curso de Estatística e Probabilidade PESC - COPPE, Maio/2006.

FERNANDES, P. O. Economia da informação. Ciência da Informação, Brasília, v. 20, n. 2, p. 165-168, jul./dez. 1991.

FOINA, P. R. Tecnologia de informação: planejamento e gestão. 2. ed. 3. reimpr. São Paulo: Atlas, 2010.

GLOSSÁRIO/apdSI. Glossário da Sociedade da Informação: Associação para a promoção e desenvolvimento da Sociedade da Informação - apdSI, 2011. Disponível em: $\quad$ http://www.apdsi.pt/uploads/news/id432/gloss\%C3\%A1 rio\%20da\%20si\%20\%20vers\%C3\%A3०\%202011.pdf>. Acesso em 15 maio 2013.

GOUVEIA, L.M.B. Sociedade Digital, que oportunidades? In: CONGRESSO INTERNACIONAL PÓS-COLONIALISMO E IDENTIDADE, 1996, Porto. Disponível em: <www.citeseerx.ist.psu.edu/viewdoc/download>. Acesso em: 15 jul. 2011.

HJELMSLEV, L. T. Prolegômenos a uma teoria da linguagem. São Paulo: Abril Cultural, 1975.

HJØRLAND, Birger. The Foundation of the Concept of Relevance. Journal of the American Society for Information Science and Techonology. 61(2): 217-237, 2010. Disponível em: <www.interscience.wyley.com>. Acesso em: 12 jun. 2012.

JOHNSON, D. J. On contexts of information seeking. Information Processing \& management. 39 (2003) 735-760. Disponível em: <www.elsevier.com/located/ infopronam>. Acesso em: 15 jan. 2013.

HUANG, Kuan-Tsae; LEE, Y. W.; WANG, R. Quality Information and Knowledge. New Jersey: Prentice-hall, Inc. 1999.

SCHWOLOW, S; JUNGFALK, M. The Information Value Chain: Strategic Information Management for Competitive Advantage. Bachelor's Project. Copenhagen Business School, 2009. Information Value Chain. Disponível em: <http://www.informationvaluechain.com/>. Acesso em: 07 maio 2011.

KIELGAST, Soeren, HUBBARD, Bruce A. Valor agregado à informação: da teoria à prática. Ciência da Informação. Brasília, vol. 26, n. 3, Set. / Dez. 1997.

LAUDON, K. C.; LAUDON, J. P. Sistemas de informação gerencial. 4. ed. São

Paulo: Pearson - Prentice Hall, 2007. 
LE COADIC, Yves-François. A Ciência da Informação. Brasília : Brinquet de Lemos/Livros 1996. Disponível em: <http://www.restaurabr.org/siterestaurabr/ CICRAD2011/M1\%20Aulas/M1A3\%20Aula/20619171-le-coadic-francois-a-cienciada-informacao.pdf>. Acesso em: 05 jan. 2013.

Lee, Y. W. Crafting Rules: Context-Reflective Data Quality Problem Solving. Journal of Management Information Systems / Winter 2003-4, Vol. 20, N. 3, p. 93-119. Disponível em: <http://www.thespatiallab.org/resources/data\%20quality(JMIS). pdf>. Acesso em: 15 jan. 2013.

MÄNTYNIEMI, S.; KUIKKA, S.; RAHIKAINEN, M.; KELL, L. T.; KAITALA, V. The value of information in fisheries management: North Sea Herring as an example. Open Access article distributed. 2009. Disponível em: <http://icesjms.oxfordjournals.org/>. Acesso em: 23 fev. 2012.

MARCHAND, D. Managing information quality. In: WORMELL, I. (Ed.). Information quality: definitions and dimensions. London: Taylor Graham, 1990. p. 7-17.

MARCIAL, E. O Perfil do profissional de inteligência competitiva e o futuro dessa atividade no Brasil. In: STAREC, C.; GOMES E.; BEZERRA J. Gestão Estratégica da Informação e Inteligência Competitiva. - São Paulo: Saraiva, 2005. p. 242-254.

MARSHALL Junior, I.; CIERCO, A. A.; ROCHA, A. V.; MOTA E. B.; LEUSIN, S. Gestão da qualidade. 9. ed. - Rio de Janeiro: Editora FGV, 2008.

MIRANDA, S. Como as necessidades de informação podem se relacionar com as competências informacionais. Ciência da Informação. Brasília, v.35, n. 3, p. 99-114, set./dez.2006. Disponível em: <http://www.scielo.br/pdf/ci/v35n3/ v35n3a10.pdf>. Acesso em: 03 dez. 2012.

MORESI, E. A. D. Delineando o valor do sistema de informação de uma organização. Ciência da Informação, Brasília, v. 29, n. 1, p. 14-24, jan./abr. 2000. Disponível em: <http://www.scielo.br/cgi-bin/wxis.exe/iah/>. Acesso em: 10 maio 2010.

NEHMY, M.R.Q.; PAIM, I. A desconstrução do conceito de "Qualidade da Informação". Ciência da Infformação. Brasília, v. 27, n. 1, p. 36-45, jan./abr. 1998. Disponível em: <portaldeperiodicos.eci.ufmg.br/index.php/pci/article/download/8/27>. Acesso em: 15 jan. 2012.

NEVES, J.M.S. A implantação de tecnologias da informação como fator de competitividade nos sistemas produtivos e nos negócios. XIII SIMPEP, 2006, Bauru. Disponível em: <http://www.simpep.feb.unesp.br/anais/anais_13/ artigos/251.pdf>. Acesso em: 22 jan. 2011.

NONAKA, I.; TAKEUCHI, H. Criação de Conhecimento na Empresa. Rio de janeiro: Campos, 1997. 
O'BRIEN, J.A. Sistemas de informação e as decisões gerenciais na era da internet. - 2. Ed. São Paulo: Saraiva, 2004.

OLETO, Ronaldo Ronan. Percepção da qualidade da Informação. Ciência da Infformação. Brasília, v. 35, n.1, p. 57-82, jan./abr. 2006. Disponível em: $<$ www.scielo.br/pdf/ci/v35n1/v35n1a07.pdf>. Acesso 29 jul. 2011.

OLIVEIRA, A. Análise Inteligente de Falhas para Apoiar Decisões Estratégicas em Projetos de Sistemas Críticos. Tese (Doutorado). Escola Politécnica da Universidade de São Paulo, São Paulo, 2009.

OLIVEIRA, J.F. Sistemas de Informação: Um Enfoque Gerencial Inserido no Contexto Empresarial e Tecnológico. 5. ed. - São Paulo: Érica, 2007.

OLIVEIRA, D.P.R. Sistemas de Informações gerenciais. 7. ed. - São Paulo: Atlas, 2001.

PAIM, I.; NEHMY, M.R.Q.; GUIMARÃES, C.G. Problematização do conceito de "Qualidade" da Informação. Perspectivas em Ciência da Infformação. Belo Horizonte, v. 1, n. 1, p. 111-119, jan./jun. 1996. Disponível em: <portaldeperiodicos.eci.ufmg.br/index.php/pci/article/download/8/27>. Acesso em: 15 jan. 2012.

PAIM, I.; NEHMY, M.R.Q. Questões sobre a avaliação da informação: uma abordagem inspirada em Giddens. Perspectivas em Ciência da Infformação. Belo Horizonte, v. 3, n. 2, p. 81-95, jul./dez. 1998. Disponível em: <portaldeperiodicos.eci.ufmg.br/index.php/pci/article/>. Acesso em: 15 jan. 2012.

PEDRO, J.M. O valor e os custos da informação. Revista do Instituto de Informática, n. 13/1994. Disponível em: <http://www.knowkapital.com/ artigos/>. Acesso em: 01 fev. 2011.

PORTER, M.E. Vantagem Competitiva: criando e sustentando um desempenho superior. - Rio de Janeiro: Campus, 1989.

REPO, A. J., The value of information: Approaches in economics, accounting, and management science. Journal of the Americam Society for Information Science and Technology, v. 40, p. 68-85, Mar. 1989. Disponível em: <http://onlinelibrary.wiley.com/doi/10.1002/(SICI)1097-4571(198903)40:2\%3C68:: AID-ASI2\%3E3.0.CO;2-J/abstract>. Acesso em: 15 abr. 2012

REPO. A. J. The Dual Approach to the Value of Information: An appraisal of use and Exchange Values. Information Processing \& Management, v. 22, n. 5, p. 373-383, 1986. Disponível em: <http://etheses.whiterose.ac.uk/1844/1/DX177253.pdf>. Acesso em: 15 abr. 2012. 
REZENDE, Y. Informação para negócios: os novos agentes do conhecimento e a gestão do capital intelectual. Ciência da Infformação. Brasília, v.31, n.2, p.120-128, maio/ago., 2002. Disponível em: <http://www.scielo.br/cgi-bin/wxis.exe/iah/>. Acesso em: 15 jun. 2011.

SANDRONI, P. Novíssimo Dicionário de Economia. São Paulo: Best Seller, 1999. Disponível em: <http://www.scribd.com/doc/6965717/Paulo-Sandroni-NOVISSIMODICIONACIRIO-DE-ECONOMIA>. Acesso em: 20 abr. 2011.

SANTOS, G. D. Estudo empírico da relação entre qualidade da informação e impacto individual no contexto organizacional. Tese (doutorado). Universidade de São Paulo, 2009.

SANTOS, M. B. A Gestão do Conhecimento como prática corporativa geradora de vantagem competitiva sustentada. FACOM, n. 15, 2005. Disponível em: <http://www.faap.br/revista_faap/revista_facom/facom_15/_marcelo_barbosa.pdf>. Acesso em: 04 dez. 2012.

SANTOS, J. P. O Moderno Profissional da Informação: O Bibliotecário e seu perfil face aos novos tempos. Inf.\&Inf., Londrina, v.1, n.1, p.5-13, jan./jun. 1996. Disponível em: <http://www.uel.br/revistas/uel/index.php/informacao/article/view/ 1613/1367>. Acesso em: 04 dez. 2012.

SHANNON, C. E. A Mathematical Theory of Communication. Reprinted with corrections from The Bell System Technical Journal, Vol. 27, Jul./Oct., 1948.

SILVA, S. L. Informação e competitividade: a contextualização da gestão do conhecimento nos processos organizacionais. Ciência da Informação, Ago. 2002, vol. 31, n.2, p.142-151. Disponível em: http://www.scielo.br/cgi-bin/wxis.exe/iah/. Acesso em: 15 Set.. 2012.

SILVA, A. P.; FAVARETTO, F. Análise da qualidade da informação: um estudo de caso em empresas do setor madeireiro. In: IV CONGRESSO NACIONAL DE EXCELÊNCIA EM GESTÃO. Julho/2008. Disponível em: <http://www.excelencia emgestao.org/Portals/2/documents/cneg4/anais/T7_0014_0023.pdf>. Acesso em: 29 jul. 2011.

SILVA, J. F.; FERREIRA, M. A. T.; BORGES, M. E. N. Análise metodológica dos estudos de necessidades de informação sobre setores industriais brasileiros:

proposições. Ciência da Informação, Brasília, v. 31, n. 2. p. 129-141, maio/ago. 2002. Disponível em: <http://www. scielo.br/cgi-bin/wxis.exe/iah/>. Acesso em: 06 set. 2011.

SOARES, V. D. Informação nas Organizações - Matemática, Gestalt e Cognição. Biblioteca On-line de ciências da comunicação, Seção: Comunicação nas organizações. 2001. Disponível em: <http://www.bocc.ubi.pt/pag/soares-valeriainformacao-nas-organizacoes.pdf>. Acesso em: 03 fev. 2011. 
SOUZA, A. M. Análise de Variância - ANOVA. Departamento de Estatística. PPGEMQ / PPGEP - UFSM. Disponível em: <http://w3.ufsm.br/adriano/aulas/ anova/T\% 5B0\%5Danova.pdf>. Acesso em 08 fev. 2013.

STRASSMAN, P. A. For Great IT, Focus on the Information, Not the Technology, 2005. Disponível em: <http://www.strassmann.com/pubs/ baseline/2005-10-a.html>. Acesso em: 21 fev. 2011.

STRONG, M. D; WANG, R. Y. Data Quality in Context. Communication of the ACM. May 1997, vol. 40, n. 5. Disponível em: <http://www.fing.edu.uy/inco/cursos /caldatos/articulos/StrongLeeWangCACMMay97.pdf>. Acesso em: 02 maio 2012.

TAYLOR, R. S. Value added process in the information life cycle. Syracuse, N Y: Syracuse University, School of Information Studies, 1982. Disponível em: <http://www.asis.org/Publications/JASIS/Best_Jasist/1982 Taylor.pdf>. Acesso em: 31 maio 2011.

TARAPANOFF, K; ARAÚJO Jr, R.H; CORMIER, P. M.J. Sociedade da informação e inteligência em unidades de informação. Ciência de Informação. Brasília, v. 29, n. 3, p. 91-100, set./dez. 2000. Disponível em: <http://www.scielo.br>. Acesso em: 15 maio 2011.

TARAPANOFF, K. Inteligência social e inteligência competitiva. Organizações em contexto, ano 3, n.5, jun./2007. Disponível em: <http://www.scielo.br>. Acesso em: 15 maio 2011.

VIEIRA, Sônia. Como elaborar questionários. São Paulo: Atlas, 2009.

WAGNER, G. The Value and the Quality of Information: The need for a theoretical syntesis. In: WORMELL, I. (Ed.). Information quality: definitions and dimensions. London: Taylor Graham, 1990. p.69-72.

WANG. R. Y. and STRONG, D. M. Beyond Accuracy: What Data Quality Means to Data Consumers. Journal of Management Information System, Spring 1996, v. 12, n.4, ABI/INFORM Global. Disponível em: <http://www.thespatiallab.org /resources/data\%20quality(JMIS).pdf>. Acesso em: 03 maio 2012.

WANG. R. Y. A Product Perspective on Total Data Quality Management. Comunications of the ACM. Feb./1998. v. 41. n.2. Disponível em: <http://dl. acm.org/citation.cfm?id=269022 >. Acesso em: 03 maio 2012.

ZORRINHO, O. Gestão de informação, condição para vencer. IAPMEI, 1995.

Disponível em : <http://www.iapmei.pt/iapmei-ins01.php?tema_id=4\&tema_sub_id= 15\&tema_nivel2_id=0\& artigo_id=16>. Acesso em: 15 maio 2011. 
ANEXO 1 


\section{IPVI - INVENTÁRIO de PERCEPÇÃo de VALOR dAs INFORMAÇões}

Prezado(a) amigo(a)

Agradeço antecipadamente sua contribuição nesta pesquisa!

Para o sucesso de sua participação e para que traga as informações necessárias e alinhadas com os objetivos do estudo, solicito que faça uma leitura atenta das informações abaixo, antes de responder o questionário.

\section{Apresentação da pesquisa:}

A pesquisa é parte de um projeto de doutorado que investiga a percepção de uso das informações no ambiente de trabalho e você estará contribuindo diretamente com o corpo de conhecimento sobre a gestão das informações nas organizações.

É importante que você reflita e responda sobre a importância das informações no seu dia a dia, como você percebe a influência delas no desenvolvimento de suas atividades, na organização onde trabalha.

Não é necessário que você se identifique.

Não existem respostas certas ou erradas.

Não responda a lápis.

Não deixe nenhuma questão sem responder.

As informações aqui coletadas serão utilizadas em um estudo sobre a percepção de valor da informação.

O nome da instituição não será divulgado sem o consentimento dos seus responsáveis.

\{ Em caso de dúvidas sobre as características da informação, consulte na última página, o detalhamento de cada uma das dimensões da informação utilizadas neste estudo.

\section{PARTe 1}

INSTITUIÇÃO:
RAMO DE ATIVIDADE: $\square$ Comércio $\square$ Serviços $\square$ Industria $\square$ Educação $\square$ Outro
CARGO QUE OCUPA: $\square$ Chefia $\square$ Supervisão $\square$ Operacional $\square$ Outro
FUNÇÃO: Assinale, abaixo, a sua função em relação à informação, de acordo com as opções:
PRODUTOR $\square$ Atua diretamente nos processos de produção das informações, que criam
ou coletam dados para os sistemas (programadores, analistas).
GUARDIÃo $\quad \square$ Mantém e garante a segurança e qualidade das informações (DBAs,
Suporte, gerentes de TI).




\section{PARTE 2}

Por favor, considerando a percepção das informações que utiliza diariamente para a realização de suas atividades no ambiente de trabalho, assinale, nas questões abaixo, o quão verdadeiro você considera cada uma das afirmações:

Nada verdadeiro

Verdadeiro

Totalmente verdadeiro

Em seguida, para as questões do números 4 ao 12, assinale as características da informação que considera relacionadas com sua resposta. Pode assinalar quantas características desejar.

Assinale de um a sete, na escala à esquerda de cada item, a fim de indicar o quão importante você considera cada uma das dimensões da informação.

\section{Lembre-se:}

- quanto mais próximo do número um você se posicionar, menor o grau de importância;

- quanto mais próximo do número sete você se posicionar, maior o grau de importância.

\begin{tabular}{lcccclc}
$\mathbf{1}$ & $\mathbf{2}$ & $\mathbf{3}$ & $\mathbf{4}$ & $\mathbf{5}$ & $\mathbf{6}$ & $\mathbf{7}$ \\
\hline Nada & & Importante & & Muito \\
Importante & & & & Importante
\end{tabular}

Observacão: Por favor, procure ser o mais sincero possível nas suas respostas.

Questão 1- Eu conheço os conceitos da qualidade da informação.
$\square$ Nada verdadeiro
$\square$ Verdadeiro
Totalmente verdadeiro

Questão 2- Eu utilizo os conceitos da qualidade da informação nas atividades diárias do meu trabalho.
$\square$ Nada verdadeiro
Verdadeiro
Totalmente verdadeiro

Questão 3- Acredito que a qualidade da informação é fundamental para o sucesso das atividades onde são utilizadas.

$\square$ Nada verdadeiro $\quad \square$ Verdadeiro $\quad \square$ Totalmente verdadeiro

Questão 4- A falta de qualidade da informação diminui o seu valor.
$\square$ Nada verdadeiro
$\square$ Verdadeiro
Totalmente

verdadeiro

Assinale abaixo, as características da informação relacionadas à resposta da questão 4.

\begin{tabular}{|c|c|c|c|c|c|c|c|}
\hline 1 & 2 & 3 & 4 & 5 & 6 & 7 & Eficácia da recuperação \\
\hline 1 & 2 & 3 & 4 & 5 & 6 & 7 & Utilidade \\
\hline 1 & 2 & 3 & 4 & 5 & 6 & 7 & Valor de uso \\
\hline 1 & 2 & 3 & 4 & 5 & 6 & 7 & Completude \\
\hline 1 & 2 & 3 & 4 & 5 & 6 & 7 & Quantidade adequada \\
\hline 1 & 2 & 3 & 4 & 5 & 6 & 7 & Indexação e Classificação \\
\hline 1 & 2 & 3 & 4 & 5 & 6 & 7 & Relevância \\
\hline 1 & 2 & 3 & 4 & 5 & 6 & 7 & Valor esperado \\
\hline 1 & 2 & 3 & 4 & 5 & 6 & 7 & Valor percebido \\
\hline 1 & 2 & 3 & 4 & 5 & 6 & 7 & Valor agregado \\
\hline 1 & 2 & 3 & 4 & 5 & 6 & 7 & Impacto \\
\hline 1 & 2 & 3 & 4 & 5 & 6 & 7 & Pontualidade \\
\hline
\end{tabular}


Questão 5- Acredito que as informações que utilizo diariamente no meu trabalho têm mais valor do que outras informações que utilizo apenas de vez em quando.

Nada verdadeiro

$\square$ Verdadeiro

$\square$ Totalmente verdadeiro

Assinale abaixo, as características da informação relacionadas à sua resposta.

\begin{tabular}{|c|c|c|c|c|c|c|c|}
\hline 1 & 2 & 3 & 4 & 5 & 6 & 7 & Eficácia da recuperação \\
\hline 1 & 2 & 3 & 4 & 5 & 6 & 7 & Utilidade \\
\hline 1 & 2 & 3 & 4 & 5 & 6 & 7 & Valor de uso \\
\hline 1 & 2 & 3 & 4 & 5 & 6 & 7 & Completude \\
\hline 1 & 2 & 3 & 4 & 5 & 6 & 7 & Quantidade adequada \\
\hline 1 & 2 & 3 & 4 & 5 & 6 & 7 & Indexação e Classificaç \\
\hline 1 & 2 & 3 & 4 & 5 & 6 & 7 & Relevância \\
\hline 1 & 2 & 3 & 4 & 5 & 6 & 7 & Valor esperado \\
\hline 1 & 2 & 3 & 4 & 5 & 6 & 7 & Valor percebido \\
\hline 1 & 2 & 3 & 4 & 5 & 6 & 7 & Valor agregado \\
\hline 1 & 2 & 3 & 4 & 5 & 6 & 7 & Impactc \\
\hline 1 & 2 & 3 & 4 & 5 & 6 & 7 & Pontualidade \\
\hline
\end{tabular}

Questão 6- Para mim, a informação de maior valor é a informação estratégica porque ela pode influênciar nos processos de tomada de decisão da organização onde trabalho.

Nada verdadeiro verdadeiro

$\square$ Verdadeiro

Totalmente

Assinale abaixo, as características da informação relacionadas à sua resposta.

\begin{tabular}{|c|c|c|c|c|c|c|c|}
\hline 1 & 2 & 3 & 4 & 5 & 6 & 7 & Eficácia da recuperação \\
\hline 1 & 2 & 3 & 4 & 5 & 6 & 7 & Utilidade \\
\hline 1 & 2 & 3 & 4 & 5 & 6 & 7 & Valor de uso \\
\hline 1 & 2 & 3 & 4 & 5 & 6 & 7 & Completude \\
\hline 1 & 2 & 3 & 4 & 5 & 6 & 7 & Quantidade adequada \\
\hline 1 & 2 & 3 & 4 & 5 & 6 & 7 & Indexação e Classificaça \\
\hline 1 & 2 & 3 & 4 & 5 & 6 & 7 & Relevância \\
\hline 1 & 2 & 3 & 4 & 5 & 6 & 7 & Valor esperado \\
\hline 1 & 2 & 3 & 4 & 5 & 6 & 7 & Valor percebido \\
\hline 1 & 2 & 3 & 4 & 5 & 6 & 7 & Valor agregado \\
\hline 1 & 2 & 3 & 4 & 5 & 6 & 7 & Impacto \\
\hline 1 & 2 & 3 & 4 & 5 & 6 & 7 & Pontualidade \\
\hline
\end{tabular}


Questão 7- Entendo que o valor da informação está diretamente relacionado com a qualidade da informação.

Nada verdadeiro

$\square$ Verdadeiro

Totalmente verdadeiro

Assinale abaixo, as características da informação relacionadas à sua resposta.

\begin{tabular}{|c|c|c|c|c|c|c|c|}
\hline 1 & 2 & 3 & 4 & 5 & 6 & 7 & Eficácia da recuperação \\
\hline 1 & 2 & 3 & 4 & 5 & 6 & 7 & Utilidade \\
\hline 1 & 2 & 3 & 4 & 5 & 6 & 7 & Valor de uso \\
\hline 1 & 2 & 3 & 4 & 5 & 6 & 7 & Completude \\
\hline 1 & 2 & 3 & 4 & 5 & 6 & 7 & Quantidade adequada \\
\hline 1 & 2 & 3 & 4 & 5 & 6 & 7 & Indexação e Classificação \\
\hline 1 & 2 & 3 & 4 & 5 & 6 & 7 & Relevância \\
\hline 1 & 2 & 3 & 4 & 5 & 6 & 7 & Valor esperado \\
\hline 1 & 2 & 3 & 4 & 5 & 6 & 7 & Valor percebido \\
\hline 1 & 2 & 3 & 4 & 5 & 6 & 7 & Valor agregado \\
\hline 1 & 2 & 3 & 4 & 5 & 6 & 7 & Impacto \\
\hline 1 & 2 & 3 & 4 & 5 & 6 & 7 & Pontualidade \\
\hline
\end{tabular}

Questão 8- Relatórios que apontam tendências para a organização são mais valorizados, pois estão vinculados às ações estratégicas da empresa.

Nada verdadeiro

$\square$ Verdadeiro

Totalmente verdadeiro

Assinale abaixo, as características da informação relacionadas à sua resposta.

\begin{tabular}{|c|c|c|c|c|c|c|c|}
\hline 1 & 2 & 3 & 4 & 5 & 6 & 7 & Eficácia da recuperação \\
\hline 1 & 2 & 3 & 4 & 5 & 6 & 7 & Utilidade \\
\hline 1 & 2 & 3 & 4 & 5 & 6 & 7 & Valor de uso \\
\hline 1 & 2 & 3 & 4 & 5 & 6 & 7 & Completude \\
\hline 1 & 2 & 3 & 4 & 5 & 6 & 7 & Quantidade adequada \\
\hline 1 & 2 & 3 & 4 & 5 & 6 & 7 & Indexação e Classificação \\
\hline 1 & 2 & 3 & 4 & 5 & 6 & 7 & Relevância \\
\hline 1 & 2 & 3 & 4 & 5 & 6 & 7 & Valor esperado \\
\hline 1 & 2 & 3 & 4 & 5 & 6 & 7 & Valor percebido \\
\hline 1 & 2 & 3 & 4 & 5 & 6 & 7 & Valor agregado \\
\hline 1 & 2 & 3 & 4 & 5 & 6 & 7 & Impacto \\
\hline 1 & 2 & 3 & 4 & 5 & 6 & 7 & Pontualidade \\
\hline
\end{tabular}


Questão 9- Eu valorizo a informação em função de seu uso, ou seja, quanto mais utilizada, maior será o seu valor.

Nada verdadeiro verdadeiro

$\square$ Verdadeiro

$\square$ Totalmente

Assinale abaixo, as características da informação relacionadas à sua resposta.

\begin{tabular}{|c|c|c|c|c|c|c|c|}
\hline 1 & 2 & 3 & 4 & 5 & 6 & 7 & Eficácia da recuperação \\
\hline 1 & 2 & 3 & 4 & 5 & 6 & 7 & Utilidade \\
\hline 1 & 2 & 3 & 4 & 5 & 6 & 7 & Valor de uso \\
\hline 1 & 2 & 3 & 4 & 5 & 6 & 7 & Completude \\
\hline 1 & 2 & 3 & 4 & 5 & 6 & 7 & Quantidade adequada \\
\hline 1 & 2 & 3 & 4 & 5 & 6 & 7 & Indexação e Classificação \\
\hline 1 & 2 & 3 & 4 & 5 & 6 & 7 & Relevância \\
\hline 1 & 2 & 3 & 4 & 5 & 6 & 7 & Valor esperado \\
\hline 1 & 2 & 3 & 4 & 5 & 6 & 7 & Valor percebido \\
\hline 1 & 2 & 3 & 4 & 5 & 6 & 7 & Valor agregado \\
\hline 1 & 2 & 3 & 4 & 5 & 6 & 7 & Impacto \\
\hline 1 & 2 & 3 & 4 & 5 & 6 & 7 & Pontualidade \\
\hline
\end{tabular}

Questão 10- O valor das informações que utilizo depende sempre da qualidade das informações.

Nada verdadeiro

$\square$ Verdadeiro

Totalmente verdadeiro

Assinale abaixo, as características da informação relacionadas à sua resposta.

\begin{tabular}{|l|l|l|l|l|l|l|l}
\hline 1 & 2 & 3 & 4 & 5 & 6 & 7 & Eficácia da recuperação \\
\hline 1 & 2 & 3 & 4 & 5 & 6 & 7 & Utilidade \\
\hline 1 & 2 & 3 & 4 & 5 & 6 & 7 & Valor de uso \\
\hline 1 & 2 & 3 & 4 & 5 & 6 & 7 & Completude \\
\hline 1 & 2 & 3 & 4 & 5 & 6 & 7 & Quantidade adequada \\
\hline 1 & 2 & 3 & 4 & 5 & 6 & 7 & Indexação e Classificação \\
\hline 1 & 2 & 3 & 4 & 5 & 6 & 7 & Relevância \\
\hline 1 & 2 & 3 & 4 & 5 & 6 & 7 & Valor esperado \\
\hline 1 & 2 & 3 & 4 & 5 & 6 & 7 & Valor percebido \\
\hline 1 & 2 & 3 & 4 & 5 & 6 & 7 & Valor agregado \\
\hline 1 & 2 & 3 & 4 & 5 & 6 & 7 & Impacto \\
\hline 1 & 2 & 3 & 4 & 5 & 6 & 7 & Pontualidade \\
\hline
\end{tabular}


Questão 11- Para mim, as informações mais utilizadas (no dia a dia) têm valor maior do que as informações que são pouco utilizadas.

Nada verdadeiro

$\square$ Verdadeiro

Totalmente verdadeiro

Assinale abaixo, as características da informação relacionadas à sua resposta.

\begin{tabular}{|c|c|c|c|c|c|c|c|}
\hline 1 & 2 & 3 & 4 & 5 & 6 & 7 & Eficácia da recuperação \\
\hline 1 & 2 & 3 & 4 & 5 & 6 & 7 & Utilidade \\
\hline 1 & 2 & 3 & 4 & 5 & 6 & 7 & Valor de uso \\
\hline 1 & 2 & 3 & 4 & 5 & 6 & 7 & Completude \\
\hline 1 & 2 & 3 & 4 & 5 & 6 & 7 & Quantidade adequada \\
\hline 1 & 2 & 3 & 4 & 5 & 6 & 7 & Indexação e Classificação \\
\hline 1 & 2 & 3 & 4 & 5 & 6 & 7 & Relevância \\
\hline 1 & 2 & 3 & 4 & 5 & 6 & 7 & Valor esperado \\
\hline 1 & 2 & 3 & 4 & 5 & 6 & 7 & Valor percebido \\
\hline 1 & 2 & 3 & 4 & 5 & 6 & 7 & Valor agregado \\
\hline 1 & 2 & 3 & 4 & 5 & 6 & 7 & Impacto \\
\hline 1 & 2 & 3 & 4 & 5 & 6 & 7 & Pontualidade \\
\hline
\end{tabular}

Questão 12- Entendo que informações com alto valor estratégico possuem maior valor para a organização.

Nada verdadeiro

$\square$ Verdadeiro

$\square$ Totalmente verdadeiro

Assinale abaixo, as características da informação relacionadas à sua resposta.

\begin{tabular}{|c|c|c|c|c|c|c|c|}
\hline 1 & 2 & 3 & 4 & 5 & 6 & 7 & Eficácia da recuperação \\
\hline 1 & 2 & 3 & 4 & 5 & 6 & 7 & Utilidade \\
\hline 1 & 2 & 3 & 4 & 5 & 6 & 7 & Valor de uso \\
\hline 1 & 2 & 3 & 4 & 5 & 6 & 7 & Completude \\
\hline 1 & 2 & 3 & 4 & 5 & 6 & 7 & Quantidade adequada \\
\hline 1 & 2 & 3 & 4 & 5 & 6 & 7 & Indexação e Classificação \\
\hline 1 & 2 & 3 & 4 & 5 & 6 & 7 & Relevância \\
\hline 1 & 2 & 3 & 4 & 5 & 6 & 7 & Valor esperado \\
\hline 1 & 2 & 3 & 4 & 5 & 6 & 7 & Valor percebido \\
\hline 1 & 2 & 3 & 4 & 5 & 6 & 7 & Valor agregado \\
\hline 1 & 2 & 3 & 4 & 5 & 6 & 7 & Impacto \\
\hline 1 & 2 & 3 & 4 & 5 & 6 & 7 & Pontualidade \\
\hline
\end{tabular}




\section{Características das dimensões da informação baseadas no contexto.}

\begin{tabular}{|c|c|}
\hline Dimensões & Significados \\
\hline $\begin{array}{l}\text { Eficácia da } \\
\text { recuperação }\end{array}$ & $\begin{array}{l}\text { Grau em que as informações podem ser recuperadas, classificadas e } \\
\text { estruturadas para uso. }\end{array}$ \\
\hline Completude & $\begin{array}{l}\text { Refere-se à completeza da informação. Quanto mais completa for a } \\
\text { informação, melhor ela atenderá uma necessidade. }\end{array}$ \\
\hline $\begin{array}{l}\text { Quantidade } \\
\text { adequada }\end{array}$ & $\begin{array}{l}\text { Extensão em que a quantidade ou volume de dados disponibilizados } \\
\text { são adequados para uso. Informação em excesso nem sempre é } \\
\text { sinônimo de qualidade, porém a escassez de informação também } \\
\text { prejudica a qualidade das atividades. } \\
\text { - Gráficos podem ser mais fáceis de se analisar do que um relatório } \\
\text { com muitas páginas; ou } \\
\text { - Relatórios devem conter informações realmente necessárias. }\end{array}$ \\
\hline $\begin{array}{l}\text { Adequação da } \\
\text { Indexação e } \\
\text { Classificação }\end{array}$ & $\begin{array}{l}\text { Facilidade de classificação e organização da informação para o seu } \\
\text { uso. Está relacionado às formas de documentação e armazenamento } \\
\text { da informação. }\end{array}$ \\
\hline Relevância & $\begin{array}{l}\text { Grau em que a informação é relevante para a realização de } \\
\text { determinada tarefa. }\end{array}$ \\
\hline Valor esperado & $\begin{array}{l}\text { Expectativa de valor que se tem da informação. O quanto se acredita } \\
\text { que ela seja suficiente para determinado evento. }\end{array}$ \\
\hline Valor percebido & $\begin{array}{l}\text { Percepção que se tem do Valor real da informação, geralmente } \\
\text { atribuído após o seu uso. }\end{array}$ \\
\hline Valor agregado & $\begin{array}{l}\text { Benefícios obtidos e percebidos pelo uso da informação, além daqulilo } \\
\text { que era esperado. }\end{array}$ \\
\hline Impacto & $\begin{array}{l}\text { Capacidade da informação em impactar os resultados de uma tarefa } \\
\text { ou decisão em mãos. }\end{array}$ \\
\hline Pontualidade & $\begin{array}{l}\text { Relacionado à disponibilidade da informação no momento em que é } \\
\text { necessária. Pouco valor terá uma informação disponibilizada } \\
\text { tardiamente. }\end{array}$ \\
\hline
\end{tabular}


ANEXO 2 


\section{IPQI - INVEnTÁRIO de Percepção de Qualidade das INFormações}

Prezado(a) amigo(a)

Agradeço antecipadamente sua contribuição nesta pesquisa!

Para o sucesso de sua participação e para que traga as informações necessárias e alinhadas com os objetivos do estudo, solicito que faça uma leitura atenta das informações abaixo, antes de responder o questionário.

\section{Apresentação da pesquisa:}

A pesquisa é parte de um projeto de doutorado que investiga a percepção de uso das informações no ambiente de trabalho e você estará contribuindo diretamente com o corpo de conhecimento sobre a gestão das informações nas organizações.

É importante que você reflita e responda sobre a importância das informações no seu dia a dia, como você percebe a influência delas no desenvolvimento de suas atividades, na organização onde trabalha.

Não é necessário que você se identifique.

Não existem respostas certas ou erradas.

Não responda a lápis.

Não deixe nenhuma questão sem responder.

As informações aqui coletadas serão utilizadas em um estudo sobre a percepção de valor da informação.

O nome da instituição não será divulgado sem o consentimento dos seus responsáveis.

Em caso de dúvidas sobre as características da informação, consulte a última página deste material, a relação e o detalhamento de cada uma das dimensões da informação.

\section{PARTE 1}

INSTITUIÇÃO:

RAmo de ATIVIDAde: ( ) Comércio ( ) Serviços ( ) Indústria ( ) Educação ( ) Outro

CARGo QUE OCUPA: ( ) Gerência ( ) Supervisão （）Operacional ( ) Consultor （ ) Outro

FUnÇão: Assinale, abaixo, a sua função em relação à informação, de acordo com as opções:

Produtor ( ) Atua diretamente nos processos de produção das informações, trabalha com atividades que criam, coletam, processam e armazenam dados para os sistemas (Analistas de Sistemas, Programadores)

Consumıdor ( ) Utiliza informações dos Sistemas de Informação para a realização de suas tarefas (usuários em geral)

GESTOR ( ) Mantém garante a segurança e qualidade das informações (DBAs, Gerentes de TI, Gerentes de suporte, outros) 


\section{PARTE 2}

Por favor, considerando a percepção das informações que utiliza diariamente para a realização de suas atividades no ambiente de trabalho, assinale, nas questões abaixo, o quão verdadeiro você considera cada uma das afirmações:

1 - Eu conheço os conceitos da qualidade da informação.

Nada verdadeira $\square$ Totalmente verdadeira

2 - Eu geralmente utilizo os conceitos da qualidade da informação nas atividades do meu trabalho.

$\square$ Nada verdadeira $\square$ Totalmente verdadeira

3 - A empresa onde trabalho incentiva as práticas da qualidade da informação.

Nada verdadeira $\square$ Totalmente verdadeira

4 - Acredito que as informações têm valor para as organizações.

Nada verdadeira

$\square$ Totalmente verdadeira

5 - Entendo que o valor da informação depende da qualidade da informação.

Nada verdadeira

Totalmente verdadeira

Para as questões de 6 a 15, assinale a escala à esquerda de cada item, de 1 a 5, para indicar quão importante você considera cada uma das dimensões da informação.

\section{Lembre-se:}

- quanto mais próximo do número um você se posicionar, menor o grau de importância;

- quanto mais próximo do número cinco você se posicionar, maior o grau de importância.

\begin{tabular}{lrrrr}
1 & 2 & 3 & 4 & 5 \\
\hline Nada & & & Muito \\
Importante & & & Importante
\end{tabular}

Se desejar, deixe sua opinião sobre as dimensões no campo "Observação" disponibilizado em cada uma das dimensões. 
Por favor, procure ser o mais sincero possível nas suas respostas.

06- Relevância: Representa o grau de utilidade da informação, isto é, para o quê e por quem ela será utilizada. Determinada informação pode ser extremamente útil para um indivíduo e nada útil para outros em função do contexto em que será utilizada.

\begin{tabular}{|l|l|l|l|l|l|}
\hline 1 & 2 & 3 & 4 & 5 & $\begin{array}{l}\text { Importância desta dimensão para a realização das minhas } \\
\text { atividades. }\end{array}$ \\
\hline 1 & 2 & 3 & 4 & 5 & $\begin{array}{l}\text { As informações de maior relevância, na minha opinião, têm mais } \\
\text { valor para a organização. }\end{array}$ \\
\hline
\end{tabular}

Observação:

07- Valor esperado: Representa a expectativa de valor da informação para a realização de uma atividade. O uso ou não da informação é baseado na expectativa de valor que o usuário tem da informação para a realização de uma atividade.

\begin{tabular}{|l|l|l|l|l|l|}
\hline 1 & 2 & 3 & 4 & 5 & $\begin{array}{l}\text { Importância desta dimensão para a realização das minhas } \\
\text { atividades. }\end{array}$ \\
\hline 1 & 2 & 3 & 4 & 5 & $\begin{array}{l}\text { As informações que apresentam melhor valor esperado têm mais } \\
\text { valor para a minha organização. }\end{array}$ \\
\hline
\end{tabular}

Observação:

08- Valor percebido: Representa a percepção real de uso da informação em determinada situação baseada na experiência do usuário. Refere-se à compreensão que o usuário tem do valor da Informação pelo seu uso.

\begin{tabular}{|l|l|l|l|l|l|}
\hline 1 & 2 & 3 & 4 & 5 & $\begin{array}{l}\text { Importância desta dimensão para a realização das minhas } \\
\text { atividades. }\end{array}$ \\
\hline 1 & 2 & 3 & 4 & 5 & $\begin{array}{l}\text { As informações que apresentam melhor valor percebido têm mais } \\
\text { valor para a minha organização. }\end{array}$ \\
\hline
\end{tabular}

Observação:

09- Valor agregado: Refere-se ao processo de transformar dados sem significado em informação. Representa os benefícios adicionais que uma informação pode gerar em termos de conhecimento para a realização de uma atividade.

\begin{tabular}{|l|l|l|l|l|l|}
\hline 1 & 2 & 3 & 4 & 5 & $\begin{array}{l}\text { Importância desta dimensão para a realização das minhas } \\
\text { atividades. }\end{array}$ \\
\hline 1 & 2 & 3 & 4 & 5 & $\begin{array}{l}\text { As informações que apresentam melhor valor agregado têm mais } \\
\text { valor para a minha organização. }\end{array}$ \\
\hline
\end{tabular}

Observação:

10- Completude: Refere-se à importância da informação completa. Informações representadas por siglas, ou abreviadas sem a correta descrição do seu significado, podem levar a interpretações equivocadas.

\begin{tabular}{|l|l|l|l|l|l|}
\hline 1 & 2 & 3 & 4 & 5 & $\begin{array}{l}\text { Importância desta dimensão para a realização das minhas } \\
\text { atividades. }\end{array}$ \\
\hline 1 & 2 & 3 & 4 & 5 & $\begin{array}{l}\text { Informações que se apresentam mais completas têm mais valor } \\
\text { para a organização. }\end{array}$ \\
\hline
\end{tabular}

Observação: 
11- Impacto: Refere-se à influência positiva ou negativa da informação para as atividades em que está envolvida. Representa o quanto uma informação perfeita em determinada situação pode contribuir para a resolução de problemas.

\begin{tabular}{|l|l|l|l|l|l|}
\hline 1 & 2 & 3 & 4 & 5 & $\begin{array}{l}\text { Importância desta dimensão para a realização das minhas } \\
\text { atividades. }\end{array}$ \\
\hline 1 & 2 & 3 & 4 & 5 & $\begin{array}{l}\text { As informações que têm maior impacto têm mais valor para a } \\
\text { organização. }\end{array}$ \\
\hline
\end{tabular}

Observação:

12- Pontualidade: Refere-se à disponibilidade da informação quando é necessária. Pouco valor terá uma informação disponibilizada tardiamente, quando não é mais necessária para determinada atividade.

\begin{tabular}{|l|l|l|l|l|l|}
\hline 1 & 2 & 3 & 4 & 5 & $\begin{array}{l}\text { Importância desta dimensão para a realização das minhas } \\
\text { atividades. }\end{array}$ \\
\hline 1 & 2 & 3 & 4 & 5 & $\begin{array}{l}\text { As informações com mais pontualidade têm mais valor para a } \\
\text { organização. }\end{array}$ \\
\hline
\end{tabular}

Observação:

13- Eficácia da recuperação: refere-se aos atributos de sistemas de informação referentes à eficiência da recuperação dentro de um sistema, ou seja, a facilidade de recuperar informação.

\begin{tabular}{|l|l|l|l|l|l|}
\hline 1 & 2 & 3 & 4 & 5 & $\begin{array}{l}\text { Importância desta dimensão para a realização das minhas } \\
\text { atividades }\end{array}$ \\
\hline 1 & 2 & 3 & 4 & 5 & $\begin{array}{l}\text { As informações que são recuperadas com maior eficácia têm } \\
\text { mais valor para a organização. }\end{array}$ \\
\hline
\end{tabular}

Observação:

14- Quantidade adequada: Refere-se ao volume de informações necessárias para que determinada tarefa se torne eficaz: o excesso assim como a escassez podem ser prejudiciais à organização.

\begin{tabular}{|l|l|l|l|l|l|}
\hline 1 & 2 & 3 & 4 & 5 & $\begin{array}{l}\text { Importância desta dimensão para a realização das minhas } \\
\text { atividades. }\end{array}$ \\
\hline 1 & 2 & 3 & 4 & 5 & $\begin{array}{l}\text { As informações apresentadas em quantidade adequada têm mais } \\
\text { valor para a organização. }\end{array}$ \\
\hline
\end{tabular}

Observação:

15- Adequação da Indexação e Classificação: Diz respeito às atividades de obtenção ou aquisição da informação e às formas de acesso à informação.

\begin{tabular}{|l|l|l|l|l|l|}
\hline 1 & 2 & 3 & 4 & 5 & $\begin{array}{l}\text { Importância desta dimensão para a realização das minhas } \\
\text { atividades. }\end{array}$ \\
\hline 1 & 2 & 3 & 4 & 5 & $\begin{array}{l}\text { Informações com maior facilidade de indexação e classificação } \\
\text { têm mais valor para a organização. }\end{array}$ \\
\hline
\end{tabular}

Observação: 